\title{
Sports Investment, Beliefs about Food-related Behaviors, and Engagement in Problematic Eating Behaviors during Adolescence
}

\author{
Kaitlyn A. Ferris
}

Follow this and additional works at: https://researchrepository.wvu.edu/etd

\section{Recommended Citation}

Ferris, Kaitlyn A., "Sports Investment, Beliefs about Food-related Behaviors, and Engagement in Problematic Eating Behaviors during Adolescence" (2015). Graduate Theses, Dissertations, and Problem Reports. 5593.

https://researchrepository.wvu.edu/etd/5593

This Dissertation is protected by copyright and/or related rights. It has been brought to you by the The Research Repository @ WVU with permission from the rights-holder(s). You are free to use this Dissertation in any way that is permitted by the copyright and related rights legislation that applies to your use. For other uses you must obtain permission from the rights-holder(s) directly, unless additional rights are indicated by a Creative Commons license in the record and/ or on the work itself. This Dissertation has been accepted for inclusion in WVU Graduate Theses, Dissertations, and Problem Reports collection by an authorized administrator of The Research Repository @ WVU.

For more information, please contact researchrepository@mail.wvu.edu. 
Sports Investment, Beliefs about Food-related Behaviors, and Engagement in Problematic Eating Behaviors during Adolescence

Kaitlyn A. Ferris, M.S.

Dissertation submitted to The Eberly College of Arts and Sciences at West Virginia University

in partial fulfillment of the requirements for the degree of

Doctor of Philosophy in

Psychology

Aaron Metzger, Ph.D., Chair

Julie Hicks Patrick, Ph.D.

Kevin Larkin, Ph.D.

Ryan Flett, Ph.D.

Christa Lilly, Ph.D.

Department of Psychology

Morgantown, West Virginia

2014

Keywords: Organized sports involvement, problematic eating behaviors, social-cognitive domain theory, adolescence

Copyright 2014 Kaitlyn A. Ferris 


\title{
ABSTRACT \\ Sports Investment, Beliefs about Food-related Behaviors, and Engagement in Problematic Eating Behaviors during Adolescence
}

\author{
Kaitlyn A. Ferris
}

Involvement in sport is the most widely reported organized activity among children and adolescents. To date, organized sports also represent the only organized activity examined in conjunction with youths' eating behaviors. Organized sports serve as contexts where messages about healthy eating and body image are communicated, and adolescents' beliefs about food and their bodies' degree of thinness and muscularity has the potential to be amplified in such settings as youth strive to perform at high levels during athletic competitions. However, inconsistency in the measurement of both organized sports participation and adolescents' engagement in problematic under- and over-eating behaviors has resulted in a more limited understanding of the developmental trajectories of both constructs during adolescence. Moreover, explanatory mechanisms, specifically adolescents' belief systems about food and their bodies, may explain associations between sports involvement and problematic eating behaviors, and such associations may be especially prevalent for youth involved in multiple organized activities simultaneously (e.g., sports and church activities). Therefore, the goals of current study were threefold: (1) examine associations between multidimensional constructs of sports investment and problematic under- and over-eating behaviors, (2) examine explanatory associations between sports investment and problematic under- and over-eating behaviors through adolescents' beliefs about food, and their bodies' degree of thinness and muscularity, and (3) examine whether explanatory associations vary as a function of adolescents' participation in additional organized activities simultaneously with sports. Participants included 610 adolescents $(M=15.93, S D=1.10$, Range $=14-$ 19 years, 58.6\% female) who completed measures assessing participation in organized activities, athletic identity status, beliefs about thinness, muscularity, and under- and over-eating behaviors, and engagement in problematic under- and over-eating behaviors. Across all youth, sports investment was associated with binge eating and over-eating behaviors, and such associations were explained by beliefs about the body's degree of muscularity. In addition, being highly invested in sports was associated with higher levels of moderate and severe under-eating behaviors through lower food autonomy of overeating behaviors. Several significant gender differences also emerged. Sports investment was directly associated with binge eating for boys, while sports investment was indirectly associated with both under- and over-eating behaviors for girls. Finally, involvement in additional organized activities simultaneously with sports was associated with protective and adverse outcomes. Results indicate that church activities are a context promoting healthy eating habits, while participation in club-related activities may lead to increased scheduling demands, and a decreased focus on healthy eating patterns. Overall, these findings indicate that organized sports represent an important context contributing to adolescents' conceptualizations of food-related behaviors and the body's degree of muscularity and, as well differences in problematic under- and over-eating behaviors. 
Table of Contents

I. Introduction (pp. 1-18)

a. Adolescent Problematic Eating Behaviors: Measurement and Development Correlates (pp. 3-6)

b. Sports Involvement and Problematic Eating Behaviors (pp. 6-8)

c. Sports Involvement: A Multidimensional Constructs (pp. 8-10)

d. Explanatory Mechanisms for the Association between Sports Investment and Problematic Under- and Over-eating Behaviors (pp. 10-14)

e. Sports involvement and Problematic Eating: Demographic and Behavioral Moderators (pp. 14-16)

f. The Current Study (pp. 16-18)

II. Research Questions and Hypotheses (pp. 18-21)
a. Research Question 1 (pp. 18)
b. Research Question 2 (pp. 18-19)
c. Research Question 3 (pp. 19-21)

III. Method (pp. 21-32)
a. Participants (pp. 21-23)
b. Measures (pp. 23-29)
c. Procedure (pp. 29-30)
d. Data Analysis Strategy (pp. 30-32)

IV. Results (pp. 32-40)

a. Data Cleaning and Preliminary Analysis (pp. 32) 
b. Measurement Model: Sports Involvement and Food-related Beliefs Latent Constructs (pp. 32-34)

c. Structural Models: Associations between Sports Investment and Problematic Eating (pp. 35)

d. Structural Models: Examining Personal and Food-related Beliefs as Mediators (pp. 35-40)

V. Discussion (pp. 40-53)

a. Gender Differences in Associations between Sport Investment and Problematic Under- and Over-eating Behaviors (pp. 43-46)

b. Associations between Sports Investment and Problematic Eating Outcomes by Involvement in Church, Club-related, and Arts/music Activities (pp. 46-47)

c. Exercise, BMI, and Problematic Under- and Over-eating Behaviors (pp. 47-48)

d. Limitations and Future Directions (pp. 48-53)

VI. References (pp. 54-70)

VII. Tables (pp. 71-94)

VIII. Figures (pp. 95-103)

IX. Appendices (pp. 104-133) 
Many adult health concerns, such as cardiovascular disease and obesity, have been linked to unhealthy eating patterns established in childhood and adolescence (Dowdell \& Santucci, 2004). Research also indicates adolescents' food-related behaviors are influenced by a variety of sources, including the media (Miller \& Halberstadt, 2005), peer-weight comparisons (Sanderson et al., 2008), and domain beliefs about the harmfulness of different eating behaviors (Ferris, 2012). Given the substantial changes in these belief systems during adolescence, it is not surprising that teenagers are particularly vulnerable to the development of problematic under- and over-eating patterns (Fay \& Lerner, 2013), which makes adolescence a critical age period for further examination of the antecedents of problematic eating behaviors in adulthood (Swanson, Crow, Le Grange, Swendsen, \& Merikangas, 2011). Additional research is needed which explores potential social and contextual predictors of these problematic eating behaviors.

Developmental researchers have also been especially interested in adolescents' involvement in organized sports since it is a widely reported organized activity during childhood and adolescence (Eccles, Barber, Stone, \& Hunt, 2003; Larson \& Seepersad, 2003). Although involvement in other forms of organized activities (e.g., clubs, church groups, arts/music activities) is generally linked with positive youth outcomes, research examining the impact of sports participation on youth development has noted both positive and negative effects. For instance, involvement in organized sports has been associated with the acquisition of positive developmental outcomes and lower levels of delinquent activity (Fletcher et al., 2003; Jacobs et al., 2005), but such participation may also promote engagement in other forms of risky behavior, such as alcohol consumption (Fauth et al., 2007; Linver et al., 2009). Similarly, involvement in sports has been linked 
with increased body image dissatisfaction and engagement in both problematic underand over-eating behaviors (Fay \& Lerner, 2013; Petrie, Greenleaf, Reel, \& Carter, 2008). Associations between sports involvement and clinical levels of disordered eating have received much attention (e.g., Holm-Denoma, Scaringi, Gordon, Van Orden, \& Joiner, 2009). Fewer studies have examined the impact of sports participation on less severe levels of problematic eating or normative eating behaviors (e.g., Sanford-Martens, Davidson, Yakushko, Martens, Hinton, \& Beck, 2005). Less research has considered potential psychological explanatory mechanisms, which may explain associations between youth sports participation and problematic eating behaviors. Additionally, much previous research has relied on measures of sports participation that focus solely on the time spent participating in the activity and not the quality of involvement within sporting contexts or youth's appraisal of the importance of sports to their identity development (Bohnert, Fredricks, \& Randall, 2010). Finally, research has not explored how associations between sports involvement and problematic under- and over-eating patterns may vary as a function of adolescents' age, gender, or participation in other organized activities outside of sports, specifically church, arts/music, and club-related activities.

The current study examined associations between sports investment, psychological mediators, and adolescent under- and over-eating behaviors. Associations between sports involvement and problematic under- and over-eating behaviors may be explained by factors that are shaped by competitive sporting contexts. As a result, several explanatory mechanisms, specifically adolescents' beliefs about food-related behaviors (e.g., harmfulness of a variety of eating behaviors) and their bodies (e.g., body image dissatisfaction) were investigated. Explanatory associations between sports involvement 
and problematic under- and over-eating behaviors may also be present for specific groups of adolescents (e.g., girls, early adolescents, youth involved in other organized activities), so several potential moderating variables were examined (see Figure 1).

\section{Adolescent Problematic Eating Behaviors: Measurement and Developmental}

\section{Correlates}

Adolescence is an ideal developmental period to study nuances in problematic eating behaviors. Today's teenagers are especially vulnerable to the development of problematic eating patterns as they experience the dramatic physical, cognitive, social, and emotional changes associated with puberty (Lieberman, Gauvin, Bukowski, \& White, 2001). Predictors of problematic under- and over-eating behaviors during adolescence include biological variables (e.g., childhood obesity/being overweight, body mass index, pubertal timing), psychological factors (e.g., body image dissatisfaction, negative perceptions of weight status, and low self-esteem), and demographic characteristics (e.g., gender, socioeconomic status, race; Keel \& Forney, 2013; Krug et al., 2012). However, isolating the unique influence of these factors on adolescents' body image dissatisfaction and engagement in problematic eating behaviors is difficult as these factors are often inter-related (Walcott et al., 2003).

Measuring dimensions of problematic eating behaviors. Problematic eating behaviors involve a range of unhealthy food-related activities that include both undereating (e.g., restricting one’s diet in an unhealthy manner) and over-eating (e.g., consuming too many calories, compulsive eating, and eating unhealthy foods that are low in essential nutrients) behaviors (Sundgot-Borgen \& Torstveit, 2010). Under-eating problems have been studied extensively in adolescence and develop out of a 
preoccupation with food, weight, and body size and shape (Beato-Fernandez, RodriguezCano, Belmonte-Llario, \& Martinez-Delgado, 2004). When individuals are dissatisfied with their physical appearance, they enact pathogenic weight-control behaviors in order to manage their emotions and weight (Wood \& Petrie, 2010). At the other extreme, chronic over-eating involves excessive caloric intake over and above the number of calories recommendations for daily consumption by pediatricians and nutritionists (Golley, Hendrie, \& McNaughton, 2011). Over-eating behaviors include eating junk food and/or snacks between meals, continuing to eat when satiated, and eating when emotionally upset or bored (Ruhm, 2012). Prolonged, consistent engagement in overeating behaviors can lead to clinical diagnoses of obesity (Center for Disease Control (CDCa), 2013), and the number of studies examining pediatric obesity has increased in recent years as the prevalence of childhood obesity is continuing to rise internationally (e.g., Swinburn et al., 2011).

Although clinically-diagnosed eating disorders have received much empirical attention, disordered under- and over-eating can also be divided into sub-types of problematic eating behavior based on the severity of the symptoms (APA, 2013). Clinically diagnosed eating disorders provide researchers with categorical distinctions between individuals meeting criteria for clinical diagnoses, such as anorexia nervosa and binge eating disorder, and individuals who engage in normative eating behaviors appropriate for their age and weight. However, recent research suggests that it is also important to consider additional dimensions of problematic eating behaviors because negative health outcomes may also result from engagement in less extreme problematic 
eating patterns (e.g., intentionally dieting; eating junk food/fast food regularly; Greenleaf, Petrie, Carter, \& Reel, 2010; Peck \& Lightsey, 2008).

Research that has isolated dimensions of problematic eating has linked distinct under- versus over-eating behaviors to adverse outcomes. Dimensions of problematic under-eating include behaviors such as extreme-avoidance of certain food groups (e.g., meats, carbohydrates), counting calories, and implementing crash diets to achieve a desired weight (e.g., Sundgot-Borgen \& Torstveit, 2010). Such behaviors are associated with digestive problems, stunted growth, and suicidal thoughts and depression (Mayo Foundation for Medical Education and Research [MFMER], 2013). Dimensions of problematic over-eating behaviors include binge eating, regularly eating unhealthy foods such as foods high in fat, and continuing to eat when already full. These behaviors may result in excessive weight gain, childhood obesity, health-related issues (e.g., diabetes and high cholesterol), and ridicule from peers (de Sausmarez \& Dunsmuir, 2011).

Assessing problematic under- and over-eating behaviors simultaneously entails measuring a range of eating behaviors spanning from those consistent with a clinical diagnosis to under- and over-eating patterns, which can be considered healthy if carried out in moderation (e.g., eating snacks between meals, eating junk food, dieting, and counting calories). Measuring dimensions of under- and over-eating behaviors along a continuum allows researchers to capture a fuller spectrum of problematic eating behaviors. Even non-clinical eating behaviors may become problematic when adolescents are unaware of the health risks associated with under- or over-eating behaviors, or carry out such behaviors over a long-term, continuous basis (Jacobi, Abascal, \& Taylor, 2004). 
Demographic predictors of problematic eating behaviors. Previous research suggests that socioeconomic status (SES), which is comprised of family income, parental education level, and occupational status (Cameron et al., 2012; Simpkins, Delgado, Price, Quach, \& Starbuck, 2013), in addition to youths’ body mass index (BMI:

weight/[height $\left.{ }^{2}\right]$; Ogden, Carroll, Curtin, Lamb, \& Flegal, 2010) and degree of involvement in unstructured physical activities (e.g., exercise outside of formally organized sports such as jogging, walking, swimming, biking; CDCb, 2013; Department of Health, 2008; Faigenbaum \& Micheli, 2015; Hallal, Victora, Azevedo, \& Wells, 2006; White \& Halliwell, 2010) each impact engagement in problematic eating behaviors and access to organized sports. Because findings from studies examining these variables have been mixed, these constructs will be controlled for in the current study.

\section{Sports Involvement and Problematic Eating Behaviors}

Researchers have compared problematic eating patterns between individuals who participated or did not participate in sports, as well as explored differences in eating problems among individuals involved in different types of sports (Fay et al., 2011; Fay \& Lerner, 2013; Petrie \& Greenleaf, 2012), and at differing levels of competition (e.g., Holm-Denoma, Scaringi, Gordon, Van Orden, Joiner, 2009). The overall results of this research have been mixed. For instance, multiple studies have found that compared to individuals who are uninvolved in organized sports, youth who participate at high levels are more likely to adopt unhealthy eating attitudes and behaviors, such as dieting, excessive exercising, binging and purging, and using laxatives/enemas to prevent weight gain, as well as eating until nauseated, and utilizing steroids/protein supplements to gain muscle mass (Bloodworth, Petroczi, Bailey, Pearce, \& McNamee, 2012; Milligan \& 
Pritchard, 2006; Smolak, Murnen, \& Ruble, 2000; Torstveit, Rosenvinge, \& SundgotBorgen, 2008). These results have led researchers to postulate that individuals participating in sports may be susceptible to problematic under- or over-eating behaviors because of the dual pressures linked to meeting Westernized cultural standards of beauty, while also struggling with pressures from parents, coaches, and teammates to maintain peak physical fitness to succeed in sport (Byrne \& McLean, 2001; Ferrand, Magnan, Rouveix, \& Filaire, 2007). However, additional studies have found athletes to be at a decreased risk for body image dissatisfaction and the development of problematic undereating behaviors, including dieting (Hausenblas \& McNally, 2004; Martinsen, BratlandSanda, Eriksson, \& Sundgot-Borgen, 2010). Still other studies have found no difference in risk factors for clinical symptomology associated with under-eating disorders (i.e., anorexia nervosa), such as dieting behaviors, binging and purging behaviors, drive for thinness, and body image dissatisfaction based on involvement in organized sports (Rosendahl, Bormann, Aschenbrenner, Aschenbrenner, \& Strauss, 2009).

This lack of consistency in results from the research literature on sports participation and eating behaviors could stem from measurement equivalence issues in the assessment of under- and over-eating behaviors. Previous research has relied on measures designed to assess clinical levels of under-eating behaviors, such as the Eating Attitudes Test (e.g., preoccupation with food, dieting; Garner \& Garfinkel, 1979), the Eating Disorder Inventory (e.g., drive for thinness, tendency to engage in binging and purging behavior; Garner et al., 1983), the Bulimia Test - Revised (Thelen, Mintz, \& Vander Wal, 1996), and the Questionnaire for Eating Disorder Diagnosis (Mintz, O’Halloran, Mulholland, \& Schneider, 1997). Less research has considered the influence 
of sports participation on a wider range of under-eating behaviors, specifically

distinctions between more severe levels of under-eating (e.g., use of laxatives/diuretics) and less severe aspects of under-eating (e.g., counting calories or dieting).

In addition, few studies with individuals participating in sports have captured attitudes and behaviors related to dimensions of over-eating behaviors or unhealthy eating habits, such as excessive caloric intake or strategies utilized to increase muscle mass (e.g., weight lifting, supplement use). If these behaviors are carried out over prolonged periods of time, they have the potential to result in clinically-diagnosed overeating disorders. Measuring over-eating behaviors and expanding the definition of body image dissatisfaction to include muscle dissatisfaction may also provide evidence to more fully investigate suggestions by some researchers that rates of problematic eating behaviors are lower among males involved in sports (Petrie et al., 2008).

\section{Sports Investment: A Multidimensional Construct}

Sport is the most popular organized activity in which youth participate during adolescence (e.g., Larson \& Seeparsed, 2003). Organized sports encompass both schooland community-sponsored athletic teams, and provide youth with an environment for structured, group participation and mentorship established around a common purpose or goal (Dawes, Vest, \& Simpkins, 2014). However, participation in organized sports constitutes more than just the number of hours spent attending practices and competing against other youth. Sports involvement also involves mental components, including individual investment in sports and self-identification with athletics. Mere involvement in organized sports is not necessarily synonymous with sports investment, as the athletic domain may not be salient for all individuals involved in sports (Brewer, Van Raalte, \& 
Linder, 1993). Investigating adolescents’ sports involvement as a multifaceted construct involving both time/energy and mental investment components provides researchers with a more robust measure of sports involvement that has the potential to capture greater inter-individual variability in this multidimensional construct.

Bohnert and colleagues (2010) discuss how there is currently no consensus on the “best practices” for measuring different dimensions of sports participation (e.g., breadth, intensity, duration of involvement). They suggest using measures, which assess combinations of these dimensions of involvement in order to capture the complexity of organized sports participation. Intensity of involvement is a commonly assessed dimension of sports participation and it can be defined as how often or frequently youth are involved in sports activities. However, different sports may not be equivalent in the number of hours required for participants (e.g., seasonal demands). Thus, along with measuring the number of hours adolescents participate in school- and communitysponsored sports, it may be equally important to assess teens' subjective appraisal of their participation through Likert scales in which reports of how often one is involved in sports is also provided (Ferris, Oosterhoff, \& Metzger, 2013).

Furthermore, identifying with a peer group or crowd can impact adolescents’ identity development, and the “Jock” crowd may be especially important for adolescents involved in organized sports (Daddis, 2010; Eccles \& Barber, 1999). Involvement in sports and identification with peer groups whose identity centers on success in athletics may lead adolescents to subscribe to the Jock identity or to identify more strongly with the athlete role (Eccles, Barber, Hunt, \& Stone, 2003; Brewer, Van Raalte, Linder, 1993). The degree to which an individual identifies with the athlete role can be defined as one's 
athletic identity, and this construct represents an additional yet understudied component of sports investment (Brewer, Van Raalte, Linder, 1993). Individuals with a strong athletic identity develop a sturdier sense of self within the sports domain, increased confidence, and increased social interaction skills. However, individuals high in athletic identity are also more likely to engage in riskier levels of athletic activity, such as excessive exercising and competing while injured (Brewer, Van Raalte, \& Linder, 1993). Thus, more research is needed to better understand how athletic identity contributes to other health related behaviors, such as problematic under- and over-eating.

Devoting large quantities of time to sports in combination with a strong athletic identity may lead youth to participate in unhealthy eating behaviors to maintain their status within the "Jock" crowd. An assessment of time/energy and mental investment in organized sports may provide a more complete picture of sports participation during adolescence (Figure 2). In addition, accounting for these different components may allow for a more precise examination of athletically-engaged adolescents’ susceptibility and vulnerability to engagement in problematic under- and over-eating behaviors (Bohnert, Fredricks, \& Randall, 2010; Milligan \& Pritchard, 2006).

\section{Explanatory Mechanisms for the Association between Sports Investment and}

\section{Problematic Under- and Over-eating Behaviors}

Although previous studies have explored mean-level differences in problematic under- and over-eating behaviors between sub-groups of athletes and normatively developing members of the population, less research has focused on potential explanatory mechanisms linking organized sports involvement to problematic under- and over-eating behaviors (Ferrand et al., 2007; Ranby et al., 2009; Shanmugarn, Jowett, \& Meyer, 
2012). Explanatory factors, such as adolescents' beliefs about food-related behaviors and their bodies, may explain associations between sports investment and engagement in problem eating. Hansen and colleagues' (2003) research suggests that experiences within organized activities, including sports, provide adolescents with a unique set of developmental skills and assets, which have the potential to promote or protect against engagement in problem behaviors. Experiences within the sports context, such as interactions with coaches and competition with teammates, may shape the way adolescents think about food-related behaviors and their bodies’s shape and size. Belief systems, which develop as a result of such experiences, have the potential to explain why sports investment is associated with engagement in problematic under- and over-eating behaviors (Figure 3a; Figure 3b). Specifically, sports involvement may lead to beliefs about body shape and size (i.e., thinness, muscularity) and eating behaviors (i.e., harmfulness, wrongness, decision-making), which may lead to engagement in distinct patterns of problematic under- or over-eating behaviors (Figure 4).

Beliefs about thinness and muscularity. Cultural norms and values related to thinness and muscularity are influential in the promotion and maintenance of problematic eating behaviors during adolescence (Striegel, Moore, \& Bulik, 2007). Social norms help individuals understand what society defines as acceptable in terms of eating habits, and body size and shape (Jones, 2004; Sanderson et al., 2008). Body image dissatisfaction results when adolescents believe their body type does not align with cultural definitions of attractiveness. Social norms impacting adolescents' engagement in problematic eating behaviors are related to two sub-types of body image dissatisfaction: the thinness ideal (e.g., Sanderson, Darley, \& Messinger, 2002) and the muscular ideal (e.g., Ridgeway \& 
Tylka, 2005). The thinness ideal can be defined as excessive concern with dieting, preoccupation with one’s weight, and the pursuit of being thinner (Garner, Olmstead, \& Polivy, 1983), while the muscular ideal is the desire for a muscular body reflecting masculinity and male gender roles (Ricciardelli \& McCabe, 2004). Media portrayals of thin or muscular individuals contribute to adolescents' internalization of the thin and muscular ideals as prototypes for physical attractiveness (Agliata \& Tantleff-Dunn, 2004; Anschutz et al., 2011). These belief systems are associated with adolescents' beliefs about their bodies and whether their bodies are consistent with cultural standards of beauty in regard to losing weight and reduction in body size, or gaining weight and increasing muscle mass (Figure 3b). Feeling discrepant from either the thinness or muscular norm is associated with engagement in self-presentation strategies, such as dieting and exercising for aesthetic reasons (Sanderson et al., 2002), and weight training and steroid use (Cafri et al., 2005).

The primary goal of many adolescents involved in organized sports is to remain in peak physical condition in order to compete at elite levels, and oftentimes, one's physical abilities in the sports arena are directly related to body shape and size (Thompson \& Sherman, 2010). Thus, adolescents highly invested in organized sports may be especially susceptible to expectations about body size and shape, and vulnerability to such expectations may result in problematic eating behaviors. Because this is the case, adolescents' beliefs related to thinness and muscularity may explain associations between sports investment and engagement in problematic under- and over-eating behaviors.

Beliefs about food-related behaviors. Body image dissatisfaction beliefs are well-established predictors of problematic eating (e.g., Striegel-Moore \& Bulik, 2007). 
However, adolescents' beliefs about food-related behaviors may also explain associations between sports investment and problematic under- and over-eating during adolescence. Research from a social domain perspective may be useful for elucidating how adolescents' conceptualizations of under- and over-eating behaviors contribute to engagement in problematic eating patterns (e.g., Ferris, 2012).

According to Social Domain Theory (e.g., Turiel, 1989), beliefs about different behaviors may include universal concerns about welfare, rights, and fairness (i.e., moral domain), entail normative and shared expectations (i.e., conventional domain) or health risk concerns (i.e., prudential domain), or involve personal prerogative and individual choice (i.e., personal domain). Ferris (2012) assessed adolescents’ domain-specific beliefs about food-related behaviors, such as eating snacks between meals, eating junk food, dieting, and continuing to eat when already full. Adolescents were asked about the degree to which parents have authority over eating behaviors (conventional beliefs) and how harmful different eating behaviors were (prudential beliefs). These domain-specific judgments about food-related behaviors indicated individual variation in adolescents' conceptualizations of eating behaviors that were aligned with personal, conventional, or prudential domains of social reasoning. In addition, adolescents' beliefs were associated with their actual engagement in dimensions of problematic under- and over-eating behaviors (Ferris, 2012). Viewing food-related behaviors as more harmful was associated with increased under-eating behaviors, while viewing food as requiring less parental input was associated with increased over-eating behaviors. These findings suggest adolescents who are hypersensitive to the risks of unhealthy eating behaviors (e.g., view such behavior as extremely harmful) relative to their peers may engage in higher rates of 
under-eating behaviors. Furthermore, teens who believe they are mature enough to make individual decisions about what foods they consume may view food-related behaviors as a personal issue that is up to them to decide, which may be associated with poorer foodrelated choices and over-eating behaviors.

These findings are consistent with other studies utilizing social cognitive frameworks, whose results indicate that domain-related beliefs and reasoning can be used to explain inter-individual differences in behavior (Metzger \& Smetana, 2009; Nucci, Guerra, \& Lee, 1991). Similarly, adolescents’ beliefs about food may usefully explain associations between youth sports investment and engagement in problematic under- and over-eating. Adolescents' conceptualizations of food-related behaviors may represent a complementary belief system to adolescents' beliefs about their bodies (Figure 3b).

\section{Sports Investment and Problematic Eating: Demographic and Behavioral}

\section{Moderators}

Gender. Previous research suggests that gender differences in body image dissatisfaction and subsequent engagement in problematic eating behaviors may be derived from separate, gender-specific, weight-related concerns (e.g., Petrie, Greenleaf, Reel, \& Carter, 2008; Smolak et al., 2000). Both thinness and muscularity desired by girls and boys, respectively, are often also salient for adolescents involved in sports since physical fitness and the pressure to excel are often intertwined within such environments (Byrne \& McClean, 2001). Females typically desire thin, lean bodies, while males may strive for more muscular physiques as such body types help girls and boys to excel at their chosen sport (e.g., Milligan \& Pritchard, 2006). Because this is the case, it can be expected that the explanatory associations between sports investment and problematic 
under- and over-eating behaviors may differ for girls and boys. Specifically, girls highly invested in sports may be hypersensitive to the risks of unhealthy food-related behaviors (e.g., unnecessary weight gain) and dissatisfied with their bodies (e.g., view themselves as overweight), which may impact greater engagement in under-eating behaviors to achieve a thin, lean body shape. On the other hand, adolescent boys who are highly invested in sports may view food-related decisions as personal and up to them to decide as they engage in over-eating behaviors to increase muscle mass.

Age. Results from previous studies also suggest adolescent age impacts both the availability of organized activities, including sports, and body image concerns resulting from pubertal maturation (Denault \& Poulin, 2009; Makinen, Pukko-Viertomies, Lindberg, Siimes, \& Aalberg 2012). As a result, the explanatory associations between sports investment and engagement in problematic under- and over-eating behaviors may differ for early and late adolescents. For example, greater sports investment may lead to increased body image dissatisfaction and under-eating for early adolescents but not late adolescents because younger teens are more preoccupied with how their bodies have begun to move away from cultural standards of beauty due to pubertal maturation (Bearman, Presnell, Martinez, \& Stice, 2006).

Patterns of organized activity involvement. Finally, adolescents' involvement in additional "non-sports" activities may moderate the associations between sports investment and engagement in problematic under- and over-eating behaviors. Although youth are highly involved in sports during this age period, adolescents are also involved in other organized activities at high levels (e.g., Metzger, Crean, \& Forbes-Jones, 2009). Involvement in additional organized activities, such as church organizations, arts/music 
groups, and club-related activities, may be particularly important for the development of positive beliefs about healthy living and reductions in problematic under- and over-eating behaviors (Hansen et al., 2010; Larson et al., 2006). Capturing unique combinations of organized activity participation through person-centered approaches will allow for the exploration of potential under- and over-eating problems associated with involvement in sports alone versus involvement in sports along with other types of organized activities.

\section{The Current Study}

Participation in sport is the most widely reported organized activity among youth (e.g., Larson \& Seepersad, 2003), and it is the only organized activity which has been examined in relation to adolescents’ eating behaviors. Previous research focusing specifically on adolescents’ sports involvement has found positive associations between sports participation and engagement in problematic under- and over-eating patterns (e.g., Fay \& Lerner, 2013). However, there is a great deal of inconsistency in the measurement of sports involvement and problematic eating behaviors within this previous research.

Assessments of sports involvement have primarily focused on subjective or objective ratings of time commitments to the activity (Bohnert, Fredricks, \& Randall, 2010) and neglected to account for youth’s identification with sports. Sports investment may be more robustly measured as a multidimensional construct consisting of adolescents’ athletic identity status and time/energy commitments to sport. Similarly, previous research examining associations between sports involvement and eating behaviors have focused on clinical levels of under-eating problems and has not considered a wide array of food-related behaviors, including variations in severity dimensions of under- and over-eating behaviors. An examination of a wider array of both 
clinical and non-clinical problematic eating items (e.g., eating fast food, eating snacks, intentionally dieting, counting calories) will allow for a more in-depth understanding of the developmental trajectories of problematic eating among adolescents. Therefore, the first aim of the current study examined associations between sports involvement and engagement in problematic under- and over-eating behaviors utilizing multidimensional measures of sports investment, and under- and over-eating behaviors.

Organized sports potentially serve as contexts where messages about healthy eating and body image are discussed. Adolescents’ beliefs about their bodies (i.e., thinness, muscularity), may be amplified in sports contexts where there is increased pressure to remain in peak physical condition in order to perform at high levels of competition. Sports involvement may also affect how adolescents view food and eatingrelated behaviors. Adolescents who are highly invested in organized sports may develop atypical beliefs about food, such as viewing certain eating behaviors as excessively harmful or outside of their own personal control. Recent research indicates that such judgments are associated with adolescents’ problematic eating behaviors (Ferris, 2012). Thus, the second aim of the current study assessed adolescents' belief systems about food-related behaviors and their bodies as explanatory mechanisms, which have the potential to explain associations between higher levels of sports investment and engagement in problematic under- and over-eating behaviors.

Finally, previous research has not examined how associations between sports investment and problematic eating behaviors may be moderated by adolescents’ age or their participation in distinct patterns of organized activities. Therefore, the third aim of the current study explored whether explanatory associations between sports investment 
and problematic under- and over-eating behaviors vary as a function of adolescents' gender, age, and participation in non-sports activities.

\section{Research Questions and Hypotheses}

\section{Research Question 1}

Are there associations between adolescents' sports investment and engagement in problematic under- and over-eating behaviors?

Hypothesis 1. Capturing the multidimensional nature of sports participation through the construct of sports investment will provide a more in-depth understanding of this activity's contribution to under- and over-eating. Therefore, it is hypothesized that:

a. Increased sports investment will be associated with increased under-eating behaviors. b. Increased sports investment will be associated with decreased over-eating behaviors.

\section{Research Question 2}

Are associations between sports investment and problematic eating behaviors explained by adolescents' beliefs about food-related behaviors and beliefs about thinness and muscularity?

Hypothesis 2. Similar to previous research examining associations between these constructs (Byrne \& McClean, 2001; Ferris, 2012), it is hypothesized that:

a. Beliefs about under-eating behaviors will explain the association between sports investment and problematic under-eating behaviors, and provide a good fit to the data. Increased sports investment will be associated with greater food autonomy of under-eating behaviors, which will, in turn be positively associated with higher levels of under-eating behaviors. 
b. Beliefs about over-eating behaviors will explain the association between sports investment and problematic over-eating behaviors, and provide a good fit to the data. Increased sports investment will be associated with greater food autonomy of overeating behaviors, which will, in turn be positively associated with higher levels of over-eating behaviors.

c. Beliefs about thinness will explain the association between sports investment and problematic under-eating behaviors, and provide a good fit to the data. Increased sports investment will be associated with the desire to be thin, which will, in turn be positively associated with higher levels of under-eating behaviors.

d. Beliefs related to muscularity will explain the association between sports investment and problematic over-eating behaviors, and provide a good fit to the data. Increased sports investment will be associated with the desire to be muscular, which will, in turn be negatively associated with higher levels of over-eating behaviors.

\section{Research Question 3}

Do the previously defined explanatory models vary as a function of adolescent gender, age, and participation in distinct patterns of organized activities?

Hypothesis 3. Previous research indicates that it is important to examine whether such explanatory associations differ for sub-groups of adolescents (Petrie et al., 2008; Wheatley et al., 2012). Therefore, it is hypothesized that:

a. The proposed explanatory models will vary as a function of adolescent gender and will provide a good fit to the data:

a. The indirect pathway through beliefs about thinness will be significant for girls, but not boys. Increased sports investment will be associated with the 
desire to be thin, which will, in turn be positively associated with higher levels of under-eating behaviors for adolescent girls.

b. The indirect pathway through beliefs about muscularity will be significant for boys, but not girls. Increased sports investment will be associated with the desire to be muscular, which will, in turn be positively associated with higher levels of over-eating behaviors for adolescent boys.

b. The proposed explanatory models will vary as a function of adolescent age and will provide a good fit to the data:

a. The indirect pathway through beliefs about under-eating behaviors will be significant for late, but not early adolescents. Increased sports investment will be associated with greater food autonomy of under-eating behaviors, which will, in turn be positively associated under-eating behaviors for older youth.

b. The indirect pathway through beliefs about over-eating behaviors will be significant for late, but not early adolescents. Increased sports investment will be associated with greater food autonomy of over-eating behaviors, which will, in turn be positively associated with over-eating behaviors for older youth.

c. The indirect pathway through beliefs about thinness will be significant for early adolescents, but not late adolescents. Increased sports investment will be associated with the desire to be thin, which will, in turn be positively associated with under-eating behaviors for early adolescents.

d. The indirect pathway through beliefs about muscularity will be significant for early, but not late adolescents. Increased sports investment will be associated 
with the desire to be muscular, which will, in turn be positively associated with over-eating behaviors for early adolescents.

c. The proposed explanatory models will vary as a function of youths' participation in distinct patterns of organized activities and will provide a good fit to the data:

a. Beliefs about under-eating behaviors will explain the association between sports investment and under-eating behaviors for adolescents only involved in sports, but not adolescents involved in sports and other organized activities.

b. Beliefs about over-eating behaviors will explain the association between sports investment and over-eating behaviors for adolescents only involved in sports, but not adolescents involved in sports and other organized activities.

c. Beliefs about thinness will explain the association between sports investment and under-eating behaviors for adolescents only involved in sports, but not adolescents involved in sports and other organized activities.

d. Beliefs about muscularity will explain the association between sports investment and over-eating behaviors for adolescents only involved in sports, but not adolescents involved in sports and other organized activities.

\section{Method}

\section{Participants}

The initial sample consisted of 614 adolescents in grades nine through twelve from two public high schools in the eastern United States. Of the original sample, 4 participants were missing a substantial proportion of key study variables and were removed from further analyses. The final analytic sample included 610 adolescents $(M=$ 15.93, $S D=1.10$, Range $=14-19$ years, $58.6 \%$ female, $41.4 \%$ sophomore class rank). 
Adolescents identified as Caucasian/White $(82.6 \%, n=502)$, African-American/Black (2.3\%, $n=14)$, Asian-American/Pacific Islander (7.1\%, $n=43)$, Hispanic/Latino (2.5\%, $n=15)$, Native American $(.5 \%, n=3)$, biracial/mixed identities $(4.4 \%, n=27)$, and other $(.7 \%, n=4)$. Two participants failed to report their ethnicity. Adolescents' report of their GPA indicated that $41 \%$ of the sample earned “Mostly A's.” Participants' parents varied in education levels, ranging from completion of eighth grade (1.4\% mothers, $n=8 ; 2.2 \%$ fathers, $n=12$ ), high school graduates (26.2\% mothers, $n=153$; 29.5\% fathers, $n=163$ ), completed college (52.8\% mothers, $n=308$; 42.9\% fathers, $n=237$ ), and completed a graduate degree (e.g., Ph.D., MBA; 19.6\% mothers, $n=114$; 25.5\% fathers, $n=141$ ). Some adolescents were unsure of one of their parents' education level (8.2\%, $n=50)$, and 17 participants were missing reports of both mother’s and father's education level (2.8\%). Mother's and father's education level were moderately correlated ( $r=.35, p<.001)$, and were combined to form a single measure representing parental education. A full list of demographic measures completed by participants is listed in Appendix A.

Participants in the current study attended public high school in one of two communities in the eastern United States. Participants from the first community (39.5\%, $n=241)$ resided in a mid-sized city in a mid-Atlantic state with a population of 70,000 residents. Although this city is located in a rural region (U.S. Census, 2010a), this community represents the economic, commercial, and medical epicenter of the region (Oosterhoff, Ferris, \& Metzger, in press). Adolescents from the second community $(60.5 \%, n=369)$ resided in a suburban town in a northeastern state with a population of 12,000 residents. This town was previously an agricultural community; however, 
"suburbanization" from a major metropolitan area to its west has resulted in rapid population growth over the last 20 years (U.S. Census, 2010b).

Two versions of the survey (i.e., A, B) were administered in order to counterbalance the presentation of the Dutch Eating Behavior Questionnaire (DEBQ; van Strien, Frijters, \& Bergers, 1986), and a scale assessing problematic eating behaviors, which was developed by the author for the purpose of the current study (henceforth referred to as the Problematic Eating Behaviors Scale [PEBS]). Survey Version A questionnaire packets presented the DEBQ scale directly after the demographic questions (p. 2) followed by the PEBS (p. 8), while Survey Version B questionnaire packets presented these scales in reverse order (DEBQ: p. 8; PEBS: p. 2). Survey versions were distributed relatively equally (Version A: 52.0\%, $n=317$; Version B: 48.0\%, $n=293$ ).

A series of independent samples t-tests and Pearson chi-square tests were used to examined mean differences in demographic and key study variables based on participant recruitment location (i.e., mid-sized city versus suburban town), and version of the survey completed (i.e., Survey Version A versus Survey Version B). Although the types of organized activities available to adolescents in both communities were relatively similar, participants from the two communities significantly differed on a number of demographic and key study variables (Table 1; Table 2). Participants' also significantly differed on a number of demographic and key study variables based on the version of the survey they completed (Table 3; Table 4). Appendix B provides an overview and potential explanations for the differences that emerged for demographic characteristic and key study variables based on participants' school location and survey version.

\section{Measures}




\section{Sports investment.}

Involvement in organized sports. Adolescents' intensity of involvement in organized sports was assessed using 2 items $(\alpha=.59)$, which measured involvement in school- and community-sponsored athletic teams (e.g., "How often do you participate with a school sports team in an average month?”). Both items were scored using a 5point Likert scale ( 1 = Never; 5 = Very often $)$, and a composite score was created representing participants’ average involvement across school- and community-sponsored sports. In addition, participants' reported the number of hours they were involved in organized school- and community-sponsored sports in an average month using a freeresponse format, and these items were averaged to create a composite score representing hours of organized sports involvement in an average month. Thirteen and six participants' reported an unrealistic estimation of the number of hours each month they were involved in school- and community-sponsored sports (i.e., > 100 hours), respectively. As a result, such cases were recoded to 100 hours per month (e.g., 25 hours per week), which was estimated to be the maximum number of hours adolescents could devote to organized sports given academic commitments and lifestyle factors (e.g., sleep patterns) as well as based on the distribution properties of the variables. In both cases, higher scores indicated greater involvement in organized sports. Participants' subjective (i.e., scale scores) ratings of sports involvement and hours of sports involvement were moderately correlated $(r=.60, p<.001$; Appendix C).

Athletic identity measurement scale (AIMS). Ten items $(\alpha=.94)$ were used to assess participants' identification with the athlete role (e.g., I consider myself an athlete; Brewer et al., 1993). This measure was scored using a 7-point Likert scale ranging from 1 
(strongly disagree) to 7 (strongly agree), and higher scores indicated greater identification with the athlete role (Appendix D).

\section{Problematic Eating Behaviors.}

Dutch Eating Behavior Questionnaire (DEBQ). Thirty-three items were used to assess restrained, emotional, and external eating behaviors (van Strien et al., 1986; Appendix E). Participants' scores on the external and emotional eating subscales were standardized and then averaged to assess over-eating behaviors ( $\alpha=.92$; 23 items), while scores on the restrained eating subscale measured moderate under-eating behaviors ( $\alpha=$ .93; 10 items). Higher scores indicated more problematic under- and over-eating.

Problematic Eating Behaviors Scale (PEBS). Participants completed 17 items, which were created for the purpose of this study to assess engagement in dimensions of problematic under- and over-eating behaviors (Appendix F; Table 5). Items were scored using a 6-point Likert scale ( 1 = Never, 6 = Very often $)$. Under- and over-eating behaviors were divided into subscales based on the severity of the problematic eating behaviors carried out. For example, under-eating behaviors were divided into categories, which separated food conscious behaviors (e.g., "I consistently eat low calorie or reduced fat foods"; $\alpha=.72 ; 3$ items) from more severe under-eating behaviors (e.g., "I intentionally diet"; $\alpha=.78 ; 5$ items). In addition, over-eating behaviors were divided into subcategories representing unhealthy eating behaviors (e.g., "I eat junk food"; $\alpha=.79 ; 5$ items) and binge eating behaviors (e.g., "I binge eat"; $\alpha=.78$; 4 items). Higher scores on each subscale represented greater problematic eating behaviors. This measure was developed through pilot testing with college-aged students. Appendix G outlines the piloting procedures used to develop this measure. 


\section{Domain beliefs about under- and over-eating food-related behaviors.}

Harmfulness beliefs about food. Twenty items were used to assess adolescents’ beliefs about the harmfulness of different food-related behaviors (Ferris, 2012). Subscales were created to distinguish participants’ harmfulness beliefs about under- (e.g., "How harmful is dieting?"; $\alpha=.81 ; 10$ items) and over-eating (e.g., "How harmful is eating fast food regularly?”; $\alpha=.87 ; 10$ items) behaviors. Items were scored using a 5-point Likert scale ( 1 = Not harmful at all, 5 = Extremely harmful $)$, and higher scores indicated greater harmfulness ratings of food-related behaviors (Appendix H).

Wrongfulness beliefs about food. Participants reported how wrong it is to engage in 20 food-related behaviors using a 5-point Likert scale ranging from 1 (Not at all wrong) to 5 (Very wrong). Higher scores indicated stronger beliefs that under- and overeating behaviors are wrong to carry out. Subscales were created to distinguish participants’ wrongfulness beliefs about under- (e.g., “How wrong is dieting?”; $\alpha=.84$; 10 items) and over-eating (e.g., "How wrong is eating fast food regularly?”; $\alpha=.89$; items) behaviors (Appendix H).

Decision-making beliefs about food. Participants completed 17 items asking who in their family should make decisions (i.e., parent versus adolescent) about food-related behaviors. Items were scored using a 5-point Likert scale ranging from 1 (Parent decides alone) to 5 (Adolescent decides alone; Kahn, 1992). Higher ratings indicated greater adolescent unilateral decision-making about different food-related behaviors. Subscales were created to distinguish participants’ decision-making beliefs about under- (e.g., “Who should decide if teens diet?”; $\alpha=.84 ; 8$ items) and over-eating (e.g., "Who should decide if teens eat fast food regularly?’; $\alpha=.83 ; 9$ items) behaviors (Appendix H). 


\section{Beliefs about thinness.}

Drive for thinness. Seven items $(\alpha=.91)$ comprising the "Drive for Thinness” subscale from the Eating Disorders Inventory were used to assess participants' drive for thinness (Garner et al., 1983; Appendix I). For example, participants responded to items, such as, "I think about dieting”, and "I am terrified of gaining weight” using a 6-point Likert scale (1 = Never, 6 = Always). Higher scores indicated greater drive for thinness.

Thinness Body Dissatisfaction. Consistent with previous research, adolescents were presented with a series of seven body size pictures on a spectrum from thin to obese, which were adapted from previous research (Stunkard, Sorensen, \& Schulsinger, 1983; Appendix J). Adolescents circled the image that was closest to their "real” body shape, and the image that was closest to their "ideal” body shape. This item was scored by subtracting participants' “ideal” body image number from their "real” body image number. Positive values (higher scores) indicated that the participant wants to be thinner, while negative values (lower scores) indicated that the participant wants to be heavier.

\section{Beliefs about muscularity.}

Drive for muscularity. Twenty-three items $(\alpha=.95)$ adapted from previous research were used to examine participants’ drive for muscularity (e.g., McCreary, Saucier, Sasse, \& Dorsch, 2004; Appendix K). For example, participants completed items, including, “I wish I were more muscular”, using a 7-point Likert scale (1 = Definitely not, 7 = Definitely). Higher scores indicated greater drive for muscularity.

Muscularity Body Dissatisfaction. Adolescents were presented with a series of four body size pictures on a spectrum from skinny/no muscles to muscular, which was based on previous research, but designed specifically for the purpose of the current study 
(Stunkard, Sorensen, \& Schulsinger, 1983; Appendix L). Adolescents circled the image that was closest to their "real" body shape, and the image that was closest to their "ideal" body shape. This item was scored by subtracting participants' “ideal” body image number from their "real” body image number. Positive values (higher scores) indicated that the participant wants to be more muscular, while negative values (lower scores) indicated that the participant wants to be less muscular.

Organized activity involvement. Fourteen items were used to assess adolescents' subjective rating of how often they are involved in a wide array of organized activities during an average month using a 5-point Likert scale ranging from 1 (Never) to 5 (Very often) (e.g., How often do you, take part in a school art, music, or drama group?; Ferris, Oosterhoff, \& Metzger, 2013). Similar to previous research (Oosterhoff, Ferris, \& Metzger, in press), subscales were created to assess involvement in distinct types of organized activities using participants’ mean score within each organized activity: Church ( $\alpha=.81 ; 4$ items), Volunteering ( $\alpha=.62 ; 3$ items), Community Clubs $(\alpha=.42 ; 3$ items), School Clubs ( $\alpha=.42 ; 2$ items), and Arts/music ( $\alpha=.68 ; 2$ items). Higher scores indicated greater involvement in organized activities during an average month. The subscales utilized in this study were similar to those used in previous research (Eccles \& Barber, 1999; Eccles, Barber, Stone, \& Hunt, 2003), and exhibited similar internal consistencies as an earlier study utilizing a rural sample (Ferris et al., 2013; Appendix C).

Unstructured exercise. Participants’ involvement in unstructured exercise was assessed using two items (CDCb, 2013; Faigenbaum \& Micheli, 2015). Participants responded to the following question, "The U.S. Department of Health and Human Services recommends that children and adolescents between the ages of 6-17 participate 
in 30 minutes of physical activity each day. Examples of physical activity include the following: walking, jogging, running, lifting weights, strength training, stretching/flexibility training, swimming, biking, and yoga/dance/Pilates fitness classes. Outside of structured organized sports contexts, how many days during an average week do you meet the recommended guidelines for exercise?”. The same question was asked inquiring how many days in an average week participants engage in 60 minutes of physical activity each day. For both items, higher scores indicated greater involvement in unstructured exercise in an average week. Participants’ involvement in different time increments (i.e., 30 versus 60 minutes) of unstructured exercise per day were highly correlated $(r=.74, p<.001)$; therefore, participants' responses to the question measuring involvement in unstructured exercise for 30 minutes per day was used in the current analyses (Appendix M).

\section{Procedure}

Adolescents with signed parental consent and assent forms completed the survey. In both high schools, completion of surveys took place during regularly-scheduled class time with trained research assistants present to answer questions. In the mid-sized city, students in Health Education classes (e.g., approximately 25\% of the student body) were eligible to participate, while students enrolled in Physical Education classes (i.e., entire student body) at the high school in the Suburban Town had the opportunity to complete the survey. Two versions of the survey were distributed to participants to counterbalance the presentation of the DEQB and the PEBS in order to reduce the priming effect of exposure to one set of items assessing problematic eating behaviors influencing participants' responses to a second set of items measuring similar constructs (Zeelenberg 
\& Pecher, 2015). Because the topics covered in the questionnaire may produce negative self-evaluation views, all participants were debriefed and given materials outlining psychological services available in their communities (e.g., National Suicide Prevention Lifeline, eating disorder treatment centers). Participating adolescents at each high school were eligible to win 18 randomly drawn cash prizes ranging in value from $\$ 25$ to $\$ 50$.

\section{Data Analysis Strategy}

Study hypotheses were examined using a series of structural equation models in MPlus Version 6 (Muthen \& Muthen, 2010) and AMOS 20 (Byrne, 2013). Both MPlus Version 6 and AMOS 20 were utilized for the subsequent analyses due to the strengths of each program. For instance, MPlus Version 6 is able to test multiple indirect effects simultaneously, which is an improvement over AMOS 20. On the contrary, calculation of the critical ratio (C.R.) of the difference values when comparing standardized parameter estimates in multigroup models is more easily generated in AMOS 20. AMOS 20 was also utilized due to practical reasons; the Psychology Department at West Virginia University has a limited number of software licenses for MPlus Version 6, whereas doctoral students can more easily access AMOS 20.

In both measurement and structural models, model fit statistics, such as chi-square difference, condition fit indices (CFI), and root mean square error of approximation (RMSEA) values were used to assess how well the collected data fit the hypothesized theoretical model. A chi-square difference value of $\leq$ three, a CFI value $\geq .90$, and a RMSEA value $\leq .08$ were used to distinguish a well-fitting model (Hooper, Coughlan, \& Mullen, 2008). Measurement models were first run to assess the robustness of latent variables representing 1) sports investment, 2) domain beliefs about under-eating 
behaviors, 3) domain beliefs about over-eating behaviors, 4) beliefs about muscularity, 5) beliefs about thinness, 6) under-eating behaviors, and 7) over-eating behaviors. Multigroup models tested whether these latent constructs were equivalent across participant gender, data collection location, and survey version completed. Next, structural models examined direct and indirect associations between adolescents' sports investment and measures of under- and over-eating behaviors. All models controlled for participants' BMI, involvement in unstructured exercise, parents' education, and adolescent age and gender. In order to conserve parsimony and reduce unnecessary parameters, bivariate correlations were used to indicate significant associations between control and key study variables to better inform where control variables should be added to the models. In order to improve model fit, non-significant pathways and parameters were trimmed from each model for parsimony. Explanatory variables (i.e., domain beliefs about under-eating behaviors, domain beliefs about over-eating behaviors, beliefs about muscularity, beliefs about thinness) were added to each model to examine indirect associations between sports investment and under- and over-eating behaviors. Multigroup models were used to examine structural differences in associations between sports investment and under- and over-eating behaviors based on adolescents' gender, age, and patterns of involvement in organized activities. Similar to analyses conducted to examine measurement invariance across participant gender, data collection location, and survey version completed, multigroup analyses compared an unconstrained model to one in which model parameters were constrained to be equal across comparison groups (e.g., boys versus girls). Structural weights were examined in order to assess whether main effects differed across comparison groups. Post-hoc examinations of the C.R. of the 
difference values were then examined for all significant standardized parameter estimates. Hierarchical and iterative clustering analyses were used to create the moderating variable representing patterns of organized activity involvement. In both the full and multigroup models, bootstrap procedures (Bollen \& Stine, 1990) with biascorrected confidence intervals were utilized to estimate direct and indirect effects.

\section{Results}

\section{Data Cleaning and Preliminary Analyses}

Data were analyzed for missing values, outliers, and distribution properties of all continuous variables. Tables 6 - 10 present the means, standard deviations, and correlations for key study variables. There was a small amount of missing data $(<2 \%)$ for demographic characteristic and key study variables. However, 44 (7.7\%) participants failed to complete the items needed to compute muscularity body image dissatisfaction scores, and 47 (8.3\%) participants did not report the number of hours they were involved in organized sports in an average month. Since structural equation modeling is robust against problems related to variable distribution and auxiliary variables can be used to estimate missing data (Graham, 2003), missing data on demographic characteristic and key study variables was not imputed. Six cases had multivariate outliers; however, these cases were retained after examination of the individual survey responses for each of these participants.

\section{Measurement Model: Sports Investment and Food-related Beliefs Latent Constructs}

Using SPSS AMOS 20, structural equation modeling with maximum likelihood estimation was used to examine the measurement structure of the key latent constructs (Figure 5). Adolescents' reports of athletic identity status, subjective scale ratings of 
organized sports involvement, and free-response reports of the number of hours per month involved in organized sports served as indicators of a sports investment latent variable. Adolescents' harmfulness, wrongfulness, and should decision-making judgments about under- and over-eating behaviors, were used as indicators of their respective latent variables measuring domain beliefs about under- and over-eating. (NOTE: The initial model also included four additional latent constructs assessing participants' beliefs about thinness [i.e., thinness body dissatisfaction and drive for thinness scores], beliefs about muscularity [i.e., muscularity body dissatisfaction and drive for muscularity scores], over-eating behaviors [i.e., DEBQ over-eating scale, PEBS binge eating scale, and PEBS unhealthy eating behaviors scale], and under-eating behaviors [i.e., DEBQ moderate under-eating scale, PEBS severe under-eating scale, and PEBS food conscious behaviors scale]. However, significant multicollinearity among the indicators of these latent variables led to model specification errors including negative error variances [See Appendix $\mathrm{N}$ for a lengthier discussion of these modeling issues]. Thus, in subsequent structural models, the indicators of these latent variables were included as individual manifest variables [Figure 3b]).

The measurement model provided a good fit to the data $\left(\chi^{2} / d f=3.01\right.$, CFI $=.98$, RMSEA $=.057)$. In order to achieve a well-fitting model, modifications were made to the proposed conceptual model based on theory and statistical modification indices generated from AMOS 20 (Byrne, 2014). Similar to previous research, which has assessed domainrelated beliefs as latent variables (e.g., Metzger, Oosterhoff, Palmer, \& Ferris, 2014), the measurement errors for similar judgments were allowed to covary across the latent variables assessing beliefs about under-eating and over-eating behaviors (i.e., should 
decision-making and wrongfulness beliefs about under-eating with should decisionmaking and wrongfulness beliefs about over-eating). Table 11 displays the factor loadings for the indicators of each latent variable and the covariances among the latent constructs.

Factor loadings for all indicator variables were strong and significant (.62 - .97). However, the should decision-making indicators loaded poorly onto both domain belief latent variables (Domain beliefs under-eating $=.16$; Domain beliefs about over-eating $=$ .17). Participants' should decision-making beliefs were retained as indicators because three indicators were originally hypothesized and the model provided a good fit to the data. Higher scores on both latent variables corresponded to greater food autonomy (i.e., less harm, less wrong to carry out, more adolescent unilateral decision-making) of underand over-eating behaviors. All latent constructs were significantly related (Table 11). Multigroup measurement models were run to compare the fit of the measurement model for boys versus girls, participants from the mid-sized city versus youth from the suburban town, and youth completing Survey Version A versus participants completing Survey Version B (Byrne, 2004). A model in which measurement weights were freely estimated for boys and girls did not significantly differ from a model where the measurement weights were constrained to be equal $\left(\Delta \chi^{2}=13.69, d f=9, p=.13\right)$. Similarly, the free and constrained models did not differ based on data collection location $\left(\Delta \chi^{2}=10.11, d f=9, p=.34\right)$. Finally, the a model in which the measurement weights were freely estimated for participants completing Survey Version A and Survey Version B did not significantly differ from a model where the measurement weights were constrained to be equal across the two groups $\left(\Delta \chi^{2}=4.51, d f=6, p=.61\right)$. 


\section{Structural Models: Associations between Sports Investment and Problematic Eating}

Using AMOS 20, a structural equation model tested associations between participants' sports investment and varying severity levels of under- (i.e., food conscious behaviors, moderate under-eating, severe under-eating) and over-eating (i.e., unhealthy eating behaviors, over-eating, binge eating) behaviors (Figure 6). The model provided a good fit to the data $\left(\chi^{2} / d f=2.63, \mathrm{CFI}=.97, \mathrm{RMSEA}=.052\right.$, structural parameters listed in Table 12). Higher BMI scores were associated with higher levels of food conscious behaviors, and moderate and severe under-eating behaviors, but lower levels of unhealthy eating behaviors. Higher levels of involvement in unstructured exercise were associated with higher levels of food conscious behaviors and lower levels of unhealthy eating behaviors. Adolescent girls were more likely to engage in food conscious behaviors, and moderate and severe under-eating behaviors, over-eating behaviors, and binge eating behaviors. Sports investment was marginally associated with lower levels of food conscious behaviors.

\section{Structural Models: Examining Personal and Food-related Beliefs as Mediators}

The latent variables assessing participants' beliefs about under- and over-eating behaviors, and muscularity body dissatisfaction, thinness body dissatisfaction, drive for muscularity, and drive for thinness manifest variables were added to the model as

explanatory mechanisms (Figure 4). The model provided a good fit to the data $\left(\chi^{2} / d f=\right.$ 3.02, CFI $=.94$, RMSEA $=.058)$.

Several significant indirect effects emerged between sports investment and problematic eating behaviors via the personal and food-related beliefs variables. Sports investment was indirectly associated with increased binge eating behaviors through 
increased muscularity body dissatisfaction ( $\mathrm{B}=.01$, S.E. $=.004, p=.02$, [C.I. $95 \%$ : .003 , .02]). Sports investment was also indirectly associated with increased over-eating behaviors via increased drive for muscularity scores $(\mathrm{B}=.10$, S.E. $=.02, p<.001$, [C.I. 95\%: .07, .13]). On the other hand, sports investment was associated with increased engagement in moderate (B $=.02$, S.E. $=.01, p=.04$, [C.I. 95\%: .004, .03]) and severe $(\mathrm{B}=.01$, S.E. $=.004, p=.04$, [C.I. 95\%: .002, .02]) under-eating behaviors through greater food autonomy of over-eating behaviors.

Several significant paths also emerged which were not a part of significant indirect paths (Table 13). Higher sports investment was marginally associated with lower food autonomy of under-eating behaviors. Greater food autonomy of under-eating behaviors was associated with higher levels of each severity dimension of under-eating behavior measured. Higher drive for thinness scores were associated with higher binge eating behaviors, higher levels of all three under-eating behaviors assessed, and lower levels of unhealthy eating behaviors. Thinness body dissatisfaction was associated with higher levels of unhealthy eating behaviors and lower levels of food conscious behaviors.

Multigroup models. Multigroup analyses assessed whether the above mediated models varied as a function of adolescents' gender, age, and involvement in church, arts/music, and club-related activities. As mentioned previously, MPlus Version 6 was used for hypothesis testing related to the research question of interest, while AMOS 20 was used for model fit indices, model comparison statistics, and calculation of the C.R. of the difference values. Tables 14 - 16 display the standardized parameter estimates for each model.

\section{Demographic characteristic moderators.}


Gender differences. Multigroup modeling indicated that structural weights significantly differed for boys and girls $\left(\Delta \chi^{2}=195.63, d f=26, p<.001\right)$. All indirect pathways that resulted were significant for girls, but not boys. For girls, sports investment was indirectly associated with increased binge eating behaviors $(\mathrm{B}=.05$, S.E. $=.02, p=$ .03 , [C.I. 95\%: .01, .05]) and moderate under-eating behaviors (B $=.03$, S.E. $=.01, p=$ .04, [C.I. 95\%: .02, .03]) through drive for muscularity scores. Additionally for girls, sports investment was associated with increased food conscious behaviors ( $B=-.03$, S.E. $=.01, p=.005$, [C.I. 95\%: -.04, -.01]) and severe under-eating behaviors (i.e., PEBS; $\mathrm{B}=$ -.03 , S.E. $=.01, p=.048$, [C.I. 95\%: -.03, -.004]) through food autonomy of under-eating. Several paths that were not a part of indirect paths significantly differed for boys and girls. For girls but not boys, higher drive for thinness scores were associated with higher levels of food conscious behaviors (C.R. $=-2.22)$. For boys, higher sports investment was associated with higher levels of binge eating behaviors $(C . R .=-2.24)$.

Age differences. Structural weights did not differ for early versus late adolescents $\left(\Delta \chi^{2}=34.23, d f=26, p=.13\right)$.

Organized activity involvement moderators. In order to create categories representing patterns of organized activity involvement for use as a moderating variable, person-centered approaches were utilized. Participants' involvement in distinct types of organized activities (i.e., sports, church, arts/music, community clubs, school clubs, and volunteering) was submitted to a two-stage cluster analysis involving both agglomerative (i.e., Ward's method) and partitioning/iterative (i.e., K-means) approaches (Henry, Tolan, \& Gorman-Smith, 2005; Metzger et al., 2009). Through Ward's hierarchical agglomerative cluster analysis, dendograms and external criteria, including centroid 
graphs and pseudo- $F$ scores, were examined to determine the number of organized activity clusters present (Henry et al., 2005). A three-cluster solution was identified using this approach. Follow-up analyses utilizing non-hierarchical K-means cluster analysis were used to provide information about the stability of the three-cluster solution resulting from Ward's method. The three-cluster solution that was generated included clusters representing participants who were 1) highly involved in arts/music and involved in sports at low levels, 2) involved in all organized activities at low levels, and 3) highly involved in sports and involved in all other organized activities at low levels (Figure 7).

However, no clusters emerged which were high on both sports and another activity (as was hypothesized). Thus, in order to examine the impact of involvement in multiple organized activities simultaneously (i.e. sports plus other activities), each organized activity, aside from organized sports involvement, was examined as a separate moderator (i.e., church, arts/music, club-related activities). The church ( $\alpha=.81 ; 4$ items) and arts/music ( $\alpha=.68 ; 2$ items) activity moderating variables were created based on recommendations from previous researchers (Ferris et al., 2013; Oosterhoff et al., in press). However, in order to account for the poor reliabilities that resulted across the volunteering ( $\alpha=.62$; 3 items), community clubs ( $\alpha=.42$; 3 items), school clubs ( $\alpha=$ .42; 2 items) subscales and, as well factor cross-loadings emerging in the principal components analysis, items assessing volunteering, community clubs, and school clubs were combined to create a subscale representing club-related activities. The club-related activities subscale had an improved reliability when compared to the three individual subscales ( $\alpha=.69$; 8 items). Church, arts/music, and club-related activity involvement were each recoded into low versus high levels of involvement based on the median value 
for each scale. Table 17 displays the number of participants and percentage of the sample in the church, arts/music, and club-related activities groups.

High versus low levels of church involvement. Structural weights marginally differed for youth involved in church at high versus low levels $\left(\Delta \chi^{2}=48.13, d f=35, p=\right.$ .07). For participants involved in church at low levels, sports investment was indirectly associated with increased binge eating behaviors ( $\mathrm{B}=.04$, S.E. $=.02, p=.04$, [C.I. $95 \%$ : $-.001, .05$ ]) and moderate under-eating behaviors (B $=.03$, S.E. $=.01, p=.008$, [C.I. 95\%: .004, .03]) through drive for muscularity scores. These indirect paths were not significant for youth involved in low levels of church. Other indirect paths were only significant for youth involved in high levels of church activities. For these youth, sports investment was indirectly associated with increased food conscious behaviors $(B=.04$, S.E. $=.02, p=.04$, [C.I. 95\%: .01, .06]) and unhealthy eating behaviors $(\mathrm{B}=-.08$, S.E. $=$ $.03, p=.001$, [C.I. 95\%: -.07, -.03]) via food autonomy of over-eating behaviors.

There were also several direct effects which differed for youth engaged in church activities at high versus low levels. For participants involved in church at low levels, higher sports investment was associated with lower thinness body dissatisfaction (C.R. = 2.02). Additionally, less food autonomy of over-eating behaviors was associated with higher levels of moderate (C.R. $=2.22)$ and severe $(C . R .=2.20)$ under-eating behaviors. Involvement in arts/music activities. Structural weights did not differ based on youths' level of involvement in arts/music activities $\left(\Delta \chi^{2}=29.77, d f=27, p=.32\right)$. High versus low levels of club-related activity involvement. Structural weights significantly differed for youth based on level of involvement in club-related activities $\left(\Delta \chi^{2}=69.06, d f=31, p<.001\right)$. Several indirect paths were significant for youth involved 
in club-related activities at high levels, but not significant for youth involved at low levels. For youth highly engaged in clubs, sports investment was indirectly associated with increased food conscious behaviors $(\mathrm{B}=-.02$, S.E. $=.01, p=.002$, [C.I. 95\%: -.04, $.02])$, and both moderate (B = -.01, S.E. $=.01, p=.003$, [C.I. 95\%: -.02, -.01]) and severe (B = -.03, S.E. $=.01, p=.005$, [C.I. 95\%: -.03, -.01]) under-eating behaviors through food autonomy of under-eating behaviors. Sports investment was also indirectly associated with increased severe under-eating behaviors via drive for muscularity scores $(\mathrm{B}=.03$, S.E. $=.01, p=.001$, [C.I. 95\%: .02, .03]). Finally, sports investment was indirectly associated with increased food conscious behaviors through food autonomy of over-eating behaviors $(\mathrm{B}=.02$, S.E. $=.01, p=.048$, [C.I. 95\%: .01, .03]) for youth highly involved in club activities.

One additional direct path significantly differed for youth engaged in clubs at high versus low levels. For participants involved in club-related activities at low levels, lower food autonomy of over-eating behaviors was associated with higher levels of severe under-eating behaviors (C.R. = 3.95).

\section{Discussion}

This study examined associations between organized sports involvement and problematic under- and over-eating behaviors utilizing more nuanced measures of sports investment and assessing multiple sub-clinical dimensions of under- and over-eating behaviors. Additionally, this study incorporated social domain beliefs as explanatory mechanisms alongside complementary belief systems concerning adolescents' views of their own thinness and muscularity. Finally, this study investigated whether explanatory associations between sports investment and problematic eating outcomes varied by 
adolescent gender, age, and involvement in church, club-related, and arts/music activities. Results indicate that organized sports are a contextual experience contributing not only to adolescents' developing conceptualizations of food-related behaviors and beliefs about muscularity, but also an activity associated with variation in adolescents’ problematic eating behaviors.

Previous research has found both positive and negative outcomes associated with participation in organized sports (Eccles et al., 2003; Larson \& Seeparsed, 2003). Consistent with previous research (Fay et al., 2011; Fay \& Lerner, 2013; Holm-Denoma et al., 2009; Petrie \& Greenleaf, 2012), findings from the current study are mixed and suggest that sports involvement differentially impacts adolescents’ engagement in problematic under- and over-eating behaviors. For instance, these findings suggest that sports involvement is an environment, which may deter under-eating behaviors but promote over-eating behaviors among adolescent boys. For girls, sports investment was indirectly associated with binge eating behaviors, food conscious behaviors, and moderate and severe under-eating behaviors via both their attitudes toward food-related behaviors (i.e., how wrong, harmful, and subject to parental supervision eating behaviors were), and beliefs about their bodies' degree of thinness and muscularity. Thus, sports involvement appears to influence how adolescent girls conceptualize under- and overeating behaviors and think about their bodies. These cognitive processes were directly related to girls’ engagement in distinct dimensions of problematic eating behaviors, which is similar to findings from previous research (e.g., Ferris, 2012; Metzger \& Smetana, 2009). In addition, involvement in sports simultaneously with church or clubrelated activities was associated with positive and negative eating outcomes, respectively. 
Overall, these findings provide further insight into the link between youth sports engagement and problematic eating behavior by pointing to the importance of adolescent self- and food-related beliefs, assessing how these processes differ for boys and girls, and accounting for adolescent athletes’ engagement in other organized activities.

Several findings that emerged were consistent for all youth. Adolescents who were highly invested in organized sports engaged in higher levels of binge eating and over-eating behaviors, and this effect was mediated by both increased muscularity body dissatisfaction and higher drive for muscularity scores. The image of the modern athlete is constantly evolving (e.g., Eisenberg, Wall, \& Neumark-Sztainer, 2012). Today’s professional athletes are stronger, faster, and have more muscular and leaner body types than athletes from previous generations. These athletes serve as role models for athletic ability as well as the body type to which adolescents are encouraged to aspire. Thus, sports investment may be problematic for adolescents as such involvement may foster engagement in unhealthy over-eating behaviors as a means to compensate for negative self-evaluations and beliefs about their muscularity.

Additionally, youth highly invested in sports reported lower food autonomy of over-eating behaviors (i.e., more harmful, wrong, and subject to parental control), and lower food autonomy of over-eating behaviors was associated with higher levels of moderate and severe under-eating behaviors. Lower food autonomy of over-eating behaviors may place youth who are highly invested in organized sports at a health disadvantage. Coaches, teammates, and parents may communicate the need to maximize athletic performance by achieving a specific body type, and such messages may encourage athletic adolescents to engage in under-eating behaviors. Furthermore, 
adolescents who reported lower food autonomy of under-eating behaviors engaged in lower levels of each under-eating behavior assessed in the current study. These findings are inconsistent with previous research (Ferris, 2012), and may indicate that youth who are hypersensitive to the negative health risks associated with restrictive eating behaviors, may be less likely to engage in under-eating patterns, such as counting calories and intentionally dieting.

Contrary to earlier work, sports investment was not associated with drive for thinness scores (e.g., Van Durme, Goossens, \& Braet, 2012), though these previous researchers did not account for participants’ desire to be muscular (i.e., drive for muscularity) when examining the influence of sports participation on adolescents' desire to be thinner. However, the current finding is consistent with the results of two recent studies (Fay et al., 2011; Fay \& Lerner, 2013), which found no links between sports involvement and thinness beliefs. Higher drive for thinness scores were also associated with higher levels of food conscious behaviors and severe under-eating behaviors, which indicates that adolescents', especially girls', preoccupation with thinness may impact under-eating regardless of sports involvement.

\section{Gender Differences in Associations between Sports Investment and Problematic Under- and Over-eating Behaviors}

Being highly invested in organized sports was associated with the development of negative self-evaluation views (i.e., desiring more muscularity), reports of lower food autonomy of over-eating behaviors, and negative eating-related outcomes for adolescent girls. Although sports investment was not directly associated with eating outcomes, the inclusion of beliefs about food-related behaviors and the body's degree of thinness and 
muscularity as explanatory mechanisms, helped elucidate these associations, and provided further insight into reasons why participation in sports may result in problematic under- and over-eating behaviors for adolescent girls. Conversely, participation in organized sports was directly associated with binge eating for adolescent boys, which may suggest that such involvement supports deviation from normative, healthy eating patterns in order to achieve an athletic body type for success in one's chosen sport. No significant indirect effects resulted between sports investment, and problematic underand over-eating behaviors for adolescent boys, which also indicates that additional belief systems, including jock identity status, warrant further investigation in future studies.

For adolescent girls, sports involvement was indirectly associated with problematic under- and over-eating outcomes through beliefs about both food-related behaviors and their bodies’ degree of muscularity. For girls, being highly invested in organized sports was linked to higher levels of dieting, counting calories, and skipping meals via reports of greater food autonomy of under-eating behaviors. Attributing grater food autonomy to under-eating behaviors may lead to greater monitoring of the quantity and type of food consumed, and belief that such behaviors are acceptable to carry out and necessary for performance success. Girls highly invested in organized sports who possess such beliefs may, as a result, also be more likely to engage in restrictive eating behaviors to increase the likelihood of achieving the lean body type emphasized for their given sport (Byrne \& McLean, 2001).

In addition, girls' sports investment was associated with higher levels of moderate under-eating behaviors and binge eating behaviors through greater muscularity body dissatisfaction. Girls who are more involved in sports may be more invested in having 
lean, muscular bodies, which allow them to excel in their sport of choice. However, the current findings also indicate that increased sports involvement leads these girls to be less satisfied with their muscularity. Dissatisfaction with one's muscular physique may be derived from the media's recent emphasis on muscle tone and firm-looking bodies when defining “ideal beauty” for women (Bordo, 2003; Marchessault, 2000). Such muscular dissatisfaction, coupled with sport-specific pressures, may lead adolescent girls to engage in cyclical patterns of binge eating, and purging through vomiting or over exercising to achieve a more muscular build, as well as to possess a body that also aligns with recentlyrefined definitions of attractiveness (Anderson, Petrie, \& Neumann, 2011; Goldfield, Blouin, \& Woodside, 2006; Grogan, 2010; Hallsworth, Wade, \& Tiggemann, 2005). While sports appear to be a context that negatively affects adolescent girls’ attitudes towards their bodies’ muscularity and influences beliefs about food, sports investment was not significantly associated with either set of beliefs for adolescent boys. This potentially suggests that these belief systems are shaped outside sporting contexts (e.g., mass media, peer and family weight-teasing criticisms; Boroughs et al., 2010; Helfert \& Warschburger, 2011; Holsen, Jones, Birkeland, 2012; Pompper, 2010). On the other hand, sports investment was directly associated with higher levels of binge eating behaviors for adolescent boys. Organized sports involvement may promote binge eating behaviors because boys highly invested in sports may consume large quantities of calories more quickly because they believe such behavior will support the development of a muscular body type. Increasing the body's degree of muscularity may involve a combination of weight lifting, strength training, and aerobic exercise; however, adolescent boys' concerned with gaining muscle mass may also believe it is necessary to 
incorporate binge eating behaviors in to their diet in order to perform better and avoid injuries (Gill, Henwood, \& McLean, 2005; Steinfeldt et al., 2011).

\section{Associations between Sports Investment and Problematic Eating Outcomes by Involvement in Church, Club-related, and Arts/music Activities}

When youth were highly involved in church activities, sports investment was associated with both under- and over-eating through adolescents’ beliefs about overeating behaviors. Engagement in church activities, in addition to organized sports, may provide youth with a context for the promotion of healthy eating practices and more positive self-evaluation views (e.g., Chiswick \& Mirtcheva, 2013). Consistent with previous research, the current findings suggest that messages conveyed within religious contexts may place increased focus on developing adolescents' self-esteem and selfworth, and stress how such aspects of one’s identity are not dependent solely on physical fitness, athletic ability, or attractiveness (Benjamins, 2012; Dodor, 2012; Yonker, Schnabelrauch, \& DeHaan, 2012).

When youth were highly involved in club-related activities, sports investment was associated with negative eating outcomes. Adolescents who are highly invested in sports, while also participating in school- and community-sponsored clubs and volunteering at high levels, may have more time commitments compared to youth who are only involved in one organized activity. Previous research suggests that being overly involved in organized activities adversely impacts adolescent development (i.e., Over-scheduling Hypothesis; Mahoney \& Vest, 2012), although less research has focused on how overscheduling contributes to youths’ eating behaviors. Greater scheduling demands faced by this subgroup of adolescents may contribute to a decreased focus on healthy lifestyle 
patterns, including less emphasis on healthy eating behaviors, as youth try to balance simultaneous involvement in a variety of activities.

Significant moderation effects were not observed for youth involved in arts/music activities and organized sports, compared to youth who were only involved in sports. Youth who are involved in arts/music activities and sports may be more immune to social pressures, including Westernized, cultural standards of beauty, which may result in lower levels of problematic eating (Barber, Eccles, \& Stone, 2001; Oosterhoff et al., in press).

Overall, involvement in sports in conjunction with other organized activities, specifically church activities, has the potential to lead to positive food-related outcomes during adolescence, while participation in club-related activities in addition to organized sports may result in negative eating behaviors. These findings call for further examination of organized activity contexts simultaneously as different patterns of involvement may provide youth with distinct developmental experiences (e.g., Ferris et al., 2013; Metzger et al., 2009).

\section{Exercise, BMI, and Problematic Under- and Over-eating Behaviors}

After accounting for youths’ sports investment, participation in unstructured exercise was associated with higher levels of food conscious behaviors and lower levels of unhealthy eating behaviors. Unstructured exercise, outside formally organized sports, has the potential to promote healthy lifestyle patterns during adolescence (Department of Health, 2008). Unstructured exercise may also be critical for the development of healthy lifestyle patterns as such behavior outside organized sports may be more intrinsically motivated (i.e., driven by the adolescent) and enjoyable compared to the highly structured exercise occurring during organized sports practices or competitions (Schneider \& Kwan, 
2013). These findings point to the importance of accounting for the unique effects sports involvement and unstructured exercise have on problematic eating in future research.

Similarly, BMI was positively associated with higher levels of each dimension of under-eating measured, and lower levels of unhealthy eating behaviors after accounting for the impact of sports investment. These findings are consistent with the results of Walcott and colleagues' (2003) research, which found BMI to be the strongest predictor of body image dissatisfaction, and associations between body image dissatisfaction and weight-management strategies, including dieting and exercising (e.g., Slater \& Tiggemann, 2011). Thus, it is not surprising that adolescents with higher BMI scores are dissatisfied with their bodies, and as a result, engage in higher levels of under-eating behaviors and lower levels of unhealthy eating behaviors to achieve a desired physique.

\section{Limitations and Future Directions}

The results of this study should be interpreted in light of several limitations. The current study utilized a cross-sectional, correlational research design, which prevents discussion of causality between predictor and outcome variables, as well as intraindividual change over time in sports investment, beliefs about under- and over-eating behaviors, measures of thinness and muscularity body dissatisfaction, and problematic under- and over-eating behaviors. Third unmeasured variables, including the type of sport adolescents participate in (i.e., lean versus non-lean sports; team versus individual sports), could also account for these associations. The narrow age range of participants (i.e., ages $14-19$ years) prevents the generalizability of the findings to early adolescents (e.g., ages 12 - 13 years), and may have contributed to the fact that age did not moderate any model associations. Future research should examine these constructs over time, 
specifically prior to puberty (i.e., pre-adolescence) through early/emerging adulthood (e.g., college- and noncollege-aged adults), as access to organized sports, body image concerns, beliefs about food-related behaviors, and problematic under- and over-eating behaviors may be qualitatively different constructs across age groups.

Self-report survey measures are subject to socially desirable responses, and participants may have felt uncomfortable answering questions about sensitive topics, such as one's body shape/size, and engagement in problematic under- and over-eating behaviors. Specifically, participants' self-report of height and weight were used to calculate BMI scores. Future research should incorporate self-report survey questionnaires as well as measure participants' height and weight using a tape measure and scale during data collection to account for socially desirable reporting.

Furthermore, one of the primary outcome measures of interest, the Problematic Eating Behaviors Scale (i.e., PEBS), was designed by the author for the purpose of this study. Although this measure was pilot tested with college students before use with adolescent samples, and it exhibited solid internal and external reliabilities (see Appendix G for review of pilot data collection and analyses), the four subscales (i.e., food conscious behaviors, severe under-eating behaviors, unhealthy eating behaviors, and binge eating behaviors) were unable to be used in conjunction with the moderate underand over-eating subscales of the Dutch Eating Behavior Questionnaire (i.e., DEBQ) as indicators of two latent variables measuring under- and over-eating (see Appendix $\mathrm{N}$ for a review of measurement model issues). The PEBS was designed to assess qualitatively different aspects of problematic under- and over-eating behaviors increasing in severity along a continuum of normative eating behaviors to problematic eating behaviors 
meeting criteria for clinical diagnosis (Figure 8). However, further pilot testing with adolescents as well as cognitive interviewing with youth should be conducted in order to refine this measure for future studies.

Multicollinearity issues were also encountered when the drive for muscularity scale and muscularity body dissatisfaction measure, and drive for thinness scale and thinness body dissatisfaction measure were used as indicators of the beliefs about muscularity and beliefs about thinness latent variables, respectively. As a result, the proposed model including four mediating variables (i.e., beliefs about under- and overeating behaviors, beliefs about thinness, and beliefs about muscularity) could not be examined. Instead, the two indicators of the beliefs about muscularity and the two indicators of the beliefs about thinness latent variables were added to the model as observed, mediating variables. Future research is needed to identify additional indicators of adolescents' beliefs about muscularity and thinness, potentially appearance concerns or scale ratings of the importance of being muscular/thin, in order to more accurately define these constructs so each measure can be used as an indicator of a higher-order latent variable. Also, the muscularity body dissatisfaction scale, which asked adolescents to provide their current and ideal body size/shapes based on the silhouettes illustrated (see Appendix L), did not provide participants with an option if their body shape/size lacked muscularity or leanness (e.g., if participants were overweight/obese). As a result, a number of participants (i.e., $n=44$ ) failed to respond to this question. These two items were adapted based on the original Figure Rating Scale developed by Stunkard and colleagues (1983) to assess body image dissatisfaction; however, to the author's knowledge, no previous studies have used this format to assess body image 
dissatisfaction related specifically to muscularity. Additional pilot testing of this measure with youth is necessary to better inform the development of silhouettes that accurately reflect a wider range of muscular body types, and do not exclude participants who lack muscularity or who are overweight.

Although many significant direct and indirect effects resulted in the current study, the generalizability of the findings is limited due to several factors. The majority of participants from the current sample was White/Caucasian (82.6\%), and had parents who were highly educated (72.4\% mothers and 68.4\% fathers completed college). A mid-sized city and suburban town were represented; however, future research is needed with rural and urban youth, and samples, which vary in ethnicity and socioeconomic status. Also, the magnitude of effects was small, and may have been influenced by the large $(N=610)$ sample size, and therefore, such effects should be interpreted with caution until they are replicated by future research.

Future research must consider whether the explanatory associations investigated in the current study vary as a function of participants’ sport-type, specifically distinctions between youth involved in team versus individual sports, and lean versus non-lean sports. Much research on adolescents and emerging adults involved in sports has focused on such differences (e.g., Agans \& Geldhof, 2012); however, scholars have yet to investigate whether associations between a multidimensional construct of sports investment, which combines physical activity involvement and activity identity components, and dimensions of problematic under- and over-eating behaviors can be explained by adolescents' beliefs about food and beliefs their bodies’ degree of thinness and muscularity. For instance, 
such associations may be amplified for youth involved in weight-dependent sports, including wrestling or cheerleading (Baum, 2006; Thompson, 2003).

Finally, the measurement model, which included latent constructs representing adolescents' beliefs about under- and over-eating behaviors, fit the data well and these latent constructs held together; however, adolescents' should decision-making beliefs loaded onto the latent constructs at low levels (Table 11). These findings suggest that the degree of harmfulness and wrongfulness adolescents’ attribute to under- and over-eating behaviors may assess a different dimension of problematic eating behavior compared to the degree of regulation adolescents' believe parents should have over teenagers' eating. Previous research (e.g., Ferris, 2012) also indicates distinct associations between adolescents’ harmfulness and decision-making beliefs, and engagement in under- and over-eating behaviors. As a result, future research should also examine youths' domain beliefs about under- and over-eating behaviors as separate manifest, mediating variables.

Adolescence is a developmental time period marked by substantial changes in personal belief systems related to eating behaviors and the body's degree of muscularity and thinness, the formation of one’s social identity based on participation in organized activities of interest and value, and the establishment of healthy lifestyle factors, including the development of healthy eating behaviors. Findings from the current study add to the growing literature on organized sports involvement, body image dissatisfaction, and engagement in problematic under- and over-eating behaviors. These results indicate that the way adolescents conceptualize food-related behaviors and beliefs about their bodies, which have the potential to be shaped within organized sports contexts, impacts their engagement in different aspects of problematic eating behaviors. 
Scholars, health professionals, and leaders within the field of organized youth sports should be aware of the nutrition and exercise implications associated with organized sports involvement during adolescence. 


\section{References}

Agans, J.P., \& Geldhof, G.J. (2012). Trajectories of participation in athletics and positive youth developmental: The influence of sport type. Applied Developmental Science, 16(3), 151-165.

Agliata, D., \& Tantleff-Dunn, S. (2004). The impact of media exposure on males’ body image. Journal of Social and Clinical Psychology, 23, 7-22.

American Psychiatric Association (APA) (2013). Diagnostic and statistical manual of mental disorders: DSM-5. Washington, D.C.: American Psychiatric Association.

Anderson, C.M., Petrie, T.A., \& Neumann, C.S. (2011). Psychosocial correlates of bulimic symptoms among NCAA Division-I female collegiate gymnasts and swimmers/divers. Journal of Sport \& Exercise Psychology, 33, 483-505.

Anschutz, D., Van Strien, T., \& Engels, R.C.M.E. (2011). Exposure to slim images in mass media: Television commercials as reminders of restriction in restrained eaters. Psychology of Popular Media Culture, 1, 48-59.

Barber, B. L., Eccles, J. S., \& Stone, M. R. (2001). Whatever happened to the jock, the brain, and the princess? Young adult pathways linked to adolescent activity involvement and social identity. Journal of Adolescent Research, 16(5), 429-455.

Baum, A. (2006). Eating disorders in the male athlete. Sports Medicine, 36(1), 1-6.

Bearman, S.K., Presnell, K., Martinez, E., \& Stice, E. (2006). The skinny on body dissatisfaction: A longitudinal study of adolescent girls and boys. Journal of Youth and Adolescence, 35(2), 229-241.

Beato-Fernandez, L., Rodriguez-Cano, T., Belmonte-Llario, A., \& Martinez-Delgado, C. 
(2004). Risk factors for eating disorders in adolescents. A Spanish communitybased longitudinal study. Journal of European Child and Adolescent Psychiatry, 13(5), 287-294.

Benjamins, M.R. (2012). Religious beliefs, diet, and physical activity among Jewish Americans. Journal for the Scientific Study of Religion, 51(3), 588-597.

Bloodworth, A.J., Petroczi, A., Bailey, R., Pearce, G., \& McNamee, M.J. (2012). Doping and supplementation: The attitudes of talented young athletes. Scandinavian Journal of Medicine and Science in Sports, 22(2), 293-301.

Bohnert, A., Fredricks, J., \& Randall, E. (2010). Capturing unique dimensions of youth organized activity involvement: Theoretical and methodological considerations. Review of Education Research, 80(4), 576-610.

Bollen, K.A., \& Stine, R. (1990). Direct and indirect effects: Classical and bootstrap estimates of variability. Sociological Methodology, 20, 115-140.

Bordo, S. (2003). Unbearable weight: Feminism, Western culture, and the body (Tenth Anniversary Edition). Berkeley: University of California Press.

Boroughs, M.S., Krawczyk, R., \& Thompson, J.K. (2010). Body dysmorphic disorder among diverse racial/ethnic and sexual orientation groups: Prevalence estimates and associated factors. Sex Roles, 63, 725-737.

Brewer, B.W., Van Raalte, J.L., \& Linder, D.E. (1993). Athletic identity: Hercules’ muscles or Achilles heel? International Journal of Sport Psychology, 24, 237254. 
Byrne, B. M. (2004). Testing for multigroup invariance using AMOS graphics: A road less traveled. Structural Equation Modeling: A Multidisciplinary Journal, 11(2), 272-300. doi:10.1207/s15328007sem1102_8

Byrne, B.M. (2014). Structural equation modeling with AMOS: Basic concepts, applications, and programming. Routledge.

Byrne, S., \& McLean, N. (2001). Eating disorders in athletes: A review of the literature. Journal of Science and Medicine in Sport, 4, 145-159.

Cameron, A.J., Ball, K., Pearson, N., Lioret, S., Crawford, D.A., Campbell, K., Hesketh, K., \& McNaughton, S.A. (2012). Socioeconomic variation in diet and activityrelated behaviors of Australian children and adolescents aged 2-16 years.

Pediatric Obesity, 7(4), 329-342.

Cafri, G., Thompson, J. K., Ricciardelli, L., McCabe, M., Smolak, L., \& Yesalis, C. (2005). Pursuit of the muscular ideal: Physical and psychological consequences and putative risk factors. Clinical Psychology Review, 25, 215-239.

Center for Disease Control (CDCa). (2013). Childhood obesity facts. Retrieved from http://www.cdc.gov/healthyyouth/obesity/facts.htm

Center for Disease Control (CDCb). (2013). Youth Physical Activity Guidelines Toolkit. Retrieved from http:/www.cdc.gov/healthyyouth/physicalactivity/guidelines.htm Chiswick, B.R., \& Mirtcheva, D.M. (2013). Religion and child health: Religious affiliation, importance, and attendance and health status among American youth. Journal of Family Economic Issues, 34, 120-140.

Dawes, N.P., Vest, A., \& Simpkins, S. (2014). Youth participation in organized and 
informal sports activities across childhood and adolescence: Exploring the relationships of motivational beliefs, developmental stage and gender. Journal of Youth and Adolescence, 43, 1374-1388.

Daddis, C. (2010). Adolescent peer crowds and patterns of belief in the boundaries of personal authority. Journal of Adolescence, 33(5), 699-708.

de Sausmarez, E., \& Dunsmuir, S. (2011). Overweight and obese children's weightrelated behaviors and cognitions: Assessment and intervention. The British Psychological Society, 28(4), 14-22.

Denault, A., \& Poulin, F. (2009). Intensity and breadth of participation in organized activities during the adolescent years: Multiple associations with youth outcomes. Journal of Youth and Adolescence, 38, 1199-1213.

Department of Health. (2008). Physical activity guidelines for Americans. Retrieved from http://www.health.gov/paguidelines/guidelines/chapter2.aspx

Dodor, B. (2012). The impact of religiosity on health behaviors and obesity among African Americans. Journal of Human Behavior in the Social Environment, 22(4), 451-462.

Dowdell, E.B., \& Santucci, M.E. (2004). Health risk behavior assessment: Nutrition, weight and tobacco use in one urban seventh-grade class. Public Health Nursing, 21(2), 128-136.

Eccles, J. S., \& Barber, B. L. (1999). Student council, volunteering, basketball, or marching band: What kind of extracurricular involvement matters? Journal of Adolescent Research, 14(1), 10-43. doi:10.1177/0743558499141003 
Eccles, J. S., Barber, B. L., Stone, M., \& Hunt, J. (2003). Extracurricular activities and adolescent development. Journal of Social Issues, 59(4), 865-889. doi:10.1046/j.0022-4537.2003.00095.x

Eisenberg, M.E., Wall, M., \& Neumark-Sztainer, D. (2012). Muscle-enhancing behaviors among adolescent girls and boys. Pediatrics, 130(6), 1019-1026.

Faigenbaum, A.D., \& Micheli, L.J. (2015). Youth resistance training. Sports Medicine Bulletin, 32(2), 28.

Fauth, R.C., Roth, J.L., \& Brooks-Gunn, J. (2007). Does the neighborhood context alter the link between youth’s after-school time activities and developmental outcomes? A multilevel analysis. Developmental Psychology, 43(3), 760-777.

Fay, K., Economos, C., Lerner, R.M., Becker, A.E., \& Sacheck, J. (2011). The association between sports participation and athletic identity with eating pathology among college-aged males and females. Eating Weight Disorders, 16(2), e102-e112.

Fay, K., \& Lerner, R.M. (2013). Weighing in on the issue: A longitudinal analysis of influence of selected individual factors and the sports context on the developmental trajectories of eating pathology among adolescents. Journal of Youth and Adolescence, 42, 33-51.

Ferrand, C., Magnan, C., Rouveix, M., \& Filaire, E. (2007). Disordered eating, perfectionism and body-esteem of elite synchronized swimmers. European Journal of Sport Science, 7(4), 223-230.

Ferris, K. A. (2012). Adolescent autonomy development and problematic eating patterns 
(Order No. 1520597). Available from ProQuest Dissertations \& Theses Full Text. (1095688787). Retrieved from http://search.proquest.com/docview/1095688787? accountid $=2837$

Ferris, K.A., Oosterhoff, B., \& Metzger, A. (2013). Organized activity involvement among rural youth: Gender differences in associations between activity type and developmental outcomes. Journal of Research in Rural Education, 28(13), 1-16.

Fletcher, A.C., Nickerson, P., \& Wright, K.L. (2003). Structured leisure activities in middle childhood: Links to well-being. Journal of Community Psychology, 31, $641-659$.

Garner, D.M., \& Garfinkel, P.E. (1979). The eating attitudes test: An index of the symptoms of anorexia nervosa. Psychological Medicine, 9, 273-279.

Garner, D.M., Olmstead, M.P., \& Polivy, J. (1983). Development and validation of a multidimensional eating disorder inventory for anorexia nervosa and bulimia. International Journal of Eating Disorders, 2(2), 15-34.

Gill, R., Henwood, K., \& McLean, C. (2005). Body projects and regulation of normative masculinity. Body \& Society, 11(1), 37-62.

Goldfield, G., Blouin, A., \& Woodside, D. (2006). Body image, binge eating, and bulimia nervosa in male bodybuilders. The Canadian Journal of Psychiatry, 51, 160-168.

Golley, R.K., Hendrie, G.A., \& McNaughton, S.A. (2011). Scores on the dietary guideline index for children and adolescents are associated with nutrient intake and socioeconomic position but not adiposity. Journal of Nutrition, 141, 13401347.

Graham, J.W. (2003). Adding missing-data-relevant variables to FIML-based structural 
equation models. Structural Equation Modeling: A Multidisciplinary Journal, 10(1), 80-100.

Greenleaf, C., Petrie, T., Reel, J., \& Carter, J. (2010). Psychosocial risk factors of bulimic symptomatology among female athletes. Journal of Clinical Sport Psychology, 4, 177-190.

Grogan, S. (2010). Promoting positive body image in males and females: Contemporary issues and future directions. Sex Roles, 63, 757-765.

Hallal, P.C., Victora, C.G., Azevedo, M.R., \& Wells, J.C.K. (2006). Adolescent physical activity and health. Sports Medicine, 36(12), 1019-1030.

Hallsworth, L., Wade, T., \& Tiggemann, M. (2005). Individual differences in male bodyimage: An examination of self-objectification in recreational body builders. British Journal of Health Psychology, 10, 453-465.

Hansen, D. M., Larson, R. W., \& Dworkin, J. B. (2003). What adolescents learn in organized youth activities: A survey of self-reported developmental experiences. Journal of Research on Adolescence, 13, 25-55.

Hansen, D.M., Skorupski, W.P., \& Arrington, T.L. (2010). Differences in developmental experiences for commonly used categories of organized youth activities. Journal of Applied Developmental Psychology, 31(6), 413-421.

Hausenblas, H.A., \& McNally, K.D. (2004). Eating disorder prevalence and symptoms for track and field athletes and nonathletes. Journal of Applied Sport Psychology, 16, 274-286.

Henry, D.B., Tolan, P.H., \& Gorman-Smith, D. (2005). Cluster analysis in family psychology research. Journal of Family Psychology, 19(1), 121-132. 
Helfert, S., \& Warschburger, P. (2011). A prospective study on the impact of peer and parental pressure on body dissatisfaction in adolescent girls and boys. Body Image, 8, 101-109.

Holm-Denoma, J.M., Scaringi, V., Gordon, K.H., Van Orden, K.A., Joiner, T.E. (2009). Eating disorder symptoms among undergraduate varsity athletes, club athletes, independent exercisers, and nonexercisers. International Journal of Eating Disorders, 42, 47-53.

Holsen, I., Jones, D.C., \& Birkeland, M.S. (2012). Body image satisfaction among Norwegian adolescents and young adults: A longitudinal study of the influence of interpersonal relationships and BMI. Body Image, 9, 201-208.

Hooper, D., Coughlan, J., \& Mullen, M. (2008). Structural equation modeling: Guidelines for determining model fit. Electronic Journal of Business Research Methods, 6(1), 53-60.

Jacobi, C., Abascal, L., \& Taylor, C.B. (2004). Screening for eating disorders and highrisk behavior: Caution. International Journal of Eating Disorders, 36, 280-295.

Jacobs, J. E., Vernon, M. K., \& Eccles, J. (2005). Activity choices in middle childhood: The roles of gender, self-beliefs, and parents’ influence. In J. L. Mahoney \& R. W. Larson (Eds.), Organized activities as contexts of development: Extracurricular activities, after-school and community programs (pp. 235-254). Mahwah, NJ: Erlbaum.

Jones, D.C. (2004). Body image among adolescent girls and boys: A longitudinal study. Developmental Psychology, 40(5), 823-835.

Kahn, P.H. (1992). Children's obligatory and discretionary moral judgments. Child 
Development, 63, 416-430.

Keel, P.K., \& Forney, K.J. (2013). Psychological risk factors for eating disorders. International Journal of Eating Disorders, 46, 433-439.

Krug, I., Villarejo, C., Jimenez-Murcia, S., Perpina, C., Vilarrasa, N., Granero, R., Cebolla, A., Botella, C., Montserrat-Gill de Bernabe, M., Penelo, E., Casella, S., Islam, M.A., Orekhova, E., Casanueva, F.F., Karwautz, A., Menchon, J.M., Treasure, J., \& Fernandez-Aranda, F. (2012). Eating-related environmental factors in underweight eating disorders and obesity: Are there common vulnerabilities during childhood and early adolescence?. Journal of European Eating Disorders Review, 21, 202-208.

Larson, R. W., Hansen, D. M., \& Moneta, G. (2006). Differing profiles of developmental experiences across types of organized activities. Developmental Psychology, 42(5), 849-863. doi:10.1037/0012-1649.42.5.849

Larson, R., \& Seepersad, S. (2003). Adolescents’ leisure time in the United States: Partying, sports, and the American experiment. New Directions for Child and Adolescent Development, 99, 53-64.

Lieberman, M., Gauvin, L., Bukowski, W.M., \& White, D.R. (2001). Interpersonal influence and disordered eating behaviors in adolescent girls: The role of peer modeling, social reinforcement, and body-related teasing. Eating Behavior, 2(3), 215-236.

Linver, M.R., Roth, J.L., \& Brooks-Gunn, J. (2009). Patterns of adolescents’ participation in organized activities: Are sports best when combined with other activities? Developmental Psychology, 45(2), 354-367. 
Mahoney, J.L. \& Vest, A.E. (2012). The over-scheduling hypothesis revisited: Intensity of organized activity participation during adolescence and young adult outcomes. Journal of Research on Adolescence, 22(3), 409-418.

Makinen, M., Puukko-Viertomies, L., Lindberg, N., Siimes, M.A., \& Aalberg, V. (2012). Body dissatisfaction and body mass in girls and boys transitioning from early to mid-adolescence: Additional role of self-esteem and eating habits. BMC Psychiatry, 12, 1-8.

Marchessault, G. (2000). One mother and daughter approach to resisting weight preoccupation. In B. Miedema, J. M. Stoppard, \& V. Anderson (Eds.), Women’s bodies, women's lives (pp. 203-226). Toronto: Sumach.

Martinsen, M., Bratland-Sanda, S., Eriksson, A.K., \& Sundgot-Borgen, J. (2010). Dieting to win or to be thin? A study of dieting and disordered eating among adolescent elite athletes and non-athlete controls. British Journal of Sports Medicine, 44, 7076. doi:10.1136/bjsm.2009.068668

Mayo Foundation for Medical Education and Research (MFMER) (2013). Eating disorders. Retrieved from http://www.mayoclinic.com/health/eatingdisorders/DS00294/DSECTION=complications

McCreary, D.R., Saucier, D.M., Sasse, D.K., \& Dorsch, K.D. (2004). Measuring the drive for muscularity: Factorial validity of the drive for muscularity scale in men and women. Psychology of Men and Masculinity, 5(1), 49-58.

Metzger, A., Crean, H. F., \& Forbes-Jones, E. L. (2009). Patterns of organized activity participation in urban, early adolescents. Journal of Early Adolescence, 29, 426-442. 
Metzger, A., Oosterhoff, B., Palmer, C.A., \& Ferris, K.A. (2014). Dimensions of citizenship: Associations among adolescents’ beliefs, political attitudes, and civic judgments. PS: Political Science \& Policy, 47(2), 443-448.

Metzger, A., \& Smetana, J. (2009). Adolescent civic and political engagement: Associations between domain-specific judgments and behavior. Child Development, 80(2), 433-441.

Miller, E., \& Halberstadt, J. (2005). Media consumption, body image and thin ideals in New Zealand men and women. New Zealand Journal of Psychology, 34(3), 189195.

Milligan, B., \& Pritchard, M. (2006). The relationship between gender, type of sport, body dissatisfaction, self esteem, and disordered eating behaviors in division I athletes. Athletic Insight: The Online Journal of Sport Psychology, 8(1), 32-46.

Mintz, L.B., O’Halloran, M.S., Mulholland, A.M., \& Schneider, P.A. (1997). Questionnaire for eating disorder diagnoses: Reliability and validity of operationalizing DSM-IV criteria into a self-report format. Journal of Counseling Psychology, 44, 63-79.

Muthen, L.K., \& Muthen, B.O. (2010). Mplus User's Guide: Statistical Analysis with Latent Variables: User’s Guide. Muthen \& Muthen.

Nucci, L.P., Guerra, N., \& Lee, J. (1991). Adolescent judgments of the personal, prudential, and normative aspects of drug usage. Developmental Psychology, 27, 841-848.

Ogden, C.L., Carroll, M.D., Curtin, L.R., Lamb, M.M., \& Flegal, K.M. (2010). 
Prevalence of high body mass index in U.S. children and adolescents, 2007-2008. The Journal of the American Medical Association, 303(3), 242-249. doi:10.1001/jama.2009.2012.

Oosterhoff, B., Ferris, K.A., \& Metzger, A. (in press). Adolescents’ sociopolitical values in the context of organized activity involvement. Youth \& Society.

Peck, L.D., \& Lightsey, O.R. (2008). The eating disorders continuum, self-esteem, and perfectionism. Journal of Counseling \& Development, 86, 184-192.

Petrie, T., \& Greenleaf, C. (2012). Eating disorders in sport. In S. Murphy (Ed.), Oxford Handbook of Sport and Performance Psychology (pp. 635-659). New York: Oxford University Press.

Petrie, T.A., Greenleaf, C., Reel, J., \& Carter, J. (2008). Prevalence of eating disorders and disordered eating behaviors among male collegiate athletes. Psychology of Men \& Masculinity, 9(4), 267-277.

Pompper, D. (2010). Masculinities, the metrosexual, and media images: Across dimensions of age and ethnicity. Sex Roles, 63, 682-696.

Ranby, K.W., Aiken, L.S., MacKinnon, D.P., Elliot, D.L., Moe, E.L., McGinnis, W., \& Goldberg, L. (2009). A mediation analysis of the ATHENA intervention for female athletes: Prevention of athletic-enhancing substance use and unhealthy weight loss behaviors. Journal of Pediatric Psychology, 34(10), 1069-1083.

Ricciardelli, L. A., \& McCabe, M. P. (2004). A biopsychosocial model of disordered eating and the pursuit of muscularity in adolescent boys. Psychological Bulletin, 130, 179-205.

Ridgeway, R. T., \& Tylka, T. L. (2005). College men’s perceptions of ideal body 
composition and shape. Psychology of Men \& Masculinity, 6, 209-220.

Rosendahl, J., Bormann, B., Aschenbrenner, K., Aschenbrenner, F., \& Strauss, B. (2009). Dieting and disordered eating in German high school athletes and non-athletes. Scandinavian Journal of Medicine \& Science in Sports, 19(5), 731-739.

Ruhm, C.J. (2012). Understanding overeating and obesity. Journal of Health Economics, 31(6), 781-796.

Sanderson, C.A., Darley, J.M., \& Messinger, C.S. (2002). "I’m not as thin as you think I am": The development and consequences of feeling discrepant from the thinness norm. Personality and Social Psychology Bulletin, 28(2), 172-183.

Sanderson, C.A., Wallier, J.M., Stockdale, J.E., \& Yopyk, D.J.A. (2008). Who feels discrepant and how does feeling discrepant matter? Examining the presence and consequences of feeling discrepant from personal and social norms related to thinness in American and British high school girls. Journal of Social and Clinical Psychology, 27(9), 995-1020.

Sanford-Martens, T. C., Davidson, M. M., Yakushko, O. F., Martens, M. P., Hinton, P., \& Beck, N. (2005). Clinical and subclinical eating disorders: An examination of collegiate athletes. Journal of Applied Sport Psychology, 17, 79-86.

Schneider, M.L. \& Kwan, B.M. (2013). Psychological need satisfaction, intrinsic motivation and affective response to exercise in adolescents. Psychology of Sport and Exercise, 14, 776-785.

Shanmugam, V., Jowett, S., \& Meyer, C. (2012). Eating psychopathology amongst athletes: Links to current attachment styles. Eating Behaviors, 13(1), 5-12.

Simpkins, S.D., Delgado, M.Y., Price, C.D., Quach, A., \& Starbuck, E. (2013). 
Socioeconomic status, ethnicity, culture, and immigration: Examining the potential mechanisms underlying Mexican-origin adolescents’ organized activity participation. Developmental Psychology, 49(4), 706-721.

Slater, A., \& Tiggemann, M. (2011). Gender differences in adolescent sport participation, teasing, self-objectification and body image concerns. Journal of Adolescence, 34, 455-463.

Smolak, L., Murnen, S.K., \& Ruble, A.E. (2000). Female athletes and eating problems: A meta-analysis. International Journal of Eating Disorders, 27(4), 371-380.

Smolak, L. \& Stein, J.A. (2010). A longitudinal investigation of gender role and muscle building in adolescent boys. Sex Roles, 63, 738-746.

Steinfeldt, J.A., Halterman, A.W., Gomory, A., Gilchrist, G.A., \& Steinfeldt, M.C. (2011). Drive for muscularity and conformity to masculine norms among college football players. Psychology of Men \& Masculiniy, 12(4), 324-338.

Striegel-Moore, R.H., \& Bulik, C.M. (2007). Risk factors for eating disorders. American Psychologist, 62(3), 181-198.

Stunkard, A., Sorenson, T., \& Schulsinger, F. (1983). Use of the Danish adoption register for the study of obesity and thinness. In: Kety S., Rowland, L., Sidman, R., \& Mathysse, S. (Eds.) Genetics of Neurological and Psychiatric Disorders (pp. 115120). New York: Raven Press.

Sundgot-Borgen, J., \& Torstveit, M.K. (2010). Aspects of disordered eating continuum in elite high-intensity sports. Scandinavian Journal of Medicine and Science in Sports, 20(2), 112-121.

Swanson, S.A., Crow, S.J., Le Grange, D., Swendsen, J., \& Merikangas, K.R. (2011). 
Prevalence and correlates of eating disorders in adolescents: Results from the national comorbidity survey replication adolescent supplement. Archives of General Psychiatry, 68(7), 714-723. doi:10.1001/archgenpsychiatry.2011.22.

Swinburn, B.A., Sacks, G., Hall, K.D., McPherson, K., Finegood, D.T., Moodie, M.L., \& Gortmaker, S.L. (2011). The global obesity pandemic: Shaped by global drivers and local environments. The Lancet, 378, 804-814.

Thelen, M.H., Mintz, L.B., \& Vander Wal, J.S. (1996). The bulimia test - revised: Validation with DSM-IV criteria for bulimia nervosa. Psychological Assessment, 2, 219-221.

Thompson, R.A. (2003). Cheerleader weight standards. Eating Disorders: The Journal of Treatment \& Prevention, 11(1), 87-90.

Thompson, R. A., \& Sherman, R. T. (2010). Eating disorders in sport. New York: Routledge.

Torstveit, M.K., Rosenvinge, J.H., \& Sundgot-Borgen, J. (2008). Prevalence of eating disorders and the predictive power of risk models in female elite athletes: A controlled study. Scandinavian Journal of Medicine \& Science in Sports, 18, 108118.

Turiel, E. (1989). Domain-specific social judgments and domain ambiguities. MerrillPalmer Quarterly, 35(1), 89-114.

U.S. Census Bureau. (2010a). 2010 urban and rural classification and urban area criteria. Retrieved from http://www.census.gov/geo/reference/ua/urban-rural2010.html

U.S. Census Bureau. (2010b). State and county quickfacts: Mount Sinai CDP, New York. 
Retrieved from http://quickfacts.census.gov/qfd/states/36/3649066.html

Van Durme, K., Goossens, L., \& Braet, C. (2012). Adolescent aesthetic athletics: A group at risk for eating pathology?. Eating Behaviors, 13, 119-122.

van Strien, T., Frijters, J.E., Bergers, G.P., \& Defares, P.B. (1986). The Dutch Eating Behavior Questionnaire (DEBQ) for assessment of restrained, emotional, and external eating behavior. International Journal of Eating Disorders, 5(2), 295315.

Walcott, D.D., Pratt, H.D., \& Patel, D.R. (2003). Adolescents and eating disorders: Gender, racial, ethnic, sociocultural, and socioeconomic issues. Journal of Adolescent Research, 18(3), 223-243.

Wheatley, S., Khan, S., Szekely, A.D., Naughton, D.P., \& Petroczi, A. (2012). Expanding the female athlete triad concept to address a public health issue. Performance Enhancement \& Health, 1(1), 10-27.

White, J., \& Halliwell, E. (2010). Examination of a sociocultural model of excessive exercise among male and female adolescents. Body Image, 7, 227-233.

Wood, N., \& Petrie, T. (2010). Body dissatisfaction, ethnic identity, and disordered eating among African American women. Journal of Counseling Psychology, 57(2), 141-153.

Yonker, J.E., Schnabelrauch, C.A., \& DeHaan, L.G. (2012). The relationship between spirituality and religiosity on psychological outcomes in adolescents and emerging adults: A meta-analytic review. Journal of Adolescence, 35, 299-314.

Zeelenberg, R., \& Pecher, D. (2015). A method for simultaneously counterbalancing 
condition order and assignment of stimulus materials to conditions. Behavior Research Methods, 47(1), 127-133. 
Table 1

Descriptive Statistics for Demographic Variables by School Location

\begin{tabular}{|c|c|c|c|c|c|c|c|c|c|}
\hline & \multicolumn{4}{|c|}{$\begin{array}{l}\text { Mid-Sized City } \\
\quad(n=241)\end{array}$} & \multicolumn{4}{|c|}{$\begin{array}{l}\text { Suburban Town } \\
\quad(n=369)\end{array}$} & \multirow{2}{*}{$\begin{array}{c}\text { School } \\
\text { Comparison } \\
\text { Test-Statistic }\end{array}$} \\
\hline & $M$ & $S D$ & Range & $\%$ & $M$ & $S D$ & Range & $\%$ & \\
\hline Age & 15.96 & 0.91 & $14-19$ & - & 15.91 & 1.20 & $14-18$ & - & .56 \\
\hline GPA & 5.75 & 1.60 & $1-7$ & - & 6.04 & 1.03 & $2-7$ & - & $-2.51^{*}$ \\
\hline $\begin{array}{l}\text { Parents' } \\
\text { Education }\end{array}$ & 2.98 & 0.67 & $1-4$ & - & 2.87 & 0.59 & $1.5-4$ & - & $2.20 *$ \\
\hline Height & 66.93 & 4.03 & $58-80$ & - & 66.07 & 3.93 & $55-76$ & - & $2.61^{* *}$ \\
\hline Weight & 145.82 & 34.93 & $90-338$ & - & 139.18 & 31.29 & $71-295$ & - & $2.43^{*}$ \\
\hline BMI & 22.74 & 4.36 & $14.91-47.14$ & - & 22.29 & 3.90 & 14.91-38.01 & - & 1.32 \\
\hline Gender & - & - & - & $\begin{array}{l}57.8 \% \\
\text { Female }\end{array}$ & - & - & - & $\begin{array}{l}59.1 \% \\
\text { Female }\end{array}$ & .09 \\
\hline Class Rank & - & - & - & $\begin{array}{c}70.5 \% \\
\text { Sophomore }\end{array}$ & - & - & - & $\begin{array}{l}31.5 \% \\
\text { Seniors }\end{array}$ & $152.96 * * *$ \\
\hline Ethnicity & - & - & - & $\begin{array}{c}80.8 \% \\
\text { Caucasian/ } \\
\text { White }\end{array}$ & - & - & - & $\begin{array}{c}83.7 \% \\
\text { Caucasian/ } \\
\text { White }\end{array}$ & $13.95 *$ \\
\hline $\begin{array}{l}\text { Survey } \\
\text { Version }\end{array}$ & - & - & - & $\begin{array}{c}60.2 \% \\
\text { Version A }\end{array}$ & - & - & - & $\begin{array}{c}53.4 \% \\
\text { Version B }\end{array}$ & $10.73^{* *}$ \\
\hline
\end{tabular}

Note. ${ }^{+} p=.05-.08, * p<.05, * * p<.01, * * * p<.001$. Height values displayed in inches. Weight values displayed in pounds. 
Table 2

Descriptive Statistics for Key Study Variables by School Location

\begin{tabular}{|c|c|c|c|c|c|c|c|}
\hline & \multicolumn{3}{|c|}{$\begin{array}{l}\text { Mid-Sized City } \\
\quad(n=241)\end{array}$} & \multicolumn{3}{|c|}{$\begin{array}{c}\text { Suburban Town } \\
(n=369)\end{array}$} & \multirow{2}{*}{$\begin{array}{c}\begin{array}{c}\text { School } \\
\text { Comparisor }\end{array} \\
\text { Test } \\
\text { Statistic } \\
\end{array}$} \\
\hline & $M$ & $S D$ & Range & $M$ & $S D$ & Range & \\
\hline \multicolumn{8}{|l|}{ Sports Investment } \\
\hline Sports & 2.61 & 1.46 & $1-5$ & 2.83 & 1.46 & $1-5$ & $-1.86^{+}$ \\
\hline Sports - Hours & 12.37 & 16.55 & $0-100$ & 16.65 & 23.49 & $0-100$ & $-2.53 *$ \\
\hline AIMS & 2.69 & 1.15 & $1-5$ & 2.75 & 1.15 & $1-5$ & -.63 \\
\hline \multicolumn{8}{|l|}{ Domain Beliefs about Under-eating } \\
\hline Harmfulness Beliefs & 2.85 & .59 & $1-4.40$ & 2.77 & .69 & $1-5$ & 1.60 \\
\hline Wrongfulness Beliefs & 2.81 & .68 & $1-4.50$ & 2.74 & .77 & $1-5$ & 1.22 \\
\hline Should Decision-making Beliefs & 3.43 & .74 & $1.38-5$ & 3.48 & .84 & $1-5$ & -.86 \\
\hline \multicolumn{8}{|l|}{ Domain Beliefs about Over-eating } \\
\hline Harmfulness Beliefs & 3.21 & .66 & $1-4.70$ & 2.92 & .72 & $1-5$ & $5.00 * * *$ \\
\hline Wrongfulness Beliefs & 3.17 & .75 & $1-5$ & 2.90 & .79 & $1-5$ & $4.17 * * *$ \\
\hline Should Decision-making Beliefs & 3.56 & .78 & $1.44-5$ & 3.71 & .78 & $1.56-5$ & $-2.28 *$ \\
\hline \multicolumn{8}{|l|}{ Manifest Mediating Variables } \\
\hline Drive for Thinness & 2.61 & 1.21 & $1-6$ & 2.75 & 1.36 & $1-6$ & -1.32 \\
\hline Thinness Body Dissatisfaction & 1.00 & 1.18 & $-2-5$ & 1.15 & 1.23 & $-2-6$ & -1.54 \\
\hline Drive for Muscularity & 3.14 & 1.06 & $1-5.78$ & 3.16 & 1.15 & $1-6$ & -.26 \\
\hline Muscularity Body Dissatisfaction & -.50 & .93 & $-3-2$ & -.47 & 1.04 & $-3-3$ & -.31 \\
\hline \multicolumn{8}{|l|}{ Under-eating Behaviors } \\
\hline Food Conscious Behaviors & 2.20 & .88 & $1-5.67$ & 2.38 & 1.09 & $1-6$ & $-2.27 *$ \\
\hline Moderate Under-eating & 2.19 & .82 & $1-4.70$ & 2.21 & .95 & $1-5$ & -.25 \\
\hline Severe Under-eating & 1.88 & .83 & $1-6$ & 1.94 & .87 & $1-5$ & -.84 \\
\hline \multicolumn{8}{|l|}{ Over-eating Behaviors } \\
\hline Unhealthy Eating Behaviors & 2.67 & .73 & $1-5$ & 2.97 & .90 & $1-6$ & $-4.39 * * *$ \\
\hline Over-eating Behaviors & 2.40 & .63 & $1-4.52$ & 2.42 & .73 & $1-4.78$ & -.41 \\
\hline Binge Eating Behaviors & 1.81 & .75 & $1-6$ & 2.08 & .98 & $1-6$ & $-3.83 * * *$ \\
\hline \multicolumn{8}{|l|}{ Exploratory Moderating Variables } \\
\hline Arts/music Activities & 1.80 & 1.09 & $1-5$ & 2.00 & 1.34 & $1-5$ & $3.27^{+}$ \\
\hline Church Activities & 2.17 & 1.10 & $1-5$ & 1.89 & .84 & $1-5$ & $-1.94 * *$ \\
\hline Club-related Activities & 1.56 & .58 & $1-3.67$ & 1.66 & .62 & $.89-3.83$ & $-2.08 *$ \\
\hline \multicolumn{8}{|l|}{ Control Variable } \\
\hline Exercise - 30 & 4.54 & 1.90 & $1-7$ & 4.73 & 1.89 & $1-7$ & -1.21 \\
\hline
\end{tabular}

$$
\text { Note. }{ }^{+} p=.05-.10, * p<.05, * * p<.01, * * * p<.001 \text {. }
$$


Table 3

Descriptive Statistics for Demographic Variables by Survey Version

\begin{tabular}{|c|c|c|c|c|c|c|c|c|c|}
\hline & \multicolumn{4}{|c|}{ Version A } & \multicolumn{4}{|c|}{ Version B } & \multirow{2}{*}{$\begin{array}{c}\begin{array}{c}\text { Version } \\
\text { Comparison }\end{array} \\
\text { Test-Statistic }\end{array}$} \\
\hline & $M$ & $S D$ & Range & $\%$ & $M$ & $S D$ & Range & $\%$ & \\
\hline Age & 15.92 & 1.06 & $14-19$ & - & 15.94 & 1.13 & $14-18$ & - & -.19 \\
\hline GPA & 5.69 & 1.46 & $1-7$ & - & 6.19 & 1.01 & $1-7$ & - & $-4.85 * * *$ \\
\hline $\begin{array}{l}\text { Parents' } \\
\text { Education }\end{array}$ & 2.94 & 0.61 & $1.5-4$ & - & 2.88 & 0.64 & $1-4$ & - & 1.09 \\
\hline Height & 66.6 & 33.87 & $55-77.5$ & - & 66.21 & 3.91 & $57-80$ & - & 1.22 \\
\hline Weight & 144 & 33.87 & $85-338$ & - & 139.38 & 31.7 & $71-268$ & - & $1.73^{+}$ \\
\hline BMI & 22.72 & 4.18 & $15.96-47.14$ & - & 22.2 & 3.97 & 14.91-36.61 & - & 1.54 \\
\hline Gender & - & - & - & $\begin{array}{l}52.8 \% \\
\text { Female }\end{array}$ & - & - & - & $\begin{array}{l}64.8 \% \\
\text { Female }\end{array}$ & $8.86^{* *}$ \\
\hline $\begin{array}{l}\text { Class } \\
\text { Rank }\end{array}$ & - & - & - & $\begin{array}{c}46.5 \% \\
\text { Sophomore }\end{array}$ & - & - & - & $\begin{array}{c}35.8 \% \\
\text { Sophomore }\end{array}$ & $8.09 *$ \\
\hline $\begin{array}{l}\text { School } \\
\text { Location }\end{array}$ & - & - & - & $\begin{array}{c}81.3 \% \\
\text { Caucasian/ } \\
\text { White } \\
54.3 \% \\
\text { Suburban } \\
\text { Town }\end{array}$ & - & - & - & $\begin{array}{c}\text { 83.9\% } \\
\text { Caucasian/ } \\
\text { White } \\
67.2 \% \\
\text { Suburban } \\
\text { Town }\end{array}$ & $10.73^{* *}$ \\
\hline
\end{tabular}

Note. ${ }^{+} p=.05-.08,{ }^{*} p<.05,{ }^{* *} p<.01,{ }^{* * *} p<.001$. Height values displayed in inches. Weight values displayed in pounds. 
Table 4

Descriptive Statistics for Key Study Variables by Survey Version

\begin{tabular}{|c|c|c|c|c|c|c|c|}
\hline & \multicolumn{3}{|c|}{ Version A } & \multicolumn{3}{|c|}{ Version B } & \multirow{2}{*}{$\begin{array}{c}\begin{array}{c}\text { Version } \\
\text { Comparison }\end{array} \\
\text { Test } \\
\text { Statistic }\end{array}$} \\
\hline & Range & $M$ & $S D$ & Range & $M$ & $S D$ & \\
\hline \multicolumn{8}{|l|}{ Sports Investment } \\
\hline Sports & $1-5$ & 2.71 & 1.46 & $1-5$ & 2.71 & 1.46 & .51 \\
\hline Sports - Hours & $0-100$ & 14.25 & 20.79 & $0-100$ & 15.56 & 21.27 & -.741 \\
\hline AIMS & $1-5$ & 2.67 & 1.12 & $1-5$ & 2.67 & 1.12 & .96 \\
\hline \multicolumn{8}{|l|}{ Domain Beliefs about Under-eating } \\
\hline Harmfulness Beliefs & $1-5$ & 2.75 & .61 & $1-5$ & 2.75 & .61 & 1.64 \\
\hline Wrongfulness Beliefs & $1-5$ & 2.74 & .70 & $1-5$ & 2.74 & .70 & .65 \\
\hline Should Decision-making Beliefs & $1.38-5$ & 3.43 & .81 & $1.38-5$ & 3.43 & .81 & .64 \\
\hline \multicolumn{8}{|l|}{ Domain Beliefs about Over-eating } \\
\hline Harmfulness Beliefs & $1-4.70$ & 2.98 & .68 & $1-4.70$ & 2.98 & .68 & $1.70^{+}$ \\
\hline Wrongfulness Beliefs & $1-4.89$ & 3.03 & .76 & $1-4.89$ & 3.03 & .76 & -.92 \\
\hline Should Decision-making Beliefs & $1.44-5$ & 3.69 & .75 & $1.44-5$ & 3.69 & .75 & -1.21 \\
\hline \multicolumn{8}{|l|}{ Manifest Mediating Variables } \\
\hline Drive for Thinness & $1-6$ & 2.74 & 1.25 & $1-6$ & 2.74 & 1.25 & -.96 \\
\hline Thinness Body Dissatisfaction & $-2-5$ & 1.07 & 1.18 & $-1-6$ & 1.12 & 1.24 & -1.54 \\
\hline Drive for Muscularity & $1-5.57$ & 3.11 & 1.07 & $1-5.57$ & 3.11 & 1.07 & .93 \\
\hline Muscularity Body Dissatisfaction & $-3-3$ & -.53 & 1.05 & $-3-2$ & -.43 & .93 & -.31 \\
\hline \multicolumn{8}{|l|}{ Under-eating Behaviors } \\
\hline Food Conscious Behaviors & $1-6$ & 2.55 & 1.04 & $1-6$ & 2.55 & 1.04 & $-5.91 * * *$ \\
\hline Moderate Under-eating & $1-4.70$ & 2.18 & .94 & $1-4.70$ & 2.18 & .94 & .41 \\
\hline Severe Under-eating & $1-5$ & 1.94 & .80 & $1-5$ & 1.94 & .80 & -.91 \\
\hline \multicolumn{8}{|l|}{ Over-eating Behaviors } \\
\hline Unhealthy Eating Behaviors & $1-6$ & 3.01 & .84 & $1-6$ & 3.01 & .84 & $-4.73 * * *$ \\
\hline Over-eating Behaviors & $1-4.65$ & 2.46 & .74 & $1-4.65$ & 2.46 & .74 & $-1.77^{+}$ \\
\hline Binge Eating Behaviors & $1-6$ & 2.15 & .92 & $1-6$ & 2.15 & .92 & $-4.70 * * *$ \\
\hline \multicolumn{8}{|l|}{ Exploratory Moderating Variables } \\
\hline Arts/music Activities & $1-5$ & 1.84 & 1.19 & $1-5$ & 2.00 & 1.31 & -1.54 \\
\hline Church Activities & $1-5$ & 1.94 & .95 & $1-5$ & 2.07 & .96 & -1.61 \\
\hline Club-related Activities & $1-3.78$ & 1.59 & .60 & $.89-3.83$ & 1.66 & .61 & -1.55 \\
\hline \multicolumn{8}{|l|}{ Control Variable } \\
\hline Exercise - 30 & $1-7$ & 4.80 & 1.82 & $1-7$ & 4.80 & 1.82 & -1.80 \\
\hline
\end{tabular}

Note. ${ }^{+} p=.05-.10,{ }^{*} p<.05, * * p<.01, * * * p<.001$. 
Table 5

Subscales of the Problematic Eating Behaviors Measure

\section{Food Conscious Behaviors}

- I consistently eat low calorie or reduced fat food.

- I avoid eating certain food groups (e.g., meat, carbs).

- I count calories.

Severe Under-eating Behaviors

- I intentionally diet.

- I stop eating when I am still hungry.

- I don't eat when I am hungry.

- I “crash” diet.

- I drink water to suppress my appetite.

\section{Unhealthy Eating Behaviors}

- $\quad$ I eat junk food.

- I eat snacks while completing other activities (e.g., watching TV, completing homework).

- I eat snacks right out of the bag, box or package.

- I eat fast food regularly.

- I eat food from vending machines regularly.

\section{Binge Eating Behaviors}

- $\quad$ I continue to eat when I am full.

- I binge eat.

- $\quad$ I eat a lot of food when I am stressed.

- $\quad$ I eat more than I need when emotionally upset. 
Table 6

Descriptive Statistics for Demographic Variables

\begin{tabular}{|c|c|c|c|c|}
\hline & \multicolumn{4}{|c|}{$\begin{array}{l}\text { Overall Sample } \\
\quad(N=610)\end{array}$} \\
\hline & $M$ & $S D$ & Range & $\%$ \\
\hline Age & 15.93 & 1.10 & $14-19$ & - \\
\hline GPA & 5.93 & 1.29 & $1-7$ & - \\
\hline Height & 66.41 & 3.99 & $55-80$ & - \\
\hline Weight & 141.80 & 32.91 & 71-338 & - \\
\hline BMI & 22.47 & 4.09 & $14.91-47.14$ & - \\
\hline Gender & - & - & - & $\begin{array}{l}58.6 \% \\
\text { Female }\end{array}$ \\
\hline Parents' Education & - & - & - & \\
\hline Class Rank & - & - & - & $\begin{array}{c}41.4 \% \\
\text { Sophomore }\end{array}$ \\
\hline Ethnicity & - & - & - & $\begin{array}{c}82.6 \% \\
\text { Caucasian/White }\end{array}$ \\
\hline Survey Version & - & - & - & $\begin{array}{c}52.0 \% \\
\text { Version A }\end{array}$ \\
\hline School Location & - & - & - & $\begin{array}{c}60.5 \% \\
\text { Suburban Town }\end{array}$ \\
\hline
\end{tabular}

Note. Height displayed in inches. Weight displayed in pounds. 
Table 7

Descriptive Statistics for Key Study Variables

\begin{tabular}{|c|c|c|c|}
\hline & \multicolumn{3}{|c|}{$\begin{array}{c}\text { Overall Sample } \\
\quad(N=610)\end{array}$} \\
\hline & $M$ & $S D$ & Range \\
\hline \multicolumn{4}{|l|}{ Sports Investment } \\
\hline Sports & 2.74 & 1.46 & $1-5$ \\
\hline Sports - Hours & 14.90 & 21.02 & $0-100$ \\
\hline AIMS & 2.72 & 1.14 & $1-5$ \\
\hline \multicolumn{4}{|l|}{ Domain Beliefs about Under-eating } \\
\hline Harmfulness Beliefs & 2.80 & .65 & $1-5$ \\
\hline Wrongfulness Beliefs & 2.76 & .74 & $1-5$ \\
\hline Should Decision-Making Beliefs & 3.46 & .79 & $1.38-5$ \\
\hline \multicolumn{4}{|l|}{ Domain Beliefs about Over-eating } \\
\hline Harmfulness Beliefs & 3.03 & .70 & $1-4.70$ \\
\hline Wrongfulness Beliefs & 3.00 & .78 & $1-5$ \\
\hline Should Decision-Making Beliefs & 3.65 & .80 & $1.44-5$ \\
\hline \multicolumn{4}{|l|}{ Manifest Mediating Variables } \\
\hline Drive for Thinness & 2.69 & 1.30 & $1-6$ \\
\hline Thinness Body Dissatisfaction & 1.09 & 1.20 & $-2-6$ \\
\hline Drive for Muscularity & 2.62 & 1.11 & $1-6$ \\
\hline Muscularity Body Dissatisfaction & -.48 & 1.00 & $-3-3$ \\
\hline \multicolumn{4}{|l|}{ Under-eating Behaviors } \\
\hline Food Conscious Behaviors & 2.31 & 1.01 & $1-6$ \\
\hline Moderate Under-eating Behaviors & 2.19 & .90 & $1-5$ \\
\hline Severe Under-eating Behaviors & 1.91 & .85 & $1-6$ \\
\hline \multicolumn{4}{|l|}{ Over-eating Behaviors } \\
\hline Unhealthy Eating Behaviors & 2.85 & .85 & $1-6$ \\
\hline Over-eating Behaviors & 2.41 & .69 & $1-4.78$ \\
\hline Binge Eating Behaviors & 1.97 & .90 & $1-6$ \\
\hline \multicolumn{4}{|l|}{ Exploratory Moderating Variables } \\
\hline Arts/music Activities & 1.92 & 1.25 & $1-5$ \\
\hline Church Activities & 2.00 & .96 & $1-5$ \\
\hline Club-related Activities & 1.62 & .61 & $.89-3.83$ \\
\hline \multicolumn{4}{|l|}{ Control Variable } \\
\hline Exercise - 30 & 4.65 & .69 & $1-7$ \\
\hline
\end{tabular}


Table 8

Correlations between Demographic Characteristics, and Independent, Outcome, Moderator, and Control Variables

\begin{tabular}{|c|c|c|c|c|c|c|c|c|c|c|c|c|c|c|c|c|}
\hline & 2 & 3 & 4 & 5 & 6 & 7 & 8 & 9 & 10 & 11 & 12 & 13 & 14 & 15 & 16 & 17 \\
\hline 1.Gender & -.007 & -.02 & $.16^{* * *}$ & $-.08^{+}$ & $-.08^{+}$ & -.05 & $.35 * * *$ & $.28^{* * *}$ & $.30 * * *$ & -.07 & $.24 * * *$ & $.19^{* * *}$ & $.10^{*}$ & $.10^{*}$ & $.09 *$ & $-.10 *$ \\
\hline 2.Age & - & $-.09 *$ & $.18^{* * *}$ & -.06 & -.04 & $-.08^{+}$ & .05 & .06 & .04 & -.03 & .07 & .05 & $-.18^{* * *}$ & -.04 & -.02 & .01 \\
\hline 3. Parents' Education & & - & -.05 & $.11^{*}$ & .04 & $.10^{*}$ & -.02 & .03 & .05 & $-.08^{+}$ & -.02 & .009 & $.08^{*}$ & $.13^{* *}$ & $.20 * * *$ & .04 \\
\hline 4. BMI & & & - & -.04 & -.01 & .002 & $.25^{* * *}$ & -.05 & $.09 *$ & $-.12 * *$ & $.25 * * *$ & -.004 & $-.09 *$ & -.05 & -.06 & -.06 \\
\hline 5. Sports & & & & - & $.78^{* * *}$ & $.60^{* * *}$ & $-.09 *$ & -.01 & -.03 & .01 & $-.09 *$ & .02 & $-.19 * * *$ & .06 & .01 & $.35^{* * *}$ \\
\hline 6. AIMS & & & & & - & $.50 * * *$ & -.05 & .00 & -.04 & .03 & -.01 & .07 & $-.223 * * *$ & .01 & -.05 & $.36 * * *$ \\
\hline 7. Sports - Hours & & & & & & - & $-.11^{*}$ & .03 & $-.08^{+}$ & .03 & -.02 & .07 & $-.07^{+}$ & .03 & -.04 & $.20^{* * *}$ \\
\hline 8. Moderate Under-eating & & & & & & & - & $.15^{* * *}$ & $.62 * * *$ & $-.29 * * *$ & $.73^{* * *}$ & $.10^{*}$ & -.01 & $.12^{* *}$ & .05 & .05 \\
\hline 9. Over-eating & & & & & & & & - & .06 & $.36 * * *$ & $.10 *$ & $.65^{* * *}$ & $.08+$ & .02 & $.08^{+}$ & -.02 \\
\hline 10. Food Conscious Behaviors & & & & & & & & & - & $-.27^{* * *}$ & $.59 * * *$ & $.12 * *$ & .02 & $.11^{* *}$ & $.18^{* * *}$ & $.18^{* * *}$ \\
\hline 11. Unhealthy Eating Behaviors & & & & & & & & & & - & $-.18^{* * *}$ & $.38 * * *$ & .03 & -.07 & -.02 & $-.11 *$ \\
\hline 12. Severe Under-eating & & & & & & & & & & & - & $.17 * * *$ & -.03 & .03 & .02 & .07 \\
\hline 13. Binge Eating Behaviors & & & & & & & & & & & & - & .01 & -.05 & .05 & .05 \\
\hline 14. Arts/music & & & & & & & & & & & & & - & $.16^{* * *}$ & $.30^{* * *}$ & $-.10^{*}$ \\
\hline 15. Church & & & & & & & & & & & & & & - & $.39 * * *$ & .03 \\
\hline 16. Club-related activities & & & & & & & & & & & & & & & - & .02 \\
\hline 17. Exercise - 30 & & & & & & & & & & & & & & & & - \\
\hline
\end{tabular}

Note. ${ }^{+} p=.05-.10, * p<.05, * * p<.01, * * * p<.001$. 
Table 9

Correlations between Demographic Characteristics, and Independent and Mediating Variables

\begin{tabular}{|c|c|c|c|c|c|c|c|c|c|c|c|c|c|c|c|c|c|c|c|c|}
\hline & 2 & 3 & 4 & 5 & 6 & 7 & 8 & 9 & 10 & 11 & 12 & 13 & 14 & 15 & 16 & 17 & 18 & 19 & 20 & 21 \\
\hline 1. Gender & -.007 & $\begin{array}{l}.02 \\
\end{array}$ & $-.16^{* * *}$ & $-.08^{+}$ & $-.08^{+}$ & -.05 & $.17^{* * *}$ & $.08^{+}$ & $.28^{* * *}$ & $.09^{*}$ & .05 & .001 & $.41^{* * *}$ & -.06 & $-.42 * * *$ & $.51^{* * *}$ & $.10^{*}$ & $.10^{*}$ & $.09 *$ & $-.10^{*}$ \\
\hline 2. Age & - & $-.09 *$ & $.18^{* * *}$ & -.06 & -.04 & $-.08^{+}$ & -.03 & $-.12^{* *}$ & $-.10^{*}$ & $-.17^{* * *}$ & $.08^{*}$ & $.09 *$ & .03 & -.02 & $.09 *$ & .03 & $-.18^{* * *}$ & -.04 & -.02 & -.01 \\
\hline 3. Parents' & & - & -.05 & $.11^{*}$ & .04 & $.10^{*}$ & $.09 *$ & .06 & .06 & .07 & $-.08^{*}$ & -.03 & -.06 & -.03 & .02 & .004 & $.08^{*}$ & $.13 * *$ & $.20^{* * *}$ & .04 \\
\hline \multicolumn{21}{|l|}{ Education } \\
\hline 4. BMI & & & - & -.04 & -.01 & . 002 & $.07^{+}$ & $-.25 * * *$ & .01 & $-.22 * * *$ & -.05 & $.08^{*}$ & $.21 * * *$ & $.54 * * *$ & $.08^{+}$ & -.01 & $-.09 *$ & -.05 & -.06 & -.06 \\
\hline 5. Sports & & & & - & $.78^{* * *}$ & $.60^{* * *}$ & $.09 *$ & $.07^{+}$ & $.11^{* *}$ & $.11^{* *}$ & -.05 & -.06 & $-.08^{+}$ & $-.09 *$ & $.36^{* * *}$ & $-.122^{* *}$ & $-.19 * * *$ & .06 & .01 & $.35 * * *$ \\
\hline 6. AIMS & & & & & - & $.50 * * *$ & $.08^{*}$ & .03 & $.16^{* * *}$ & $.13^{* *}$ & .02 & -.03 & -.02 & $-.08^{+}$ & $.48^{* * *}$ & $-.11^{* *}$ & $-.22 * * *$ & .01 & -.05 & $.36 * * *$ \\
\hline 7. Sports - H & & & & & & - & .05 & .07 & $.08^{+}$ & .07 & -.02 & -.03 & $-.09 *$ & -.02 & $.23^{* * *}$ & -.04 & $-.07^{+}$ & .03 & -.04 & $.20 * * *$ \\
\hline 8. $\mathrm{H}-\mathrm{O}$ & & & & & & & - & $.30 * * *$ & $.72 * * *$ & $.24 * * *$ & $-.25 * * *$ & $-.18^{* * *}$ & $.26 * * *$ & $.08^{+}$ & -.01 & $.13^{* *}$ & .02 & $.17 * * *$ & $.11^{* *}$ & $.08^{*}$ \\
\hline 9. $\mathrm{H}-\mathrm{U}$ & & & & & & & & - & $.25^{* * *}$ & $.72 * * *$ & $-.24 * * *$ & $-.27 * * *$ & $-.22 * * *$ & $-.24 * * *$ & -.05 & -.01 & .05 & $.08^{+}$ & $.07^{+}$ & .05 \\
\hline 10.W $-\mathrm{O}$ & & & & & & & & & - & $.38 * * *$ & $-.19 * * *$ & $-.16 * * *$ & $.30 * * *$ & $.10^{*}$ & .002 & $.15^{* * *}$ & -.02 & $.17 * * *$ & .07 & $.11^{*}$ \\
\hline 11.W - U & & & & & & & & & & - & $-.20^{* * *}$ & $-.26^{* * *}$ & $-.20 * * *$ & $-.22 * * *$ & -.06 & -.01 & .05 & .04 & .02 & .03 \\
\hline 12. S-O & & & & & & & & & & & - & $.73 * * *$ & .05 & .01 & .01 & -.01 & $-.08^{+}$ & $-.15^{* * *}$ & $-.11^{* *}$ & .02 \\
\hline 13. $S-U$ & & & & & & & & & & & & - & $.09 *$ & $.10 *$ & .01 & .01 & $-.10 *$ & $-.08^{+}$ & $-.09 *$ & -.002 \\
\hline 14. DFT & & & & & & & & & & & & & - & $.43 * * *$ & -.04 & $.32 * * *$ & -.01 & $.08^{+}$ & .03 & .02 \\
\hline 15. Thin - BID & & & & & & & & & & & & & & - & .05 & .01 & -.07 & -.03 & $-.07^{+}$ & $-.10^{*}$ \\
\hline 16. DFM & & & & & & & & & & & & & & & - & $-.38^{* * * *}$ & $-.19 * * *$ & -.03 & $-.08^{+}$ & $.32 * * *$ \\
\hline 17. Muscle - & & & & & & & & & & & & & & & & - & .05 & $.09 *$ & $.10^{*}$ & $-.10^{*}$ \\
\hline \multicolumn{21}{|l|}{ BID } \\
\hline 18. Arts/music & & & & & & & & & & & & & & & & & - & $.16^{* * *}$ & $.30 * * *$ & $-.10^{*}$ \\
\hline 19.Church & & & & & & & & & & & & & & & & & & - & $.39 * * *$ & .03 \\
\hline 20. Club-related & & & & & & & & & & & & & & & & & & & - & .02 \\
\hline Activities & & & & & & & & & & & & & & & & & & & & \\
\hline
\end{tabular}

21.Exercise -30

Note. ${ }^{+} p=.05-.10, * p<.05, * * p<.01, * * * p<.001$. Sports $-\mathrm{H}=$ Hours of involvement in organized sports in an average month. $\mathrm{H}-\mathrm{O}=$ Harmfulness beliefs about over-eating behaviors. $\mathrm{H}-\mathrm{U}=$ Harmfulness beliefs about under-eating behaviors. $\mathrm{W}-\mathrm{O}=$ Wrongfulness beliefs about over-eating behaviors. $\mathrm{W}-\mathrm{U}=$ Wrongfulness beliefs about under-eating behaviors. S $-\mathrm{O}=\mathrm{Should}$ decision-making beliefs about over-eating behaviors. $\mathrm{S}-\mathrm{U}=$ Should decision-making beliefs about under-eating behaviors. DFT = Drive for Thinness. Thin - BID = Thinness Body Dissatisfaction. DFM = Drive for Muscularity. Muscle - BID = Muscularity Body Dissatisfactio 
Table 10

Correlations between Mediating and Outcome Variables

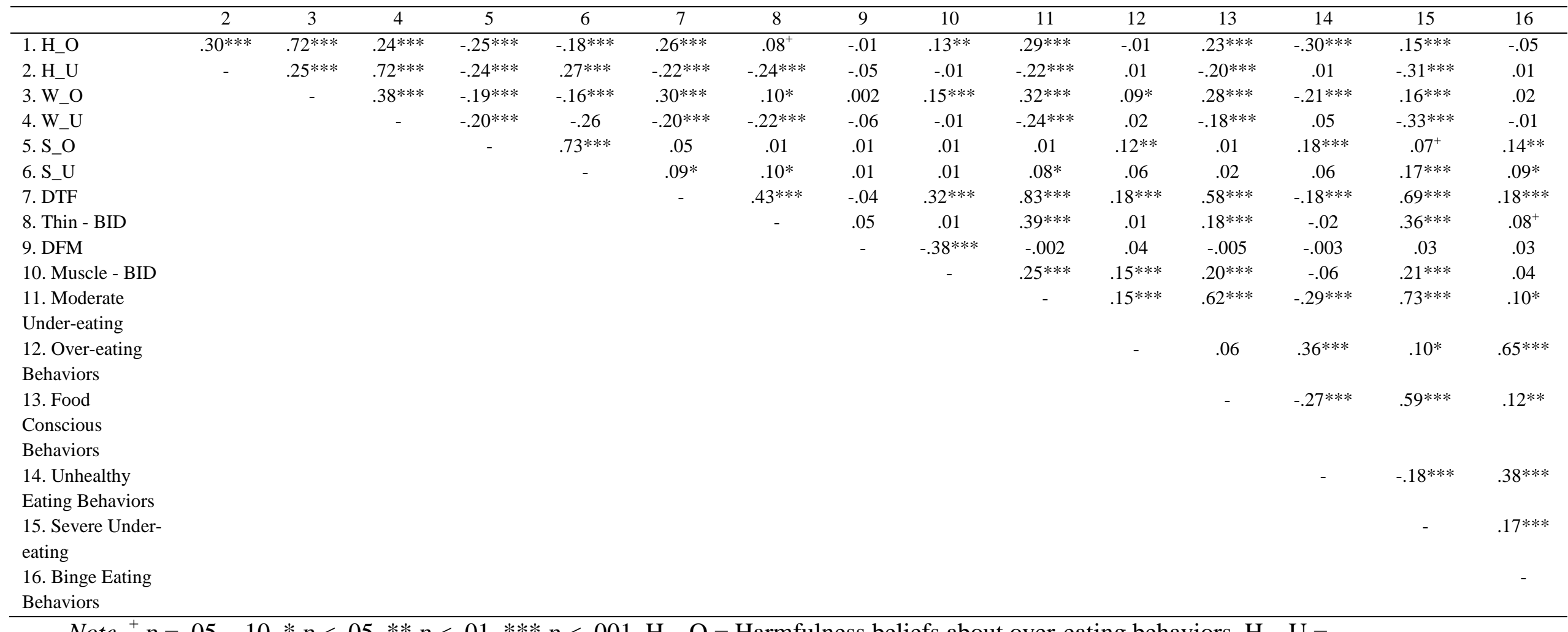

Note. ${ }^{+} p=.05-.10, * p<.05, * * p<.01,{ }^{* * *} p<.001 . \mathrm{H}-\mathrm{O}=$ Harmfulness beliefs about over-eating behaviors. $\mathrm{H}-\mathrm{U}=$

Harmfulness beliefs about under-eating behaviors. $\mathrm{W}-\mathrm{O}=$ Wrongfulness beliefs about over-eating behaviors. $\mathrm{W}-\mathrm{U}=$ Wrongfulness

beliefs about under-eating behaviors. $\mathrm{S}-\mathrm{O}=$ Should decision-making beliefs about over-eating behaviors. $\mathrm{S}-\mathrm{U}$ = Should decisionmaking beliefs about under-eating behaviors. DFT $=$ Drive for Thinness. Thin - BID $=$ Thinness Body Dissatisfaction. DFM $=$ Drive for Muscularity. Muscle - BID = Muscularity Body Dissatisfaction. 
Table 11

Indicator Factor Loadings and Covariance Pathways for the Measurement Model

\begin{tabular}{lc}
\hline \multicolumn{1}{c}{ Latent Constructs } & $\begin{array}{c}\text { Factor } \\
\text { Loading }\end{array}$ \\
\hline Sports Investment & .97 \\
Sports & .80 \\
Sports - Hours & .62 \\
AIMS & \\
Domain Beliefs about Under-eating & .89 \\
Harmfulness & .81 \\
Wrong & .16 \\
Should Decision-making & .93 \\
Domain Beliefs about Over-eating & .78 \\
Harmfulness & .17 \\
Wrong & \\
Should Decision-making & \\
Covariances & $-.10^{*}$ \\
Sports Investment \& Domain Beliefs about Under-eating & $-.11^{*}$ \\
Sports Investment \& Domain Beliefs about Over-eating & $.36 * * *$ \\
Domain Beliefs about Under-eating \& Domain Beliefs about Over-eating & \\
\hline Note. * $p<.05, * * p<.01, * * * p<.001$. Sports = Subjective Scale Ratings of Organized \\
Sports Involvement. Sports - Hours = Free Response Reports of the Number of Hours \\
per Month of Organized Sports Involvement. AIMS = Athletic Identity Measurement \\
Scale. &
\end{tabular}


Table 12

Direct Associations between Sports Investment and Problematic Under- and Over-eating Outcomes

\section{Standardize Parameter Estimates}

\section{Food Conscious Behaviors}

- Sports investment

- Gender

- BMI

$$
-.07^{+}
$$

$.32 * * *$

- Unstructured exercise

$.15^{* * *}$

$.16^{* * *}$

Moderate Under-eating Behaviors

- Sport investment

$-.04$

- Gender

$.37 * * *$

- BMI

$.30 * * *$

Severe Under-eating Behaviors

- Sport Investment

$-.05$

- Gender

$.27 * * *$

- BMI

$.29 * * *$

Unhealthy Eating Behaviors

- Sports investment

.06

- BMI

$-.13^{* * *}$

- Unstructured exercise

$-.11^{* *}$

Over-eating Behaviors

- Sport investment

.02

- Gender

$.32 * * *$

Binge Eating Behaviors

- Sports investment

.06

- Gender

$.23 * * *$

Note. ${ }^{+} p=.05-.10,{ }^{*} p<.05, * * p<.01, * * * p<.001$ 
Table 13

Standardize Parameter Estimates for Direct Effects between Sports Investment, Mediating Variables, and Problematic Eating Outcomes

\section{Standardize Parameter Estimates}

\section{Sports Investment}

- Unstructured Exercise

$.40 * * *$

- Parents' SES

$.07^{+}$

Domain Beliefs about Under-eating

- Sports Investment

$$
-.08^{+}
$$

- Age

$.08^{+}$

- BMI

Domain Beliefs about Over-eating

- $\quad$ Sports Investment

$-.11 *$

- Unstructured Exercise

$-.09 *$

- Parents' SES

- Gender

$-.08 *$

$-.25 * * *$

Drive for Muscularity

- $\quad$ Sports Investment

$.41^{* * *}$

- Unstructured Exercise

- Gender

$-.38 * * *$

- Age

$.11^{* * *}$

Drive for Thinness

- BMI

$.28 * * *$

- Gender

$.43 * * *$

Muscularity Body Dissatisfaction

- Gender

- Sports Investment

$-.51^{* * *}$

$.10 * *$

Thinness Body Dissatisfaction

- Unstructured Exercise

$-.10 * * *$

- BMI

$.54 * * *$

Food Conscious Behaviors

- Sports Investment

$-.09 * *$

- Domain Beliefs about Over-eating

$-.21 * * *$

$.21 * * *$

- Domain Beliefs about Under-eating

$.49 * * *$

- Drive for Thinness

$-.08 *$

- Thinness Body Dissatisfaction

$.17 * * *$

- Unstructured Exercise

$.09 *$

Moderate Under-eating Behaviors

- Sports Investment

$-.07 *$

- Domain Beliefs about Over-eating

$-.17 * * *$

- Domain Beliefs about Under-eating

- Drive for Thinness

$.74 * * *$ 


\begin{tabular}{|c|c|}
\hline $\begin{array}{ll}- & \text { Drive for Muscularity } \\
\text { - } & \text { BMI }\end{array}$ & $\begin{array}{l}.06^{* *} \\
.06^{+}\end{array}$ \\
\hline - $\quad$ Gender & $.07 *$ \\
\hline \multicolumn{2}{|l|}{ Over-eating Behaviors } \\
\hline - $\quad$ Sports Investment & $-.11^{*}$ \\
\hline - $\quad$ Gender & $.36 * * *$ \\
\hline - $\quad$ Drive for Muscularity & $.24 * * *$ \\
\hline \multicolumn{2}{|l|}{ Severe Under-eating Behaviors } \\
\hline - $\quad$ Domain Beliefs about Over-eating & $-.08 * * *$ \\
\hline - $\quad$ Domain Beliefs about Under-eating & $.25^{* * *}$ \\
\hline - $\quad$ Drive for Thinness & $.63 * * *$ \\
\hline - $\quad$ BMI & $.05^{+}$ \\
\hline \multicolumn{2}{|l|}{ Unhealthy Eating Behaviors } \\
\hline - $\quad$ Sports Investment & $.08^{+}$ \\
\hline - $\quad$ Domain Beliefs about Over-eating & $.30 * * *$ \\
\hline - $\quad$ Domain Beliefs about Under-eating & $-.08^{+}$ \\
\hline - $\quad$ Drive for Thinness & $-.13^{*}$ \\
\hline - $\quad$ Thinness Body Dissatisfaction & $.13^{*}$ \\
\hline - $\quad$ BMI & $-.13 * * *$ \\
\hline - $\quad$ Unstructured Exercise & $-.09 *$ \\
\hline \multicolumn{2}{|l|}{ Binge Eating Behaviors } \\
\hline - $\quad$ Domain Beliefs about Over-eating & $.07 * * *$ \\
\hline - $\quad$ Muscularity Body Dissatisfaction & $.10 * *$ \\
\hline - $\quad$ Drive for Muscularity & $.10^{* *}$ \\
\hline - $\quad$ Drive for Thinness & $.11^{* * *}$ \\
\hline - Gender & $.23 * * *$ \\
\hline
\end{tabular}

Note. ${ }^{+} p=.05-.10, * p<.05, * * p<.01, * * * p<.001$. 
Table 14

Standardize Parameter Estimates for Direct Effects between Sports Investment, Mediating Variables, and Problematic Eating Outcomes by Gender

\begin{tabular}{|c|c|c|}
\hline & Boys & Girls \\
\hline \multicolumn{3}{|l|}{ Sports Investment } \\
\hline - Unstructured Exercise & $.58 * * *$ & $.30 * * *$ \\
\hline - $\quad$ Parent’s Education & -.02 & $.11 *$ \\
\hline \multicolumn{3}{|l|}{ Domain Beliefs about Under-eating } \\
\hline - $\quad$ Sport investment & -.08 & $-.12 *$ \\
\hline - Age & $.10^{*}$ & $.07 *$ \\
\hline - $\quad$ BMI & $.30 * * *$ & $.29 * * *$ \\
\hline \multicolumn{3}{|l|}{ Domain Beliefs about Over-eating } \\
\hline - $\quad$ Sport Investment & -.03 & $-.17 * *$ \\
\hline - $\quad$ Unstructured Exercise & -.05 & $-.13 * *$ \\
\hline - $\quad$ Parents’ Education & $-.17 * *$ & -.03 \\
\hline \multicolumn{3}{|l|}{ Drive for Muscularity } \\
\hline - $\quad$ Sports Investment & $.49 * * *$ & $.43 * * *$ \\
\hline - Age & .06 & $.15^{* *}$ \\
\hline - Unstructured Exercise & .10 & $.13 * * *$ \\
\hline \multicolumn{3}{|l|}{ Drive for Thinness } \\
\hline - $\quad$ BMI & $.30 * * *$ & $.34 * * *$ \\
\hline \multicolumn{3}{|l|}{ Muscularity Body Dissatisfaction } \\
\hline - $\quad$ Sports Investment & .10 & $.10 *$ \\
\hline \multicolumn{3}{|l|}{ Thinness Body Dissatisfaction } \\
\hline - $\quad$ BMI & $.45 * * *$ & $.64 * * *$ \\
\hline - Unstructured Exercise & $-.12 * *$ & $-.08 *$ \\
\hline \multicolumn{3}{|l|}{ Food Conscious Behaviors } \\
\hline - $\quad$ Sport investment & $-.15^{*}$ & -.06 \\
\hline - $\quad$ Domain Beliefs about Over-eating & $-.19 * *$ & $-.22 * *$ \\
\hline - $\quad$ Domain Beliefs about Under-eating & $.18^{* *}$ & $.28 * * *$ \\
\hline - $\quad$ Drive for Thinness $\wedge$ & $.52 * * * \wedge$ & $.41 * * * \wedge$ \\
\hline - $\quad$ Thinness Body Dissatisfaction & $-.17 * *$ & -.03 \\
\hline - Unstructured Exercise & $.18^{*}$ & $.21 * * *$ \\
\hline \multicolumn{3}{|l|}{ Moderate Under-eating Behaviors } \\
\hline - $\quad$ Sport investment & $-.11 * *$ & -.06 \\
\hline - Domain Beliefs about Over-eating & $-.23^{* * *}$ & $-.18 * * *$ \\
\hline - $\quad$ Domain Beliefs about Under-eating & $.19 * * *$ & $.20 * * *$ \\
\hline - $\quad$ Drive for Thinness & $.72 * * *$ & $.76 * * *$ \\
\hline - $\quad$ Drive for Muscularity & .07 & $.07 *$ \\
\hline \multicolumn{3}{|l|}{ Over-eating Behaviors } \\
\hline - Domain Beliefs about Over-eating & $.13^{*}$ & .04 \\
\hline - $\quad$ Drive for Muscularity & $.22 * * *$ & $.18 *$ \\
\hline \multicolumn{3}{|l|}{ Severe Under-eating Behaviors } \\
\hline - $\quad$ Domain Beliefs about Over-eating & $-.10 * *$ & $-.08^{+}$ \\
\hline
\end{tabular}


- Domain Beliefs about Under-eating

- Drive for Thinness

- BMI

Unhealthy Eating Behaviors

- Sports Investment

- Domain Beliefs about Over-eating

- Domain Beliefs about Under-eating

- Drive for Thinness

- Thinness Body Dissatisfaction

- BMI

- Unstructured Exercise

Binge Eating Behaviors

- Sport Investment ${ }^{\wedge}$

- Domain Beliefs about Over-eating

- Drive for Muscularity

- Muscularity Body Dissatisfaction

- $\quad$ Drive for Thinness
$.35 * * *$

$.46 * * *$

$.06 *$

$.18^{+}$

$.39 * * *$

$-.04$

$-.16 * * *$

$.16^{* *}$

$-.09$

$-.12 * *$

$.21 * * * \wedge$

$.22 * * *$

$-.03$

$.15^{* * *}$

$.11^{*}$
$.22 * * *$

$.66^{* * *}$

.02

$.11 *$

$.33 * * *$

$-.15^{+}$

$-.08$

.09

$-.09^{+}$

$-.11 *$

$.03 \wedge$

.09

$.11^{+}$

.05

$.08 *$

Note. ${ }^{+} p=.05-.10, * p<.05, * * p<.01, * * * p<.001 . \wedge$ Designates significant critical ratio of the difference value. 
Table 15

Standardize Parameter Estimates for Direct Effects between Sports Investment, Mediating Variables, and Problematic Eating Outcomes by Involvement in Church Activities

\begin{tabular}{|c|c|c|}
\hline & Low Church & High Church \\
\hline \multicolumn{3}{|l|}{ Sports Investment } \\
\hline - Unstructured Exercise & $.43^{* * *}$ & $.35 * * *$ \\
\hline \multicolumn{3}{|l|}{ Domain Beliefs about Under-eating } \\
\hline - Sport Investment & $-.08^{+}$ & $-.10^{+}$ \\
\hline - Age & $.16^{* * *}$ & .01 \\
\hline - $\quad$ BMI & $.27 * * *$ & $.32 * * *$ \\
\hline \multicolumn{3}{|l|}{ Domain Beliefs about Over-eating } \\
\hline - $\quad$ Sport Investment & .00 & $-.23 * *$ \\
\hline - $\quad$ Parent Education & $-.15 * *$ & .06 \\
\hline - $\quad$ Gender & $-.24 * * *$ & $-.26 * * *$ \\
\hline - $\quad$ Unstructured Exercise & $-.12 * *$ & -.03 \\
\hline - Age & $.11^{*}$ & -.06 \\
\hline \multicolumn{3}{|l|}{ Drive for Muscularity } \\
\hline - $\quad$ Sports Investment & $.34 * * *$ & $.49 * * *$ \\
\hline - Gender & $-.35 * * *$ & $-.42 * * *$ \\
\hline - Unstructured Exercise & $.16^{* * *}$ & .07 \\
\hline - Age & $.10 * *$ & $.11^{* *}$ \\
\hline \multicolumn{3}{|l|}{ Drive for Thinness } \\
\hline - $\quad$ Sport Investment & $-.08^{+}$ & .09 \\
\hline - Gender & $.44 * * *$ & $.42 * * *$ \\
\hline - $\quad$ BMI & $.24 * * *$ & $.32 * * *$ \\
\hline \multicolumn{3}{|l|}{ Muscularity Body Dissatisfaction } \\
\hline - $\quad$ Sports Investment & $.10^{*}$ & $.10 *$ \\
\hline - Gender & $-.51 * * *$ & $-.50 * * *$ \\
\hline \multicolumn{3}{|l|}{ Thinness Body Dissatisfaction } \\
\hline - $\quad$ Sport Investment $\wedge$ & $-.10 * \wedge$ & $.06^{\wedge}$ \\
\hline - $\quad$ BMI & $.54 * * *$ & $.54 * * *$ \\
\hline - $\quad$ Unstructured Exercise & -.05 & $-.14 * *$ \\
\hline \multicolumn{3}{|l|}{ Food Conscious Behaviors } \\
\hline - $\quad$ Sport Investment & $-.17 *$ & -.01 \\
\hline - Domain Beliefs about Over-eating & $-.24 * * *$ & $-.17 *$ \\
\hline - $\quad$ Domain Beliefs about Under-eating & $.27 * *$ & $.16^{*}$ \\
\hline - $\quad$ Drive for Muscularity & $.09^{+}$ & -.07 \\
\hline - $\quad$ Drive for Thinness & $.47 * * *$ & $.47 * * *$ \\
\hline - $\quad$ Thinness Body Dissatisfaction & $-.09^{+}$ & -.06 \\
\hline - $\quad$ Gender & $.14^{* *}$ & .04 \\
\hline - Unstructured Exercise & $.19 * * *$ & $.15 * * *$ \\
\hline \multicolumn{3}{|l|}{ Moderate Under-eating Behaviors } \\
\hline - $\quad$ Sport Investment & $-.09 *$ & -.01 \\
\hline
\end{tabular}


- Domain Beliefs about Over-eating^

- Domain Beliefs about Under-eating

- Drive for Thinness

- Drive for Muscularity

- Gender

- BMI

\section{Over-eating Behaviors}

- Sports investment

- Domain Beliefs about Over-Eating

- Drive for Muscularity

- Gender

Severe Under-eating Behaviors

- Domain Beliefs about Over-eating^

- Domain Beliefs about Under-eating

- $\quad$ Drive for Thinness

- BMI

Unhealthy Eating Behaviors

- $\quad$ Sports Investment

- Domain Beliefs about Over-eating

- Domain Beliefs about Under-eating

- BMI

- Unstructured Exercise

Binge Eating Behaviors

- Domain Beliefs about Over-eating

- Drive for Muscularity

- Drive for Thinness

- Muscularity Body Dissatisfaction

- Gender

$-.23 * * * \wedge$

$.16 * * *$

$.73 * * *$

$.09 * *$

$.07 * *$

.03

$\begin{array}{ll}-.10^{+} & -.12^{+} \\ .10^{+} & -.03 \\ .26^{* * *} & .21^{* * *} \\ .46^{* * *} & .26 * * *\end{array}$

$-.15^{* * * \wedge}$

$-.00^{\wedge}$

.32

$.61^{* * *}$

$.15 *$

.02

.64

.11

.07

$.37 * * *$

$.11^{* *}$

$-.15^{+}$

$-.10^{+}$

$-.10 * *$

$.35 * * *$

$-.07$

$-.04$

$-.13^{* *}$

$.15 * * * \quad .05$

$.11^{*} \quad .11$

$.11^{*}$

.05

$.14^{*}$

$.15 *$

$.19 * * *$

Note. ${ }^{+} p=.05-.10, * p<.05, * * p<.01, * * * p<.001 . \wedge$ Designates significant critical ratio of the difference value. 
Table 16

Standardize Parameter Estimates for Direct Effects between Sports Investment, Mediating Variables, and Problematic Eating Outcomes by Involvement in Club-related Activities

\begin{tabular}{|c|c|c|}
\hline & Low Clubs & High Clubs \\
\hline \multicolumn{3}{|l|}{ Sports Investment } \\
\hline - $\quad$ Unstructured Exercise & $.42 * * *$ & $.38 * * *$ \\
\hline \multicolumn{3}{|l|}{ Domain Beliefs about Under-eating } \\
\hline - $\quad$ Sport Investment & -.05 & $-.12 * * *$ \\
\hline - $\quad$ BMI & $.30 * * *$ & $.29 * * *$ \\
\hline - Age & .13 & $.08^{+}$ \\
\hline \multicolumn{3}{|l|}{ Domain Beliefs about Over-eating } \\
\hline - $\quad$ Sport Investment & -.07 & $-.16^{+}$ \\
\hline - Unstructured Exercise & $-.12 *$ & -.07 \\
\hline - $\quad$ Gender & $-.29 * * *$ & $-.22 * * *$ \\
\hline - Age & $.20 * *$ & -.06 \\
\hline \multicolumn{3}{|l|}{ Drive for Muscularity } \\
\hline - $\quad$ Sports Investment & $.36 * * *$ & $.45 * * *$ \\
\hline - Gender & $-.41 * * *$ & $-.33 * * *$ \\
\hline - Age & -.01 & $.20 * * *$ \\
\hline - Unstructured Exercise & $.17 * *$ & $.07^{+}$ \\
\hline \multicolumn{3}{|l|}{ Drive for Thinness } \\
\hline - $\quad$ BMI & $.24 * * *$ & $.32 * * *$ \\
\hline - $\quad$ Gender & $.49 * * *$ & $.37 * * *$ \\
\hline \multicolumn{3}{|l|}{ Muscularity Body Dissatisfaction } \\
\hline - $\quad$ Sports Investment & $.14^{* *}$ & .05 \\
\hline - Gender & $-.56 * * *$ & $-.45 * * *$ \\
\hline \multicolumn{3}{|l|}{ Thinness Body Dissatisfaction } \\
\hline - $\quad$ BMI & $.53 * * *$ & $.56 * * *$ \\
\hline - Unstructured exercise & $-.10^{*}$ & $-.10 * * *$ \\
\hline \multicolumn{3}{|l|}{ Food Conscious Behaviors } \\
\hline - $\quad$ Domain Beliefs about Over-eating & $-.28 * * *$ & $-.13 *$ \\
\hline - $\quad$ Domain Beliefs about Under-eating & $.28 * *$ & $.18 * * *$ \\
\hline - $\quad$ Drive for Thinness & $.48 * * *$ & $.53 * * *$ \\
\hline - $\quad$ Thinness Body Dissatisfaction & -.04 & $-.12 * * *$ \\
\hline - $\quad$ Unstructured Exercise & $.10^{*}$ & $.17 * * *$ \\
\hline - $\quad$ Gender & .04 & $.09^{+}$ \\
\hline \multicolumn{3}{|l|}{ Moderate Under-eating Behaviors } \\
\hline - $\quad$ Sport Investment & $-.08 * *$ & -.03 \\
\hline - $\quad$ Domain Beliefs about Over-eating & $-.27 * * *$ & $-.13^{* *}$ \\
\hline - $\quad$ Domain Beliefs about Under-eating & $.23 * * *$ & $.12 * * *$ \\
\hline - $\quad$ Drive for Thinness & $.76^{* * *}$ & $.79 * * *$ \\
\hline - $\quad$ Drive for Muscularity & .04 & $.06^{+}$ \\
\hline \multicolumn{3}{|l|}{ Over-eating Behaviors } \\
\hline - $\quad$ Sport Investment & $-.12 *$ & $-.09^{+}$ \\
\hline
\end{tabular}


- Domain Beliefs about Over-eating

- Drive for Muscularity

- Gender

\section{Severe Under-eating Behaviors}

- Domain Beliefs about Over-eating^

- Domain Beliefs about Under-eating

- Drive for Thinness

- Drive for Muscularity

Unhealthy Eating Behaviors

- Sports Investment

- Domain Beliefs about Over-eating

- BMI

- Unstructured Exercise

Binge Eating Behaviors

- Domain Beliefs about Over-eating

- Drive for Muscularity

- Drive for Thinness

- Muscularity Body Dissatisfaction

- Gender

$\begin{array}{ll}.14^{+} & -.02 \\ .23^{* *} & .28 * * * \\ .45^{* * *} & .32 * * *\end{array}$

$-.24 * * * \wedge$

$.04 \wedge$

$.36 * * *$

$.20 * * *$

$.57 * * *$

$.69 * * *$

.01

$.06 * *$

.05

$.34 * *$

$-.15 * *$

$.13 *$

$-.07$

$.28 * * *$

$-.09 *$

$-.16 *$

.12

$.12 * *$

$.14^{*}$

$.09 *$

.03

$.34 * * *$
$.13 * *$

$.17^{* * *}$

$.14 *$

$.19 * * *$

Note. ${ }^{+} p=.05-.10,{ }^{*} p<.05,{ }^{* *} p<.01,{ }^{* * *} p<.001 . \wedge$ Designates significant critical ratio of the difference value. 
Table 17

Number of Participants in the Church, Club-related, and Arts/music Activities Multigroups $n(\%)$ Median Split Value Church Activities

- Low Involvement $346(57 \%)$

- High Involvement 261(43\%)

Club-related Activities

- Low Involvement $274(47.1 \%)$

- High Involvement

336 (52.9\%)

Arts/music Activities

- No Involvement 332 (54.6\%)

- Some Involvement

276 (45.6\%) 
Table 18

Factor Loadings of the Latent Variable Indicators for Subscales of the Problematic Eating Behaviors Scale

\begin{tabular}{lr}
\hline \multicolumn{1}{c}{ Latent Construct } & Factor Load \\
\hline Food Conscious Behavior & .75 \\
- I consistently eat low calorie or reduced & \\
fat/fat free foods & .72 \\
- I avoid eating certain food groups (e.g., & .66 \\
meat, carbs) & \\
- I count calories & \\
& \\
Severe Under-eating Behavior & .63 \\
- I intentionally diet* & .77 \\
- I stop eating when I am still hungry & .55 \\
- I don’t eat when I am hungry & .66 \\
- I “crash” diet & \\
- I drink water to suppress my appetite &
\end{tabular}

\section{Bad Eating Behavior}

- I eat junk food

- I eat snacks while completing other activities

(e.g., watching TV, completing homework)

- I eat snacks right out of the bag, box or

package

- I eat fast food regularly

- I eat food from vending machines regularly

\section{Binge Eating Behavior}

- I continue to eat when I am full

- I binge eat

- I eat a lot of food when I am stressed

- I eat more than I need when emotionally

upset*

Note. * Indicates items that were dropped to achieve a well-fitting model, but included in the subscales due to theoretical considerations. 
Table 19

Items Excluded from the Final Problematic Eating Behaviors Scale

\section{Item Label}

1. I intentionally eat snacks throughout the day to avoid eating a full meal.

2. I snack between meals.

3. I carb load before engaging in physical activity.

4. I eat when I am bored.

5. I drink sugary drinks. (e.g., fruit juices or soda).

6. I eat my food very quickly.

7. I finish all the food on my plate.

8. I drink enough water.

9. I drink coffee.

10. I eat a well-balanced meal containing foods from the recommended food groups.

11. I eat less around others than when I am alone.

12. I eat less around others, but when I am alone, I eat a lot.

13. I skip meals (e.g., breakfast).

14. I read food labels to determine nutrient value or calorie content.

15. I eat organic foods.

16. I use laxatives to lose weight.

17. I eat late night snacks. 
Table 20

Convergent and divergent validity for Subscales of the Problematic Eating Behaviors Scale with Established Measures of Under- and Over-eating Behaviors

\begin{tabular}{lccccccccc}
\hline & 1 & 2 & 3 & 4 & 5 & 6 & 7 & 8 & 9 \\
\hline 1. UE & - & $.70^{* * *}$ & $.33^{* * *}$ & $-.14^{*}$ & $.60^{* * *}$ & $.50^{* * *}$ & $.30^{* * *}$ & $.72^{* * *}$ & $.27^{* * *}$ \\
2. FC & & - & $.27^{* * *}$ & $-.29^{* * *}$ & $.68^{* * *}$ & $.50^{* * *}$ & $.33^{* * *}$ & $.73^{* * *}$ & $.21^{* *}$ \\
3. BG & & & - & $.24^{* * *}$ & $.44^{* * *}$ & $.55^{* * *}$ & .08 & $.31^{* * *}$ & $.72^{* * *}$ \\
4. UHEB & & & & - & $-.14^{*}$ & -.001 & -.05 & $-.26^{* * *}$ & $.30^{* * *}$ \\
5. EAT - D & & & & & - & $.82^{* * *}$ & $.65^{* * *}$ & $.75^{* * *}$ & $.46^{* * *}$ \\
6. EAT - BFP & & & & & - & $.58^{* * *}$ & $.60^{* * *}$ & $.55^{* * *}$ \\
7. EAT-OC & & & & & & & - & $.46^{* * *}$ & $.24^{* * *}$ \\
8. DEBQ-U & & & & & & & - & $.37^{* * *}$ \\
9. DEBQ-O & & & & & & & & & - \\
\hline
\end{tabular}

Note. UE = Severe Under-eating Behaviors; FC = Food Conscious Behaviors; $\mathrm{BG}=$ Binge Eating Behaviors; UHEB = Unhealthy Eating Behaviors; EAT - D = EAT Dieting Subscale; EAT - BFP = EAT Bulimia and Food Preoccupation Subscale; EAT - OC = EAT Oral Control Subscale; DEBQ - U = DEBQ - Moderate Under-eating Subscale; DEBQ - O = DEBQ - Over-eating Subscale. ${ }^{*} p<.05$, ${ }^{* *} p<.01$, *** $p<.001$. 


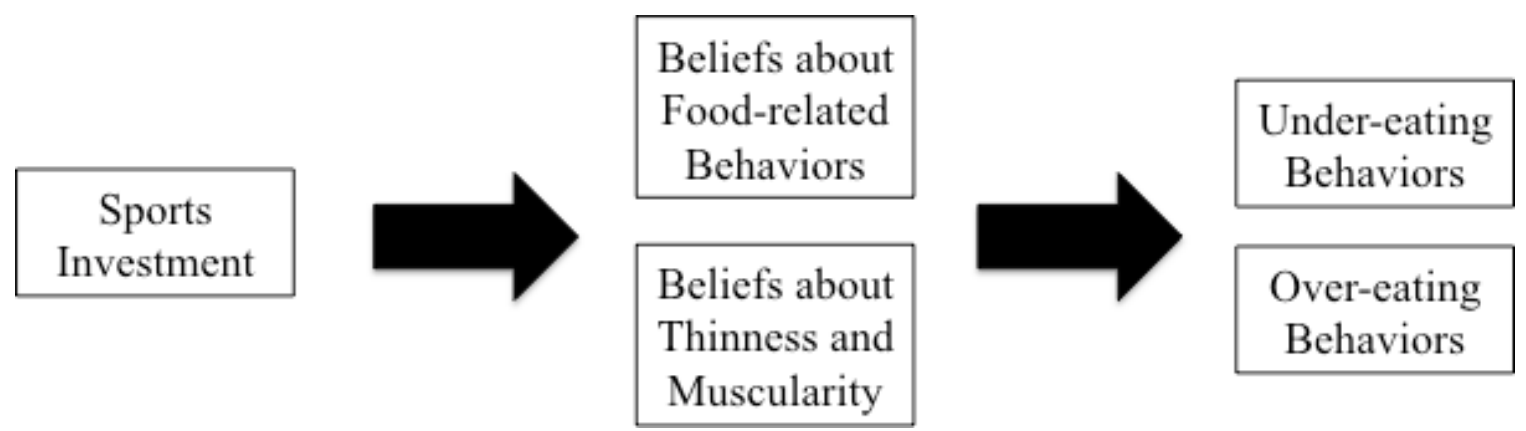

Figure 1. Conceptual diagram illustrating associations examined in the current study. Explanatory associations were also examined by several moderating variables: (1) gender, (2) age (i.e., early versus late adolescents), and (3) level of involvement in church, arts/music, and club-related activities. 


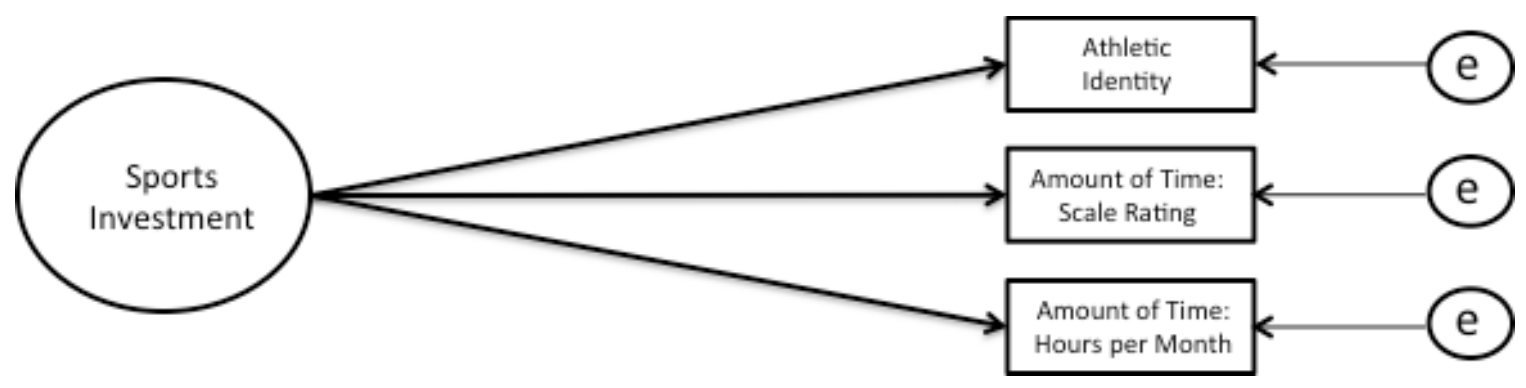

Figure 2. Sports investment latent variable and indicators. Athletic Identity = Athletic Identity Measurement Scale (i.e., AIMS). 

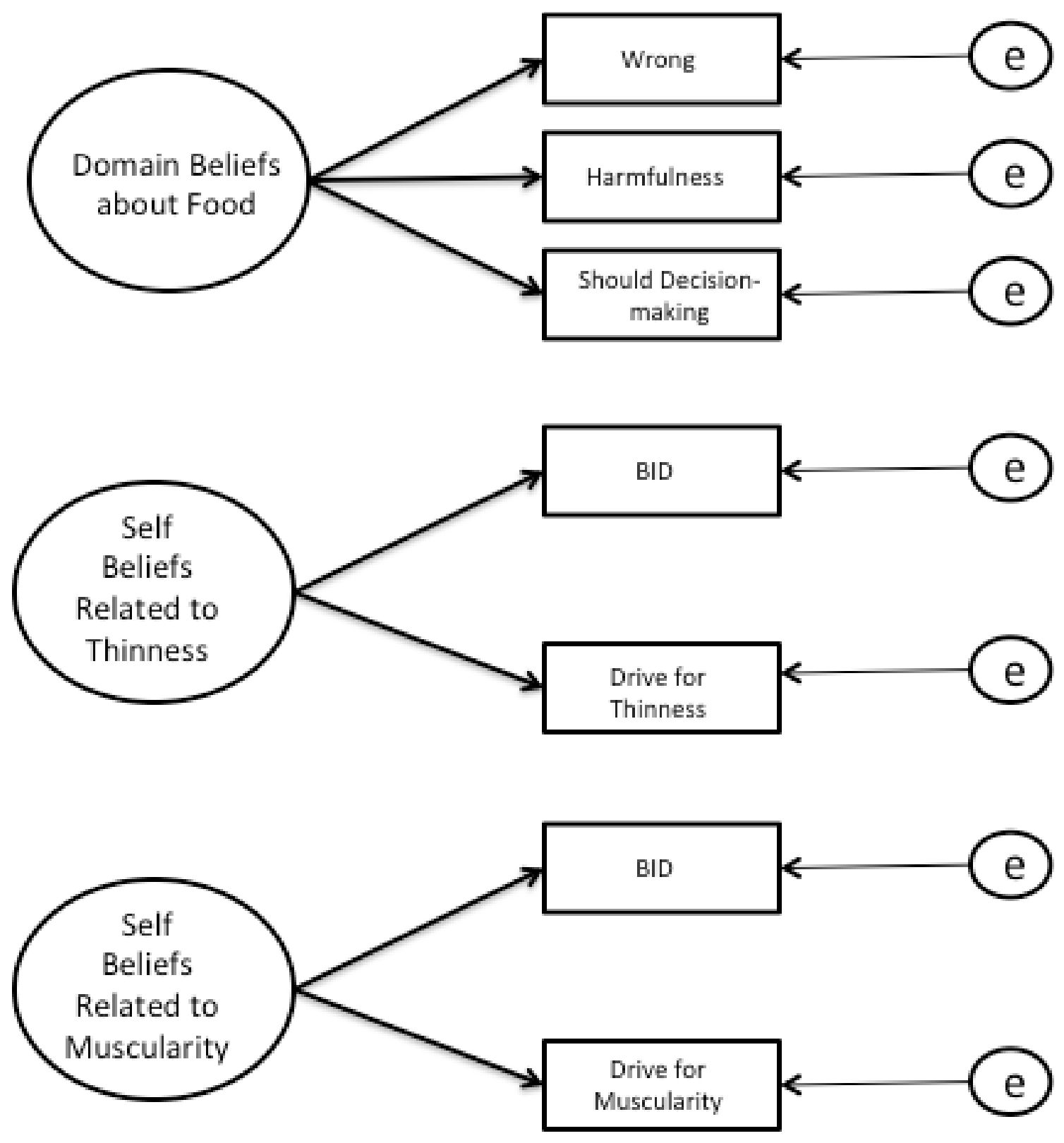

Figure 3a. Proposed mediating latent variables and indicators. BID = Body Image Dissatisfaction. 


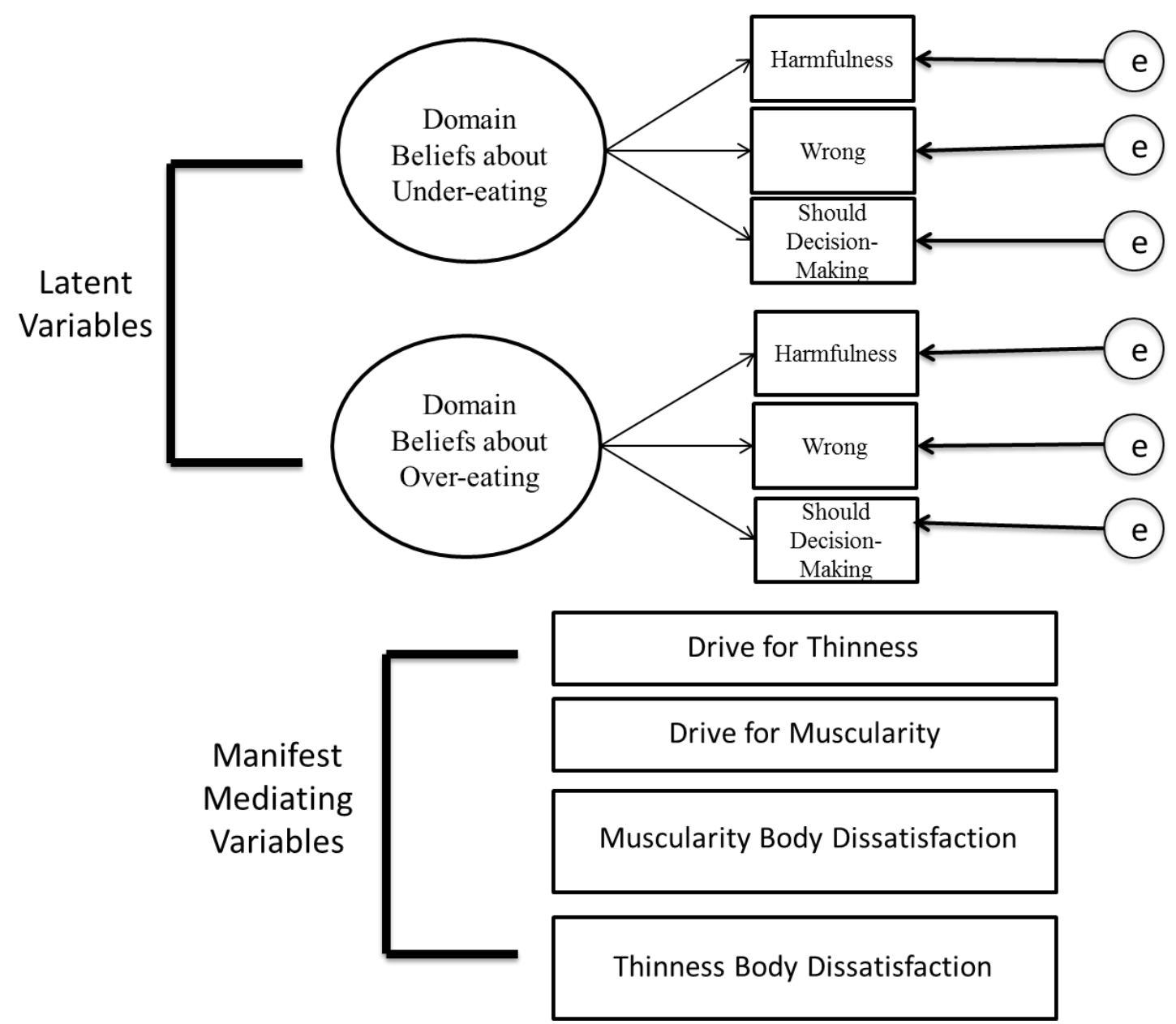

Figure $3 b$. Mediating latent and manifest variables used in statistical analyses. Latent variables represent beliefs about under- and over-eating food-related behaviors. Manifest variables represent beliefs about the body's degree of thinness and muscularity. 


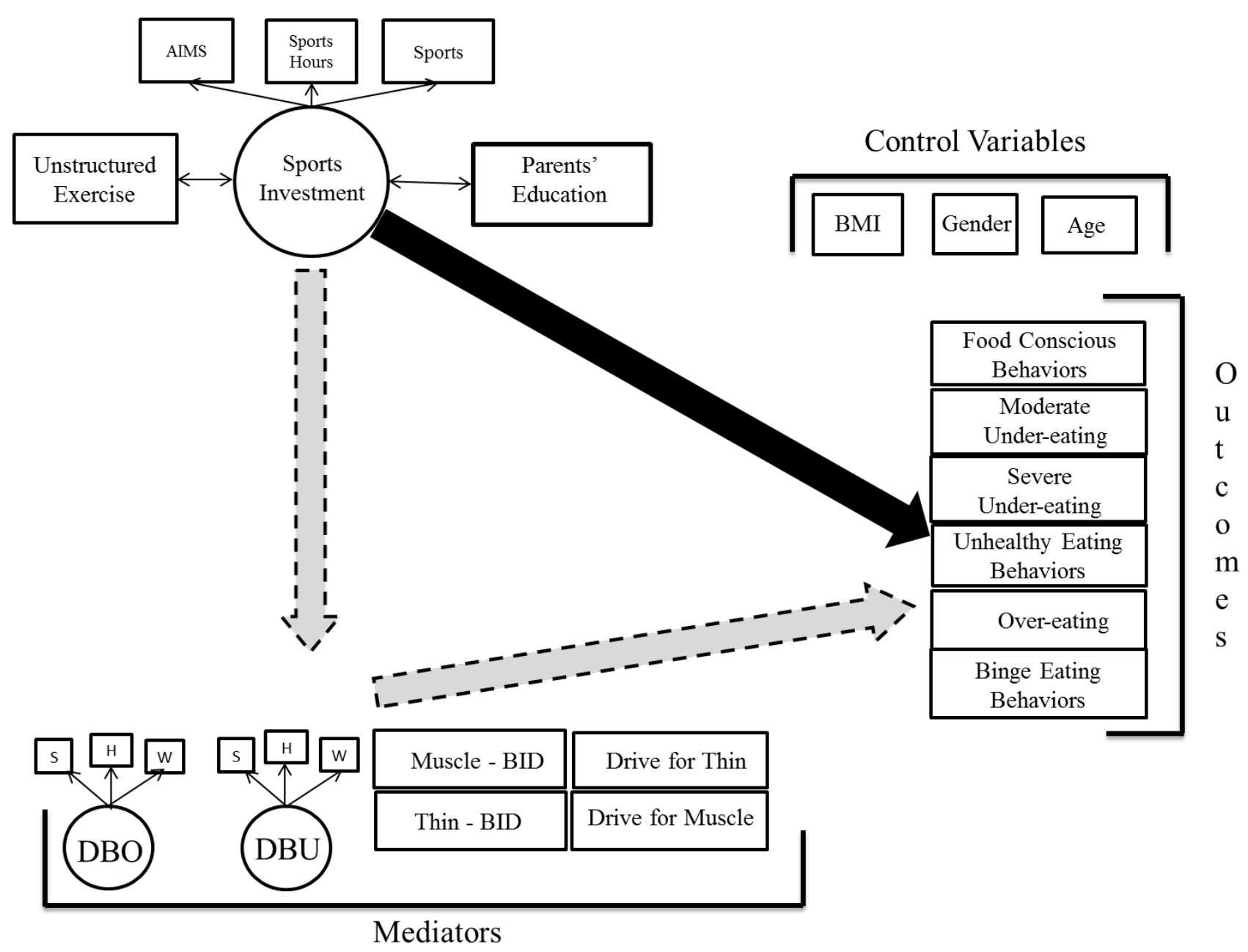

Figure 4. Direct and indirect effects between sports investment and engagement in problematic under- and over-eating behaviors through beliefs about food-related behaviors and the body's degree of thinness and muscularity. Moderation analyses examined whether such associations differed based on participants' age, gender, and involvement in other organized activities (i.e., church, arts/music, club-related activities). AIMS = Athletic Identity Measurement Scale. Muscle - BID = Muscular Body Dissatisfaction. Thin - BID = Thinness Body Dissatisfaction. 


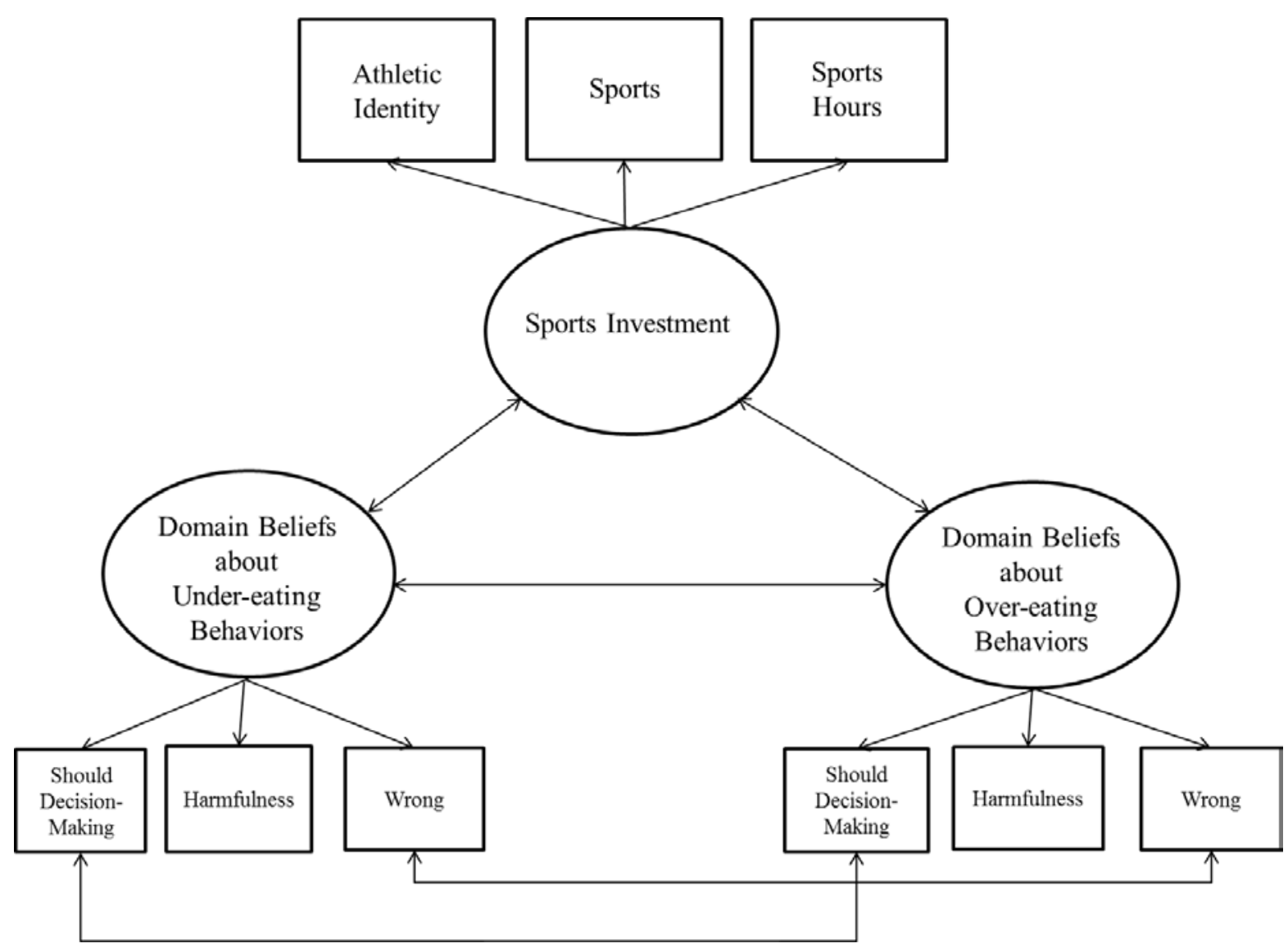

Figure 5. Measurement model. Athletic Identity = Athletic Identity Measurement Scale (i.e., AIMS). 


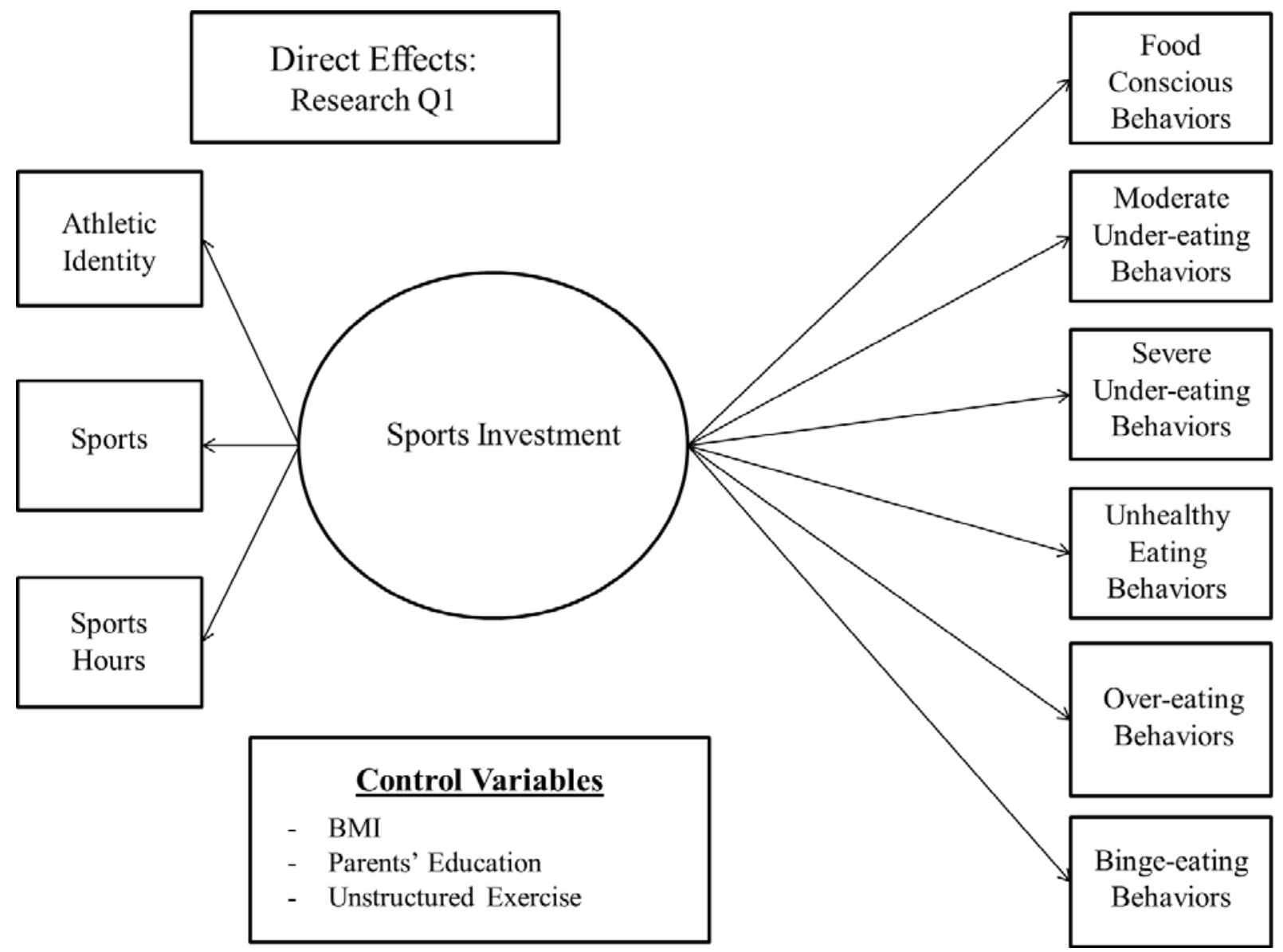

Figure 6. Direct effects between sports investment and problematic under- and over-eating outcome variables. 


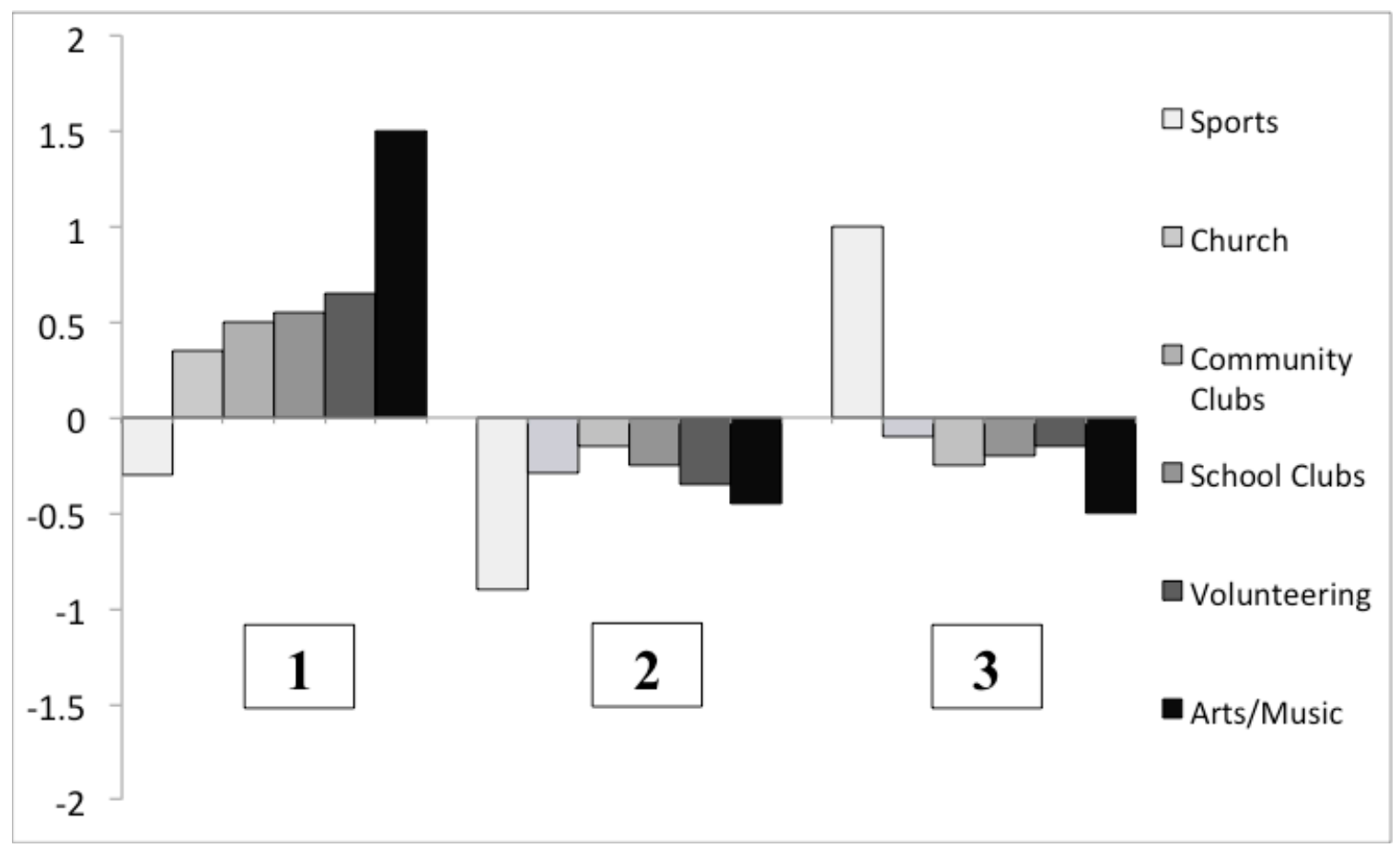

Figure 7. Cluster solutions generated through Ward's Method and K-means cluster analysis. $1=$ youth highly involved in arts/music activities and involved in sports at low levels. 2 = youth involved in all organized activities at low levels. $3=$ youth highly involved in sports and involved in all other organized activities at low levels. 
Dimensions of Problematic

Dimensions of Problematic

\begin{tabular}{|c|c|c|c|c|}
\hline \multirow{2}{*}{$\begin{array}{l}\text { Clinical } \\
\text { Diagnoses }\end{array}$} & Under-eating & \multirow{2}{*}{$\begin{array}{c}\text { Normative Eating } \\
\text { Behavior }\end{array}$} & Over-eating & Clinical \\
\hline & - I intentionally diet & & - I continue to eat & \\
\hline $\begin{array}{l}\text { Anorexia } \\
\text { Nervosa }\end{array}$ & $\begin{array}{l}\text { I count calories } \\
\text { - I "crash" diet }\end{array}$ & & $\begin{array}{l}\text { - I eat fast food } \\
\text { regularly } \\
\text { - I eat junk food }\end{array}$ & $\begin{array}{l}\text { Binge } \\
\text { Eating } \\
\text { Disorder }\end{array}$ \\
\hline
\end{tabular}

Nervosa
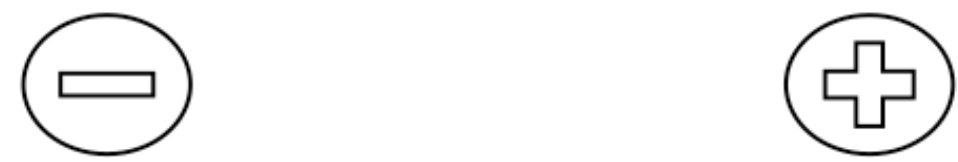

Figure 8. Spectrum of eating behaviors. 


\section{Appendix A}

\section{Demographic Measures}

1. What gender are you?

Male Female

2. How old are you? (years)

What is your birthday? (Month/Day/Year)

3. What is your grade in school? $6^{\text {th }} \quad 7^{\text {th }} 8^{\text {th }} 9^{\text {th }} \quad 10^{\text {th }} 11^{\text {th }} 12^{\text {th }}$

4. School grades (Please circle):

Mostly A's

Some A's some B's

Mostly B's

Some B's some C's

Mostly C's

Some C's some D's

Mostly D's or lower

5. What is your ethnicity (Please circle)?
African-American/Black
Hispanic/Latino
Asian-American/Pacific Islander
Native American
Caucasian/White
Other (describe)

7. What is the highest level of schooling your mother (or female guardian) completed?

Completed $8^{\text {th }}$ grade

Completed high school

Completed college

Graduate degree (doctor, lawyer, $\mathrm{PhD}$ )

Don't know or unsure

8. What is the highest level of schooling your father (or male guardian) completed?

Completed $8^{\text {th }}$ grade

Completed high school

Completed college

Graduate degree (doctor, lawyer, $\mathrm{PhD}$ )

Don't know or unsure

At what type of JOB does your MOTHER work?

At what type of JOB does your FATHER work?

9. How tall are you? __ feet __ inches

10. How much do you weigh? Pounds 


\section{Appendix B}

Explanations for Differences in Demographic Characteristic and Key Study Variables based on High School Location and Survey Version

\section{Demographic Characteristic Variables}

Participants from the mid-sized city and suburban town differed on a number of demographic characteristic variables, which included GPA, parents’ education level, height, weight, class rank (i.e., grade level), ethnicity, and survey version completed. It can be concluded that the significant differences that resulted in GPA, height, weight, and ethnicity between participants from the two high schools involved in the project were random and due to the large sample sizes collected from each location (Mid-sized city: $n=241$; Suburban town: $n=$ 369). However, significant differences that resulted in parents’ education level, class rank, and survey version completed can be attributed to limitations in study design. First of all, it is not surprising that participants from the mid-sized city had parents with higher levels of education compared to youth attending high school in the suburban town. Participants residing in the midsized city attend high school in close proximity to a state university, which employs many individuals from the community (e.g., professors, doctors/nurses, social workers), and provides opportunities for adults seeking higher educational degrees. Participants from the suburban town resided in a middle-to-upper SES community; however, for adolescents from this location, SES is potentially more closely tied to income level as opposed to parental education level. Although parental income was not measured in this study, it represents one hypothesized explanation for differences in parental educational levels that were observed.

In addition, class rank differences that emerged across high school location were directly impacted by the way in which participants were recruited at each school. Participants from the 
mid-sized city were recruited from Health Education classes, which is a course typically completed during students' sophomore year (i.e., $10^{\text {th }}$ grade). Recruiting participants in this way limited the researcher's access to students across all high-school grade levels (i.e., $9^{\text {th }}-12^{\text {th }}$ grade); however, this recruitment set-back was unable to be avoided because faculty from the Health Education Department were the only staff members willing to participate in the current study during the 2013-2014 academic year. On the other hand, participants from the suburban town were recruited from Physical Education classes, and because curriculum guidelines mandate all students to complete four years of physical education, all students (i.e., grades 9-12) enrolled in school had the opportunity to participate in the current research project. Having access to students across all grade levels contributed to the more equal spread of students across grade levels at the high school in the suburban town $\left(9^{\text {th }}: n=69,19.2 \% ; 10^{\text {th }}: n=80 ; 22.3 \%\right.$; $\left.11^{\text {th }}: n=97,27 \% ; 12^{\text {th }}: n=113,31.5 \%\right)$. Therefore, it can be concluded that high school location was confounded with participants' class rank.

Finally, high school location was also confounded with the version of the survey participants completed. Distribution of the different survey versions (Survey Version A: $n=172$, 46.6\%; Survey Version B: $n=197,53.4 \%$ ) was relatively similar for participants attending high school in the suburban town. However, at the suburban town, one faculty member assisting with the project made additional copies of Survey Version A to account for greater rates of participation than anticipated at this school. Blank surveys (i.e., both versions) remaining after data collection at the high school in the suburban town were used in conjunction with additional blank surveys in the Survey Version B format at the high school in the mid-sized city because data collection in the mid-sized city took place second. As a result, Survey Version A ( $n=145$, 60.2\%) was administered more often at the mid-sized city than Survey Version B ( $n=96$, 
29.8\%). Therefore, it can be concluded that high school location is also confounded with the survey version completed. Since high school location was previously confounded with participants’ class rank, survey version was also confounded with participants’ class rank.

\section{Key Study Variables}

Because high school location was confounded with the survey version completed by participants, as well as participants’ grade in school, 2 (school location: mid-sized town v. suburban town) X 2 (survey version: A v. B) X 4 (class rank: $9^{\text {th }} \mathrm{v} \cdot 10^{\text {th }} \mathrm{v} \cdot 11^{\text {th }} \mathrm{v} \cdot 12^{\text {th }}$ ) analysis of variance (ANOVA) were used to examine differences in key study variables. Participants did not significantly differ on binge eating behaviors or severe under-eating behaviors; church, arts/music, volunteering, school clubs, or community clubs involvement; free-response reports of hours of involvement in organized sports; assessments about the self (i.e., thinness and muscularity); should decision-making beliefs about under-eating behaviors; and wrongfulness beliefs about over-eating behaviors based on school location, survey version, or class rank.

After controlling for survey version and class rank, participants from the suburban town reported significantly more unhealthy eating behaviors $\left(F(1,574)=6.81, p=.009 ; \eta_{\mathrm{p}}{ }^{2}=.01\right)$ and involvement in arts/music activities $\left(F(1,578)=5.80, p=.02, \eta_{\mathrm{p}}{ }^{2}=.01\right)$ compared to adolescents attending high school in the mid-sized city. On the contrary, participants from the mid-sized city reported higher harmfulness beliefs about over-eating behaviors compared to adolescents from the suburban town, $F(1,577)=.571, p=.02, \eta_{\mathrm{p}}{ }^{2}=.01$. Additionally, after controlling for high school location and survey version, a significant main effect of class rank emerged for food conscious behaviors, organized sports involvement, moderate under-eating behaviors, and harmfulness beliefs about under-eating behaviors. Specifically, adolescents in grade $11(p=.002)$ and $12(p=.03)$ reported engagement in greater numbers of food conscious 
behaviors compared to individuals in grade $10, F(3,576)=2.89, p=.04, \eta_{\mathrm{p}}{ }^{2}=.02$. Adolescents in ninth grade participated in sports more often than participants in grade $10(p=.002)$ and $12(p$ $=.002), F(3,577)=2.84, p=.04, \eta_{\mathrm{p}}{ }^{2}=.02$. Participants in grade 11 engaged in more moderate under-eating behaviors compared to adolescents in $10^{\text {th }}$ grade $(p=.02), F(3,580)=3.22, p=$ $.02, \eta_{\mathrm{p}}{ }^{2}=.02$. Adolescents' in grade 10 viewed under-eating behaviors to be more harmful compared to participants in grade $11(p=.007)$ and grade $12(p=.03), F(3,577)=3.77, p=.01$, $\eta_{\mathrm{p}}^{2}=.02$.

Significant main effects of class rank on should decision-making beliefs about overeating behaviors and wrongfulness beliefs about under-eating behaviors were qualified by significant school location by class rank interactions. Participants in grade 12 from the mid-sized city $(n=22)$ reported significantly higher should decision-making beliefs about over-eating behaviors $\left(F(3,579)=3.16, p=.02, \eta_{\mathrm{p}}{ }^{2}=.02\right)$ and significantly lower wrongfulness beliefs about under-eating behaviors, $F(3,570)=3.87, p=.009, \eta_{\mathrm{p}}{ }^{2}=.02$.

A significant high school location by survey version interaction emerged for participants' exercise habits for 30 minutes per day, $F(1,566)=4.48, p=.04, \eta_{\mathrm{p}}{ }^{2}=.01$, and participants' ratings of moderate under-eating behaviors, $F(1,580)=4.88, p=.03, \eta_{\mathrm{p}}{ }^{2}=.01$. Participants from the mid-sized city who completed Survey Version B, reported exercising more often for 30 minutes per day during an average week and lower levels of moderate under-eating behaviors compared to all other participants. As previously mentioned, high school location was confounded with the survey version completed, and it is important to note that adolescents from the mid-sized city who completed Survey Version B represent the smallest group of participants $(n=96)$. 
Finally, a significant high school location by survey version interaction for over-eating behaviors was qualified by a significant three-way interaction between high school location, survey version, and class rank, $F(3,579)=3.24, p=.02, \eta_{\mathrm{p}}{ }^{2}=.02$. Ninth grade participants from the mid-sized city who completed Survey Version B reported lower over-eating behaviors scores compared to all other groups. However, it is important to note that one participant comprises this study group; therefore, these results must be interpreted with caution. 


\section{Appendix C}

Organized Activity Involvement

Organized Activities: In an average month, how often do you do the following activities OR work with the following groups. For each activity you are involved in, estimate the number of HOURS EACH MONTH you commit to the activity.

\begin{tabular}{|c|c|c|c|c|c|c|}
\hline How often do you.... & Never & $\begin{array}{c}\text { Not } \\
\text { often }\end{array}$ & Some & $\begin{array}{l}\text { Quite } \\
\text { often }\end{array}$ & $\begin{array}{l}\text { Very } \\
\text { often }\end{array}$ & $\begin{array}{c}\text { Number of } \\
\text { hours? }\end{array}$ \\
\hline 1. participate with a school sports team & 1 & 2 & 3 & 4 & 5 & \\
\hline $\begin{array}{l}\text { 2. volunteer to help with activities at your school or } \\
\text { church (setting up for a dance, working at a } \\
\text { concession stand, etc.) }\end{array}$ & 1 & 2 & 3 & 4 & 5 & \\
\hline 3. participate in a community social club & 1 & 2 & 3 & 4 & 5 & \\
\hline 4. attend religious services & 1 & 2 & 3 & 4 & 5 & \\
\hline $\begin{array}{l}\text { 5. take part in a computer, language, or academic } \\
\text { club at school }\end{array}$ & 1 & 2 & 3 & 4 & 5 & \\
\hline $\begin{array}{l}\text { 6. participate in a local or community sports team } \\
\text { outside of school }\end{array}$ & 1 & 2 & 3 & 4 & 5 & \\
\hline $\begin{array}{l}\text { 7. work for charity to collect money for a social } \\
\text { cause }\end{array}$ & 1 & 2 & 3 & 4 & 5 & \\
\hline $\begin{array}{l}\text { 8. take part in local or community art, music, or } \\
\text { drama organization }\end{array}$ & 1 & 2 & 3 & 4 & 5 & \\
\hline $\begin{array}{l}\text { 9. take part in student council or hold school } \\
\text { political positions }\end{array}$ & 1 & 2 & 3 & 4 & 5 & \\
\hline 10. participate in religious social activities & 1 & 2 & 3 & 4 & 5 & \\
\hline $\begin{array}{l}\text { 11. volunteer to help poor, sick, or disabled people } \\
\text { in your community }\end{array}$ & 1 & 2 & 3 & 4 & 5 & \\
\hline $\begin{array}{l}\text { 12. take part in a community club/group (Boy/Girl } \\
\text { Scouts, YMCA, etc.) }\end{array}$ & 1 & 2 & 3 & 4 & 5 & \\
\hline 13. take part in a school art, music, or drama group & 1 & 2 & 3 & 4 & 5 & \\
\hline $\begin{array}{l}\text { 14. volunteer to clean up your neighborhood, } \\
\text { school, or community }\end{array}$ & 1 & 2 & 3 & 4 & 5 & \\
\hline $\begin{array}{l}\text { 15. participate in religious community service } \\
\text { activities }\end{array}$ & 1 & 2 & 3 & 4 & 5 & \\
\hline 16. attend $4-\mathrm{H}$ sponsored meetings or events & 1 & 2 & 3 & 4 & 5 & \\
\hline
\end{tabular}




\section{Appendix D}

Sports Investment: Athletic Identity Measurement Scale

\begin{tabular}{|c|c|c|c|c|c|}
\hline & $\begin{array}{l}\text { Strongly } \\
\text { Disagree }\end{array}$ & $\begin{array}{c}\text { Mostly } \\
\text { Disagree }\end{array}$ & $\begin{array}{c}\text { Neither } \\
\text { Agree nor } \\
\text { Disagree }\end{array}$ & $\begin{array}{l}\text { Mostly } \\
\text { Agree }\end{array}$ & $\begin{array}{c}\text { Strongly } \\
\text { Agree }\end{array}$ \\
\hline $\begin{array}{l}\text { 1. I consider myself } \\
\text { an athlete. }\end{array}$ & 1 & 2 & 3 & 4 & 5 \\
\hline $\begin{array}{l}\text { 2. I have many goals } \\
\text { related to sport. }\end{array}$ & 1 & 2 & 3 & 4 & 5 \\
\hline $\begin{array}{l}\text { 3. Most of my friends } \\
\text { are athletes. }\end{array}$ & 1 & 2 & 3 & 4 & 5 \\
\hline $\begin{array}{l}\text { 4. Sport is the most } \\
\text { important part of my } \\
\text { life. }\end{array}$ & 1 & 2 & 3 & 4 & 5 \\
\hline $\begin{array}{l}\text { 5. I spend more time } \\
\text { thinking about sport } \\
\text { than anything else. }\end{array}$ & 1 & 2 & 3 & 4 & 5 \\
\hline $\begin{array}{l}6 . \text { I need to } \\
\text { participate in sport to } \\
\text { feel good about } \\
\text { myself. }\end{array}$ & 1 & 2 & 3 & 4 & 5 \\
\hline $\begin{array}{l}\text { 7. Other people see } \\
\text { me mainly as an } \\
\text { athlete. }\end{array}$ & 1 & 2 & 3 & 4 & 5 \\
\hline $\begin{array}{l}\text { 8. I feel bad about } \\
\text { myself with I do } \\
\text { poorly in sport. }\end{array}$ & 1 & 2 & 3 & 4 & 5 \\
\hline $\begin{array}{l}\text { 9. Sport is the only } \\
\text { important thing in my } \\
\text { life. }\end{array}$ & 1 & 2 & 3 & 4 & 5 \\
\hline $\begin{array}{l}\text { 10. I would be very } \\
\text { depressed if I were } \\
\text { injured and could not } \\
\text { compete in sport. }\end{array}$ & 1 & 2 & 3 & 4 & 5 \\
\hline
\end{tabular}




\section{Appendix E}

Dutch Eating Behavior Questionnaire

\begin{tabular}{|c|c|c|c|c|c|}
\hline & Never & Seldom & Sometimes & Often & $\begin{array}{l}\text { Very } \\
\text { often }\end{array}$ \\
\hline $\begin{array}{l}\text { 1. When you have put on weight, do you eat } \\
\text { less than you usually do? }\end{array}$ & 1 & 2 & 3 & 4 & 5 \\
\hline $\begin{array}{l}\text { 2. Do you try to eat less at mealtimes than } \\
\text { you would like to eat? }\end{array}$ & 1 & 2 & 3 & 4 & 5 \\
\hline $\begin{array}{l}\text { 3. How often do you refuse food or drinks } \\
\text { offered because you are concerned about } \\
\text { your weight? }\end{array}$ & 1 & 2 & 3 & 4 & 5 \\
\hline 4. Do you watch exactly what you eat? & 1 & 2 & 3 & 4 & 5 \\
\hline $\begin{array}{l}\text { 5. Do you deliberately eat foods that are } \\
\text { slimming? }\end{array}$ & 1 & 2 & 3 & 4 & 5 \\
\hline $\begin{array}{l}\text { 6. When you have eaten too much, do you eat } \\
\text { less than usual the following day? }\end{array}$ & 1 & 2 & 3 & 4 & 5 \\
\hline $\begin{array}{l}\text { 7. Do you deliberately eat less in order not to } \\
\text { become heavier? }\end{array}$ & 1 & 2 & 3 & 4 & 5 \\
\hline $\begin{array}{l}\text { 8. How often do you try not to eat between } \\
\text { meals because you are watching your } \\
\text { weight? }\end{array}$ & 1 & 2 & 3 & 4 & 5 \\
\hline $\begin{array}{l}\text { 9. How often in the evenings do you try not } \\
\text { to eat because you are watching your } \\
\text { weight? }\end{array}$ & 1 & 2 & 3 & 4 & 5 \\
\hline $\begin{array}{l}\text { 10. Do you take into account your weight with } \\
\text { what you eat? }\end{array}$ & 1 & 2 & 3 & 4 & 5 \\
\hline $\begin{array}{l}\text { 11. Do you have the desire to eat when you are } \\
\text { irritated? }\end{array}$ & 1 & 2 & 3 & 4 & 5 \\
\hline $\begin{array}{l}\text { 12. Do you have a desire to eat when you have } \\
\text { nothing to do? }\end{array}$ & 1 & 2 & 3 & 4 & 5 \\
\hline $\begin{array}{l}\text { 13. Do you have a desire to eat when you are } \\
\text { depressed or discouraged? }\end{array}$ & 1 & 2 & 3 & 4 & 5 \\
\hline $\begin{array}{l}\text { 14. Do you have a desire to eat when you are } \\
\text { feeling lonely? }\end{array}$ & 1 & 2 & 3 & 4 & 5 \\
\hline $\begin{array}{l}\text { 15. Do you have a desire to eat when } \\
\text { somebody lets you down? }\end{array}$ & 1 & 2 & 3 & 4 & 5 \\
\hline
\end{tabular}




\begin{tabular}{|c|c|c|c|c|c|}
\hline $\begin{array}{l}\text { 16. Do you have a desire to eat when you are } \\
\text { angry or upset? }\end{array}$ & 1 & 2 & 3 & 4 & 5 \\
\hline $\begin{array}{l}\text { 17. Do you have a desire to eat when you are } \\
\text { expecting something unpleasant to } \\
\text { happen? }\end{array}$ & 1 & 2 & 3 & 4 & 5 \\
\hline $\begin{array}{l}\text { 18. Do you get the desire to eat when you are } \\
\text { anxious, worried or tense? }\end{array}$ & 1 & 2 & 3 & 4 & 5 \\
\hline $\begin{array}{l}\text { 19. Do you have a desire to eat when things } \\
\text { are going against you or when things have } \\
\text { gone wrong? }\end{array}$ & 1 & 2 & 3 & 4 & 5 \\
\hline $\begin{array}{l}\text { 20. Do you have a desire to eat when you are } \\
\text { frightened? }\end{array}$ & 1 & 2 & 3 & 4 & 5 \\
\hline $\begin{array}{l}\text { 21. Do you have a desire to eat when you are } \\
\text { disappointed? }\end{array}$ & 1 & 2 & 3 & 4 & 5 \\
\hline $\begin{array}{l}\text { 22. Do you have a desire to eat when you are } \\
\text { emotionally upset? }\end{array}$ & 1 & 2 & 3 & 4 & 5 \\
\hline $\begin{array}{l}\text { 23. Do you have a desire to eat when you are } \\
\text { bored or restless? }\end{array}$ & 1 & 2 & 3 & 4 & 5 \\
\hline $\begin{array}{l}\text { 24. If food tastes good to you, do you eat more } \\
\text { than usual? }\end{array}$ & 1 & 2 & 3 & 4 & 5 \\
\hline $\begin{array}{l}\text { 25. If food smells and looks good, do you eat } \\
\text { more than usual? }\end{array}$ & 1 & 2 & 3 & 4 & 5 \\
\hline $\begin{array}{l}\text { 26. If you see or smell something delicious, do } \\
\text { you have a desire to eat it? }\end{array}$ & 1 & 2 & 3 & 4 & 5 \\
\hline $\begin{array}{l}\text { 27. If you have something delicious to eat, do } \\
\text { you eat it right away? }\end{array}$ & 1 & 2 & 3 & 4 & 5 \\
\hline $\begin{array}{l}\text { 28. If you walk past a convenience store or } \\
\text { fast food restaurant do you have the desire } \\
\text { to buy something delicious? }\end{array}$ & 1 & 2 & 3 & 4 & 5 \\
\hline $\begin{array}{l}\text { 29. If you walk past a snack bar or a café, do } \\
\text { you have the desire to buy something } \\
\text { delicious? }\end{array}$ & 1 & 2 & 3 & 4 & 5 \\
\hline $\begin{array}{l}\text { 30. If you see others eating, do you have the } \\
\text { desire to eat? }\end{array}$ & 1 & 2 & 3 & 4 & 5 \\
\hline 31. Can you resist eating delicious foods? & 1 & 2 & 3 & 4 & 5 \\
\hline $\begin{array}{l}\text { 32. Do you eat more than usual, when you see } \\
\text { others eating? }\end{array}$ & 1 & 2 & 3 & 4 & 5 \\
\hline $\begin{array}{l}\text { 33. When preparing a meal are you inclined to } \\
\text { eat something? }\end{array}$ & 1 & 2 & 3 & 4 & 5 \\
\hline
\end{tabular}




\section{Appendix F}

Problematic Eating Behaviors Scale

\begin{tabular}{|c|c|c|c|c|c|c|}
\hline & Never & Rarely & Sometimes & Frequently & Often & Very Often \\
\hline $\begin{array}{l}\text { 1. I consistently eat } \\
\text { low calorie or reduced } \\
\text { fat/fat free foods. }\end{array}$ & 1 & 2 & 3 & 4 & 5 & 6 \\
\hline $\begin{array}{l}\text { 2. I avoid eating } \\
\text { certain food groups } \\
\text { (e.g., meat, carbs). }\end{array}$ & 1 & 2 & 3 & 4 & 5 & 6 \\
\hline 3. I count calories. & 1 & 2 & 3 & 4 & 5 & 6 \\
\hline 4. I intentionally diet. & 1 & 2 & 3 & 4 & 5 & 6 \\
\hline $\begin{array}{l}\text { 5. I stop eating when I } \\
\text { am still hungry. }\end{array}$ & 1 & 2 & 3 & 4 & 5 & 6 \\
\hline $\begin{array}{l}\text { 6. I don't eat when I } \\
\text { am hungry. }\end{array}$ & 1 & 2 & 3 & 4 & 5 & 6 \\
\hline 7. I “crash” diet. & 1 & 2 & 3 & 4 & 5 & 6 \\
\hline $\begin{array}{l}\text { 8. I drink water to } \\
\text { suppress my appetite. }\end{array}$ & 1 & 2 & 3 & 4 & 5 & 6 \\
\hline 9. I eat junk food. & 1 & 2 & 3 & 4 & 5 & 6 \\
\hline $\begin{array}{l}\text { 10. I eat snacks while } \\
\text { completing other } \\
\text { activities (e.g., } \\
\text { watching TV, } \\
\text { completing } \\
\text { homework). }\end{array}$ & 1 & 2 & 3 & 4 & 5 & 6 \\
\hline $\begin{array}{l}\text { 11. I eat snacks right } \\
\text { out of the bag, box or } \\
\text { package. }\end{array}$ & 1 & 2 & 3 & 4 & 5 & 6 \\
\hline $\begin{array}{l}\text { 12. I eat fast food } \\
\text { regularly. }\end{array}$ & 1 & 2 & 3 & 4 & 5 & 6 \\
\hline $\begin{array}{l}13 . \text { I eat food from } \\
\text { vending machines } \\
\text { regularly. }\end{array}$ & 1 & 2 & 3 & 4 & 5 & 6 \\
\hline $\begin{array}{l}\text { 14. I continue to eat } \\
\text { when I am full. }\end{array}$ & 1 & 2 & 3 & 4 & 5 & 6 \\
\hline 15. I binge eat. & 1 & 2 & 3 & 4 & 5 & 6 \\
\hline $\begin{array}{l}\text { 16. I eat a lot of food } \\
\text { when I am stressed. }\end{array}$ & 1 & 2 & 3 & 4 & 5 & 6 \\
\hline $\begin{array}{l}\text { 17. I eat more than I } \\
\text { need when } \\
\text { emotionally upset. }\end{array}$ & 1 & 2 & 3 & 4 & 5 & 6 \\
\hline
\end{tabular}




\section{Appendix G}

\section{Pilot Data Analyses}

The purpose of the current pilot study, and subsequent data analyses, was to examine the measurement properties of the 34 items assessing dimensions of problematic under- and overeating behaviors, which were created specifically for the purpose of the proposed research project. Analyses examined subscales of these items through exploratory (EFA) and confirmatory factor analyses (CFA), internal reliability of the resulting subscales, and convergent and divergent validity of the subscales with established measures of problematic under- and over-eating behaviors (i.e., Eating Attitudes Test, Dutch Eating Behavior Questionnaire). These items were developed for the current study because previous research investigating problematic eating behaviors with community samples of adolescents has utilized measures, which either captured problematic eating behaviors through clinical distinction categories or failed to capture a wide range of problematic eating behaviors that adolescents have the potential to carry out. The items created for this study aimed to address this gap in the literature to more accurately represent problematic eating behaviors among today’s youth.

\section{Method}

\section{Participants and Procedure}

Three hundred and eighty-three students enrolled in introductory Psychology courses at West Virginia University participated in an online study for course credit. One hundred and eleven participants were removed from the sample because they failed one of three validity checks imbedded in the survey questions. Participants who failed the validity checks differed from those who did not on several key study and demographic variables. Participants who failed the validity checks viewed food-related behavior as more harmful $(M=3.20, S D=1.16)$, 
$t(144.69)=-3.53, p=.001$, and wrong $(M=2.96, S D=.87), t(162.34)=-3.14, p=.002$ compared to those who passed the validity checks (Harm: $M=2.77, S D=.73$; Wrong: $M=2.67$, $S D=.65)$. Participants who failed the validity checks were also more likely to engage in under$(M=3.27, S D=1.31), t(162.38)=-4.47, p<.001$, and over-eating $(M=3.09, S D=1.22)$, $t(139.68)=-2.07, p=.041$ behaviors, as measured by the Dutch Eating Behavior Questionnaire (DEBQ; van Strien et al., 1986), compared to participants who passed the validity checks (Under-eating: $M=2.65, S D=1.00$; Over-eating: $M=2.82, S D=.79$ ). Participants who failed the validity checks scored higher on the dieting $(M=3.30, S D=1.57), t(153.75)=-3.21, p=$ .002 ; bulimia and food preoccupation (BFP; $M=2.78, S D=1.73$ ), $t(137.49)=-4.59, p<.001$; and oral control (OC: $M=2.99, S D=1.60), t(128.08)=-4.26, p<.001$ subscales of the Eating Attitudes Test (EAT; Garner \& Garfinkel, 1979) compared to participants who passed the validity checks (Dieting: $M=2.77, S D=1.09$; BFP: $M=1.97, S D=1.00$; OC: $M=2.31, S D=$ .75). Participants who failed the validity checks significantly differed from participants who passed the validity checks on two of the four subscales of the measure created specifically for the purpose of this pilot study, which assessed engagement in dimensions of under- and over-eating behaviors. Participants who failed the validity checks scored higher on the food conscious behaviors $(M=2.76, S D=1.01), t(382)=-2.45, p=.015$, and the severe under-eating behaviors $(M=2.46, S D=1.01), t(379)=-2.57, p=.011$ subscales compared to those who passed the validity checks. An examination of the raw data indicates that participants who failed the validity checks were more likely to report the highest possible answer choice on each survey item (e.g., reporting all 5's on the DEBQ), which not only contributes to higher mean-level scores on key study variables when compared to participants who passed the validity checks, but also illustrates bias in their self-reported survey responses. The only demographic variable which differed 
between participants who passed and failed the validity checks was ethnicity; among biracial individuals, more participants passed the validity checks than expected, $\chi^{2}(4)=10.45, p=.033$. Twenty-one additional participants were excluded because they failed to complete key study measures.

The final analytic sample included 251 participants $(M=19.93, S D=2.59,77.3 \%$ female). Participants were primarily Caucasian/White $(90 \%, n=226)$. Remaining participants were African American/Black (1.2\%, $n=3)$, Asian American/Pacific Islander $(1.6 \%, n=4)$, Hispanic/Latino (.4\%, $n=1)$, and biracial/mixed identities $(6.8 \%, n=17)$. More than half of participants reported a sophomore class rank $(54.6 \%, n=137)$, although all class ranks ranging from first year students to fifth year seniors were represented in the sample. Participants were, on average, "B students” $(M=3.24, S D=.55$ on a $0-4$ point scale).

\section{Measures}

Dutch eating behavior questionnaire (DEBQ). Participants completed thirty-three items, which assessed restrained, external, and emotional eating behaviors using a 5-point Likert scale (1 = Never, 5 = Very often; van Strien et al., 1986). Higher scores on each subscale indicated more problematic eating in each area. For the purpose of the current study, participants' average score on the external and emotional eating subscales were standardized and combined to assess over-eating behaviors, while participants' average score on the restrained eating subscale assessed under-eating behaviors. These subscales exhibited good internal reliability (Under-eating behaviors: $\alpha=.96,10$ items; Over-eating behaviors: $\alpha=.96$, 23 items; Appendix E).

Eating Attitudes Test (EAT). Twenty-six items were used to assess participants’ risk for the development of clinically-diagnosed eating disorders (Garner \& Garfinkel, 1979). The full 
scale is comprised of three subscales; dieting (e.g., I am terrified about being overweight), bulimia and food preoccupation (e.g., I find myself preoccupied with food), and oral control (e.g., I avoid eating when I am hungry). Participants reported on these items using a 6-point Likert scale (1 = Never, 6 = Always); higher scores represented more problematic eating in each area. These subscales exhibited good internal reliability (Dieting: $\alpha=.94,13$ items; Bulimia and food preoccupation: $\alpha=.89,6$ items; Oral control: $\alpha=.75,7$ items; Appendix O).

Domain beliefs about food-related behaviors. Participants provided harmfulness $(\alpha=$ $.93,21$ items), wrongness ( $\alpha=.88,21$ items), and decision-making ( $\alpha=.94,26$ items) beliefs about a variety of food-related behaviors, which were questions adapted from previous research utilizing a social-cognitive framework (e.g., Ferris, 2012; Metzger \& Smetana, 2009). Participants evaluated items using 5-point Likert scales (e.g., Harm: 1 = Not harmful at all, 5 = Very harmful); higher scores represented associating greater harmfulness, wrongfulness, and adolescent unilateral decision-making to under- and over-eating behaviors (Appendix H).

Problematic eating behaviors scale (PEBS). Participants completed 34 items developed specifically for the current study, which examined dimensions of under- and over-eating behaviors, and were adapted from previous research (e.g., Maloney, McGuire, \& Daniels, 1988) (Appendix F; Table 5; Table 18; Table 19).

\section{Results}

Principal component analysis with varimax rotation was conducted on the original 34 items assessing engagement in dimensions of problematic under- and over-eating behaviors. A four factor solution that accounted for $50.94 \%$ of the variance was identified: 1) Food Conscious Behaviors ( $\alpha=.73 ; 3$ items), 2) Severe Under-eating Behaviors ( $\alpha=.82 ; 5$ items), 3) Unhealthy Eating Behaviors (.82; 5 items), and 4) Binge Eating Behaviors ( $\alpha=.89 ; 4$ items). See Table 18 
for subscales and corresponding items. Seventeen items were excluded from the original pool of items due to cross-loadings and because they did not fit conceptually with the four constructs identified through the EFA (Table 19).

Using SPSS AMOS 20 with maximum likelihood estimation, the subscales and corresponding indicators were examined as latent constructs (i.e., measurement model). The measurement model provided a good fit to the data, $\chi^{2} / d f=2.44, \mathrm{CFI}=.90, \mathrm{RMSEA}=.076$. In order to achieve a well-fitting model, modification indices were used to identify which error terms should be allowed to covary. In the final model, the error terms for the items assessing fast food consumption and eating snacks from vending machines (indicators of unhealthy eating behaviors) were allowed to covary, while the error term for the item assessing binge-eating behaviors was allowed to covary with the error terms associated with these two items. Examination of the standardized regression weights for the indicators of each latent variable indicates strong loadings onto each construct (Table 18). Results from the CFA are in line with theory and suggest that there are distinct subscales within the items used to assess dimensions of problematic under- and over-eating behaviors. There are distinctions between under- and overeating behaviors, as well as divisions within each type of problematic eating behavior, which further divides these under- and over-eating items based on the severity of the behavior carried out. For example, food conscious behaviors, such as counting calories and avoiding certain food groups are distinguished from more severe under-eating behaviors, including carrying out crash diets and drinking water to suppress one's appetite within the under-eating category.

Multigroup analyses (Byrne, 2004) were used to test whether pathways were invariant for males and females. A model in which the structural paths were freely estimated for males and females did not significantly differ from a model where the pathways were constrained to be 
equal $\left(\Delta \chi^{2}=15.97, \Delta d f=11, p=.14\right)$, and the constrained model fit the data well $\left(\chi^{2} / d f=1.90\right.$, $\mathrm{CFI}=.88$, RMSEA $=.061)$. In addition, multigroup analyses did not indicate significant differences in the measurement weights between the constrained and unconstrained models $(p=$ .078), which suggests no differences in the factor loadings of the indicators of the four subscales across participant gender.

The convergent and divergent validity of the four subscales were evaluated through examination of bivariate correlations with established scales of under- and over-eating behaviors (Table 20). The under- and over-eating subscales of the DEBQ (van Strien et al., 1986) were used as a measure comparison for sub-clinical dimensions of under- and over-eating behaviors, while the three subscales (i.e., Dieting, Bulimia and Food Preoccupation, and Oral Control) of the EAT (Garner \& Garfinkel, 1979) were used as a measure of clinical risk for under-eating disorders.

Both the food conscious behaviors subscale and the severe under-eating behaviors subscale were positively correlated with the moderate under-eating subscale of the DEBQ, and with the three subscales of the EAT, which illustrates convergent validity. The food conscious behaviors subscale and the severe under-eating behaviors subscale were also positively correlated with the over-eating behaviors subscale of the DEBQ, and the binge eating behaviors subscale. This pattern of correlations suggests that divergent validity was not achieved from one established measure of sub-clinical over-eating behaviors, which indicates that food conscious and severe under-eating behaviors, and over-eating behaviors may be carried out simultaneously within the current sample. This same pattern emerged in a recent study with normatively developing adolescents (Ferris, 2012), and as a result, it needs to be explored further. Additionally, the subscales assessing food conscious behaviors and severe under-eating 
behaviors were highly correlated. This finding suggests that the items being used to assess two distinct constructs may indeed overlap and capture the same behaviors. This correlation was found after piloting the measure with a college-aged sample, and because the intended use of these subscales is with community-dwelling adolescent populations, the four-factor solution will be retained and explored further using such samples.

Both the binge eating behaviors subscale and the unhealthy eating behaviors subscale were positively correlated with the over-eating subscale of the DEBQ, which suggests convergent validity. The unhealthy eating behaviors subscale was negatively correlated with the moderate under-eating subscale of the DEBQ and the dieting subscale of the EAT, which indicates divergent validity. However, the binge eating behaviors subscale was positively associated with the moderate under-eating subscale of the DEBQ and with two subscales from the EAT. As mentioned previously, reports of binge eating behaviors and under-eating behaviors may be linked in the current sample, and these patterns need to be explored further with adolescents. 


\section{Appendix $\mathrm{H}$}

Domain Beliefs about Food-related Behaviors: Harmfulness

\begin{tabular}{|c|c|c|c|c|c|}
\hline How harmful is... & $\begin{array}{l}\text { Not Harmful at } \\
\text { All }\end{array}$ & $\begin{array}{l}\text { A Little } \\
\text { Harmful }\end{array}$ & $\begin{array}{c}\text { Somewhat } \\
\text { Harmful }\end{array}$ & $\begin{array}{c}\text { Quite } \\
\text { Harmful }\end{array}$ & $\begin{array}{c}\text { Very } \\
\text { Harmful }\end{array}$ \\
\hline 1. dieting & 1 & 2 & 3 & 4 & 5 \\
\hline $\begin{array}{l}\text { 2. to stop eating when you are } \\
\text { still hungry }\end{array}$ & 1 & 2 & 3 & 4 & 5 \\
\hline 3. not eating when hungry & 1 & 2 & 3 & 4 & 5 \\
\hline $\begin{array}{l}\text { 4. skipping meals (e.g., } \\
\text { breakfast) }\end{array}$ & 1 & 2 & 3 & 4 & 5 \\
\hline $\begin{array}{l}\text { 5. not eating certain food } \\
\text { groups (e.g., meat, carbs) }\end{array}$ & 1 & 2 & 3 & 4 & 5 \\
\hline $\begin{array}{l}\text { 6. avoiding eating certain food } \\
\text { groups (e.g., meat, carbs) }\end{array}$ & 1 & 2 & 3 & 4 & 5 \\
\hline 7. counting calories & 1 & 2 & 3 & 4 & 5 \\
\hline 8. eating snacks between meals & 1 & 2 & 3 & 4 & 5 \\
\hline 9. eating junk food & 1 & 2 & 3 & 4 & 5 \\
\hline $\begin{array}{l}\text { 10. continuing to eat when you } \\
\text { are full }\end{array}$ & 1 & 2 & 3 & 4 & 5 \\
\hline $\begin{array}{l}\text { 11. carb loading before } \\
\text { participating in physical } \\
\text { activity }\end{array}$ & 1 & 2 & 3 & 4 & 5 \\
\hline 12. eating when you are bored & 1 & 2 & 3 & 4 & 5 \\
\hline 13. eating late night snacks & 1 & 2 & 3 & 4 & 5 \\
\hline $\begin{array}{l}\text { 14. eating snacks while } \\
\text { completing other activities } \\
\text { (e.g., watching TV, completing } \\
\text { HW) }\end{array}$ & 1 & 2 & 3 & 4 & 5 \\
\hline $\begin{array}{l}\text { 15. drinking sugary drinks } \\
\text { (e.g., fruit juices or soda) }\end{array}$ & 1 & 2 & 3 & 4 & 5 \\
\hline $\begin{array}{l}\text { 16. eating snacks right out of } \\
\text { the bag, box or package }\end{array}$ & 1 & 2 & 3 & 4 & 5 \\
\hline 17. eating fast food regularly & 1 & 2 & 3 & 4 & 5 \\
\hline $\begin{array}{l}\text { 18. eating food from vending } \\
\text { machines regularly }\end{array}$ & 1 & 2 & 3 & 4 & 5 \\
\hline $\begin{array}{l}\text { 19. drinking water to suppress } \\
\text { your appetite }\end{array}$ & 1 & 2 & 3 & 4 & 5 \\
\hline $\begin{array}{l}\text { 20. intentionally eating snacks } \\
\text { throughout the day to avoid } \\
\text { eating a full meal }\end{array}$ & 1 & 2 & 3 & 4 & 5 \\
\hline $\begin{array}{l}\text { 21. consistently eating low } \\
\text { calorie or fat free foods }\end{array}$ & 1 & 2 & 3 & 4 & 5 \\
\hline
\end{tabular}


Domain Beliefs about Food-related Behaviors: Wrongfulness

\begin{tabular}{|c|c|c|c|c|c|}
\hline How wrong is... & $\begin{array}{c}\text { Not Wrong at } \\
\text { All }\end{array}$ & $\begin{array}{l}\text { A Little } \\
\text { Wrong }\end{array}$ & $\begin{array}{l}\text { Somewhat } \\
\text { Wrong }\end{array}$ & $\begin{array}{c}\text { Quite } \\
\text { Wrong }\end{array}$ & $\begin{array}{c}\text { Very } \\
\text { Wrong }\end{array}$ \\
\hline 1. dieting & 1 & 2 & 3 & 4 & 5 \\
\hline $\begin{array}{l}\text { 2. to stop eating when you are } \\
\text { still hungry }\end{array}$ & 1 & 2 & 3 & 4 & 5 \\
\hline 3. not eating when hungry & 1 & 2 & 3 & 4 & 5 \\
\hline $\begin{array}{l}\text { 4. skipping meals (e.g., } \\
\text { breakfast) }\end{array}$ & 1 & 2 & 3 & 4 & 5 \\
\hline $\begin{array}{l}\text { 5. not eating certain food } \\
\text { groups (e.g., meat, carbs) }\end{array}$ & 1 & 2 & 3 & 4 & 5 \\
\hline $\begin{array}{l}\text { 6. avoiding eating certain } \\
\text { food groups (e.g., meat, } \\
\text { carbs) }\end{array}$ & 1 & 2 & 3 & 4 & 5 \\
\hline 7. counting calories & 1 & 2 & 3 & 4 & 5 \\
\hline $\begin{array}{l}\text { 8. eating snacks between } \\
\text { meals }\end{array}$ & 1 & 2 & 3 & 4 & 5 \\
\hline 9. eating junk food & 1 & 2 & 3 & 4 & 5 \\
\hline $\begin{array}{l}\text { 10. continuing to eat when } \\
\text { you are full }\end{array}$ & 1 & 2 & 3 & 4 & 5 \\
\hline $\begin{array}{l}\text { 11. carb loading before } \\
\text { participating in physical } \\
\text { activity }\end{array}$ & 1 & 2 & 3 & 4 & 5 \\
\hline 12. eating when you are bored & 1 & 2 & 3 & 4 & 5 \\
\hline 13. eating late night snacks & 1 & 2 & 3 & 4 & 5 \\
\hline $\begin{array}{l}\text { 14. eating snacks while } \\
\text { completing other activities } \\
\text { (e.g., watching TV, } \\
\text { completing HW) }\end{array}$ & 1 & 2 & 3 & 4 & 5 \\
\hline $\begin{array}{l}\text { 15. drinking sugary drinks } \\
\text { (e.g., fruit juices or soda) }\end{array}$ & 1 & 2 & 3 & 4 & 5 \\
\hline $\begin{array}{l}\text { 16. eating snacks right out of } \\
\text { the bag, box or package }\end{array}$ & 1 & 2 & 3 & 4 & 5 \\
\hline 17. eating fast food regularly & 1 & 2 & 3 & 4 & 5 \\
\hline $\begin{array}{l}\text { 18. eating food from vending } \\
\text { machines regularly }\end{array}$ & 1 & 2 & 3 & 4 & 5 \\
\hline $\begin{array}{l}\text { 19. drinking water to suppress } \\
\text { your appetite }\end{array}$ & 1 & 2 & 3 & 4 & 5 \\
\hline $\begin{array}{l}\text { 20. intentionally eating } \\
\text { snacks throughout the day to } \\
\text { avoid eating a full meal }\end{array}$ & 1 & 2 & 3 & 4 & 5 \\
\hline $\begin{array}{l}\text { 21. consistently eating low } \\
\text { calorie or fat free foods }\end{array}$ & 1 & 2 & 3 & 4 & 5 \\
\hline
\end{tabular}




\section{Domain Beliefs about Food-related Behaviors: Should Decision-making}

Now, circle the number that best describes who in your family SHOULD make most of the decisions about each of the topics below, using the following scale:

1. My parent(s) should decide this without discussing it with me.

2. My parent(s) should make the final decision after discussing it with me.

3. My parent(s) and I should make the decision together.

4. I should make the final decision after discussing it with my parent(s) or guardian(s).

5. I should decide this without discussing it with my parent(s) or guardian(s).

\begin{tabular}{|c|c|c|c|c|c|}
\hline Who should decide... & $\begin{array}{l}\text { Parent } \\
\text { decides }\end{array}$ & $\begin{array}{c}\text { Mainly } \\
\text { parent }\end{array}$ & $\begin{array}{l}\text { Decide } \\
\text { together }\end{array}$ & $\begin{array}{l}\text { Mainly } \\
\text { child }\end{array}$ & $\begin{array}{c}\text { Child } \\
\text { decides }\end{array}$ \\
\hline 1. if teens diet & 1 & 2 & 3 & 4 & 5 \\
\hline 2. if teens stop eating when still hungry & 1 & 2 & 3 & 4 & 5 \\
\hline 3. if teens skip meals & 1 & 2 & 3 & 4 & 5 \\
\hline $\begin{array}{l}\text { 4. if teens avoid eating certain food groups (e.g., } \\
\text { carbs, meat) }\end{array}$ & 1 & 2 & 3 & 4 & 5 \\
\hline 5. what teens eat while at home & 1 & 2 & 3 & 4 & 5 \\
\hline 6. what teens eat while away from home & 1 & 2 & 3 & 4 & 5 \\
\hline 7. what foods are bought for meals at home & 1 & 2 & 3 & 4 & 5 \\
\hline $\begin{array}{l}\text { 8. if teens eat "junk food" when outside the } \\
\text { home }\end{array}$ & 1 & 2 & 3 & 4 & 5 \\
\hline 9. if "crash diets" are carried out & 1 & 2 & 3 & 4 & 5 \\
\hline 10. if teens count calories & 1 & 2 & 3 & 4 & 5 \\
\hline $\begin{array}{l}\text { 11. if food labels are read to determine nutrient } \\
\text { value or calorie content }\end{array}$ & 1 & 2 & 3 & 4 & 5 \\
\hline 12. if organic foods are consumed & 1 & 2 & 3 & 4 & 5 \\
\hline 13. if laxatives are used to lose weight & 1 & 2 & 3 & 4 & 5 \\
\hline 14. if teens eat junk food while at home & 1 & 2 & 3 & 4 & 5 \\
\hline $\begin{array}{l}\text { 15. if teens eat low calorie or reduced fat/fat free } \\
\text { foods }\end{array}$ & 1 & 2 & 3 & 4 & 5 \\
\hline 16. if teens eat snacks between meals & 1 & 2 & 3 & 4 & 5 \\
\hline 17. if teens continue to eat when already full & 1 & 2 & 3 & 4 & 5 \\
\hline $\begin{array}{l}\text { 18. if teens carb load before engaging in } \\
\text { physical activity }\end{array}$ & 1 & 2 & 3 & 4 & 5 \\
\hline 19. if teens binge eat & 1 & 2 & 3 & 4 & 5 \\
\hline 20. if teens eat late night snacks & 1 & 2 & 3 & 4 & 5 \\
\hline $\begin{array}{l}\text { 21. if teens drink sugary drinks (e.g., soda or } \\
\text { juice) }\end{array}$ & 1 & 2 & 3 & 4 & 5 \\
\hline 22. if teens eat fast food regularly & 1 & 2 & 3 & 4 & 5 \\
\hline $\begin{array}{l}\text { 23. if teens eat food from vending machines } \\
\text { regularly }\end{array}$ & 1 & 2 & 3 & 4 & 5 \\
\hline 24. if teens drink coffee & 1 & 2 & 3 & 4 & 5 \\
\hline 25. if teens finish all the food on their plate & 1 & 2 & 3 & 4 & 5 \\
\hline $\begin{array}{l}\text { 26. if teens eat a well-balanced meal containing } \\
\text { foods from the recommended food groups }\end{array}$ & 1 & 2 & 3 & 4 & 5 \\
\hline
\end{tabular}




\section{Appendix I}

Beliefs about Thinness: Drive for Thinness Scale

\begin{tabular}{|c|c|c|c|c|c|c|}
\hline & Never & Rarely & Sometimes & Usually & Often & Always \\
\hline $\begin{array}{l}\text { 1. I eat sweets and } \\
\text { carbohydrates without feeling } \\
\text { nervous. }\end{array}$ & 1 & 2 & 3 & 4 & 5 & 6 \\
\hline 2. I think about dieting. & 1 & 2 & 3 & 4 & 5 & 6 \\
\hline $\begin{array}{l}\text { 3. I feel extremely guilty after } \\
\text { overeating. }\end{array}$ & 1 & 2 & 3 & 4 & 5 & 6 \\
\hline $\begin{array}{l}\text { 4. I am terrified of gaining } \\
\text { weight. }\end{array}$ & 1 & 2 & 3 & 4 & 5 & 6 \\
\hline $\begin{array}{l}\text { 5. I exaggerate or magnify the } \\
\text { importance of weight. }\end{array}$ & 1 & 2 & 3 & 4 & 5 & 6 \\
\hline $\begin{array}{l}\text { 6. I am preoccupied with the } \\
\text { desire to be thinner. }\end{array}$ & 1 & 2 & 3 & 4 & 5 & 6 \\
\hline $\begin{array}{l}\text { 7. If I gain a pound, I worry } \\
\text { that I will keep gaining. }\end{array}$ & 1 & 2 & 3 & 4 & 5 & 6 \\
\hline
\end{tabular}




\section{Appendix J}

Beliefs about Thinness: Thinness Body Dissatisfaction

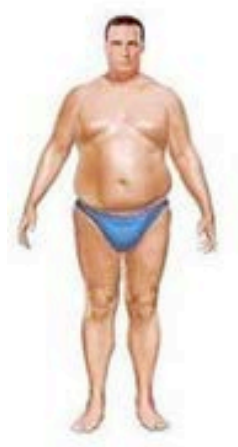

7

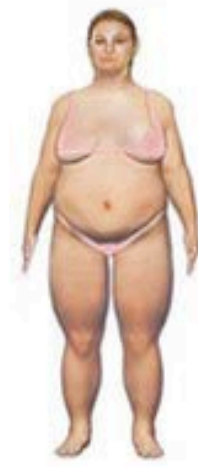

7

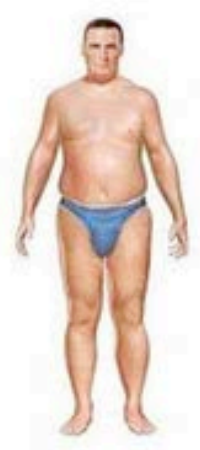

6

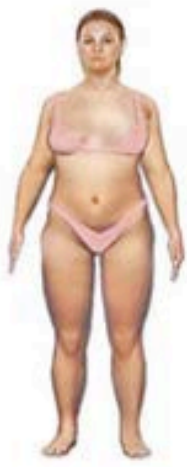

6

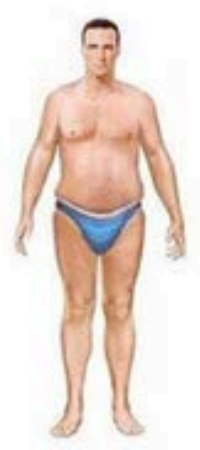

5

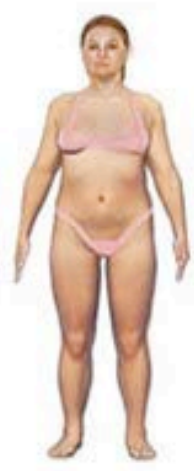

5

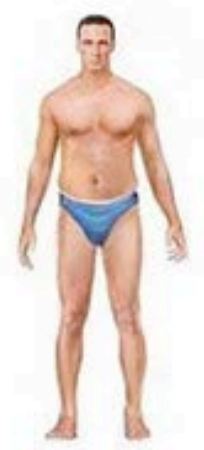

4

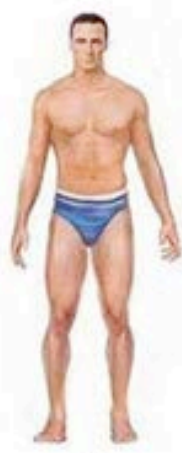

3

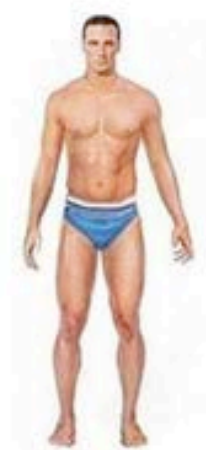

2

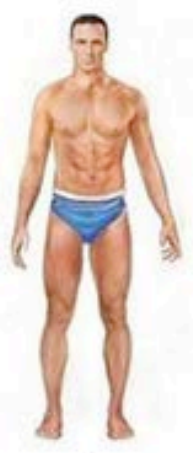

1
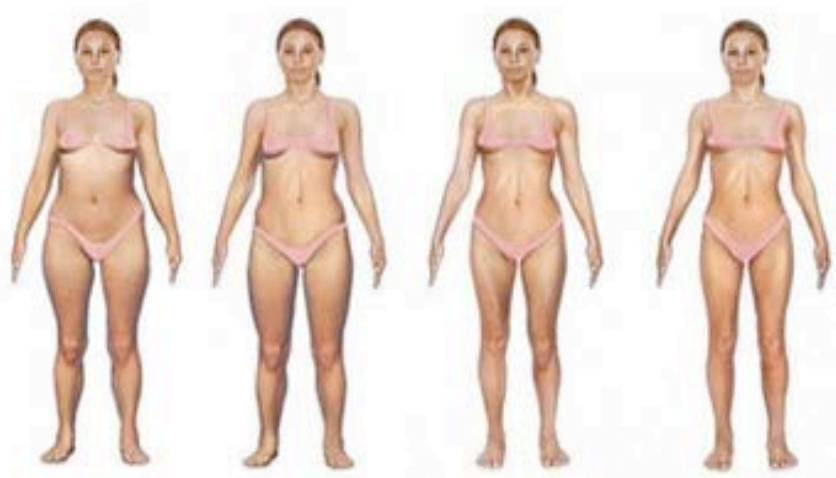

3

2

Which number shows how you currently look?

Which number shows how you wish you look? 


\section{Appendix K}

Beliefs about Muscularity: Drive for Muscularity Scale

\begin{tabular}{|c|c|c|c|c|c|c|}
\hline & $\begin{array}{l}\text { Definitely } \\
\text { Not }\end{array}$ & $\begin{array}{l}\text { Strongly } \\
\text { Disagree }\end{array}$ & Disagree & Neutral & $\begin{array}{l}\text { Strongly } \\
\text { Agree }\end{array}$ & Definitely \\
\hline $\begin{array}{l}\text { 1. I wish I were more } \\
\text { muscular. }\end{array}$ & 1 & 2 & 3 & 4 & 5 & 6 \\
\hline $\begin{array}{l}\text { 2. I lift weights to } \\
\text { build more muscle. }\end{array}$ & 1 & 2 & 3 & 4 & 5 & 6 \\
\hline $\begin{array}{l}\text { 3. I use protein or } \\
\text { energy supplements. }\end{array}$ & 1 & 2 & 3 & 4 & 5 & 6 \\
\hline $\begin{array}{l}\text { 4. I drink weight gain } \\
\text { or protein shakes. }\end{array}$ & 1 & 2 & 3 & 4 & 5 & 6 \\
\hline $\begin{array}{l}\text { 5. I try to consume as } \\
\text { many calories as I } \\
\text { can in a day. }\end{array}$ & 1 & 2 & 3 & 4 & 5 & 6 \\
\hline $\begin{array}{l}6 . \text { I feel guilty if I } \\
\text { miss a weight- } \\
\text { training session. }\end{array}$ & 1 & 2 & 3 & 4 & 5 & 6 \\
\hline $\begin{array}{l}\text { 7. Other people think } \\
\text { I work out with } \\
\text { weights too often. }\end{array}$ & 1 & 2 & 3 & 4 & 5 & 6 \\
\hline $\begin{array}{l}\text { 8. I think I would } \\
\text { look better if I gained } \\
10 \text { pounds in bulk. }\end{array}$ & 1 & 2 & 3 & 4 & 5 & 6 \\
\hline $\begin{array}{l}\text { 9. I think about } \\
\text { taking anabolic } \\
\text { steroids. }\end{array}$ & 1 & 2 & 3 & 4 & 5 & 6 \\
\hline $\begin{array}{l}\text { 10. I think I would } \\
\text { feel stronger if I } \\
\text { gained a little more } \\
\text { muscle } \quad \text { m ass. }\end{array}$ & 1 & 2 & 3 & 4 & 5 & 6 \\
\hline $\begin{array}{l}\text { 11. I think that my } \\
\text { weight-training } \\
\text { schedule interferes } \\
\text { with } \\
\text { of my life. }\end{array}$ & 1 & 2 & 3 & 4 & 5 & 6 \\
\hline $\begin{array}{l}\text { 12. I think that my } \\
\text { arms are not } \\
\text { muscular enough. }\end{array}$ & 1 & 2 & 3 & 4 & 5 & 6 \\
\hline
\end{tabular}




\begin{tabular}{|c|c|c|c|c|c|c|}
\hline & $\begin{array}{l}\text { Definitely } \\
\text { Not }\end{array}$ & $\begin{array}{l}\text { Strongly } \\
\text { Disagree }\end{array}$ & Disagree & Neutral & $\begin{array}{l}\text { Strongly } \\
\text { Agree }\end{array}$ & Definitely \\
\hline $\begin{array}{l}\text { 13. I think that my } \\
\text { chest is not muscular } \\
\text { enough. }\end{array}$ & 1 & 2 & 3 & 4 & 5 & 6 \\
\hline $\begin{array}{l}\text { 14. I think that my } \\
\text { legs are not muscular } \\
\text { enough. }\end{array}$ & 1 & 2 & 3 & 4 & 5 & 6 \\
\hline $\begin{array}{l}\text { 15. I think my abs are } \\
\text { not muscular enough. }\end{array}$ & 1 & 2 & 3 & 4 & 5 & 6 \\
\hline $\begin{array}{l}16 . \text { When I see } \\
\text { someone who is really } \\
\text { muscular it inspires } \\
\text { me to get bigger } \\
\text { myself }\end{array}$ & 1 & 2 & 3 & 4 & 5 & 6 \\
\hline $\begin{array}{l}\text { 17. I would like to be } \\
\text { bigger in the future. }\end{array}$ & 1 & 2 & 3 & 4 & 5 & 6 \\
\hline $\begin{array}{l}\text { 18. I aim to develop } \\
\text { my physique further. }\end{array}$ & 1 & 2 & 3 & 4 & 5 & 6 \\
\hline $\begin{array}{l}\text { 19. I feel bad about } \\
\text { my body when I do } \\
\text { not feel very big or } \\
\text { muscular. }\end{array}$ & 1 & 2 & 3 & 4 & 5 & 6 \\
\hline $\begin{array}{l}20 \text {. I would like to } \\
\text { spend more time } \\
\text { building up my } \\
\text { muscles. }\end{array}$ & 1 & 2 & 3 & 4 & 5 & 6 \\
\hline $\begin{array}{l}21 . \text { I often engage in } \\
\text { activities that build up } \\
\text { my muscles. }\end{array}$ & 1 & 2 & 3 & 4 & 5 & 6 \\
\hline $\begin{array}{l}\text { 22. Being muscular } \\
\text { gives me confidence. }\end{array}$ & 1 & 2 & 3 & 4 & 5 & 6 \\
\hline $\begin{array}{l}\text { 23. I feel that when I } \\
\text { have small muscles I } \\
\text { do not look as good as } \\
\text { when I have large } \\
\text { muscles. }\end{array}$ & 1 & 2 & 3 & 4 & 5 & 6 \\
\hline
\end{tabular}




\section{Appendix L}

Beliefs about Muscularity: Muscularity Body Dissatisfaction

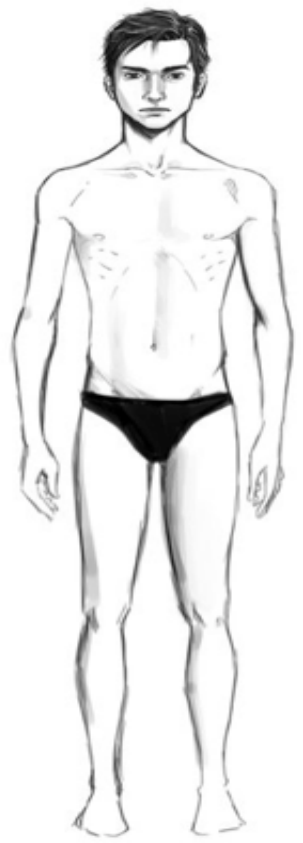

1

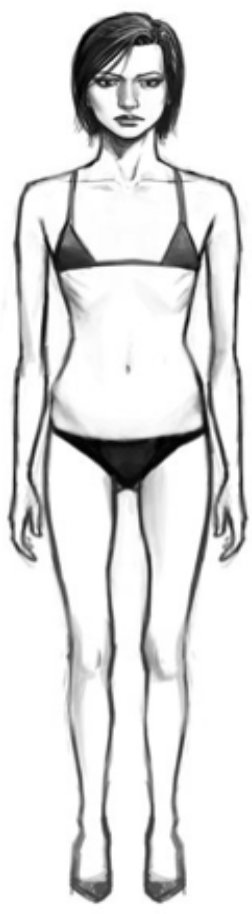

1

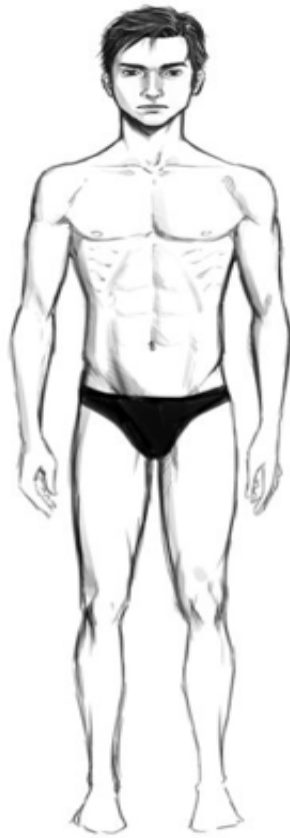

2

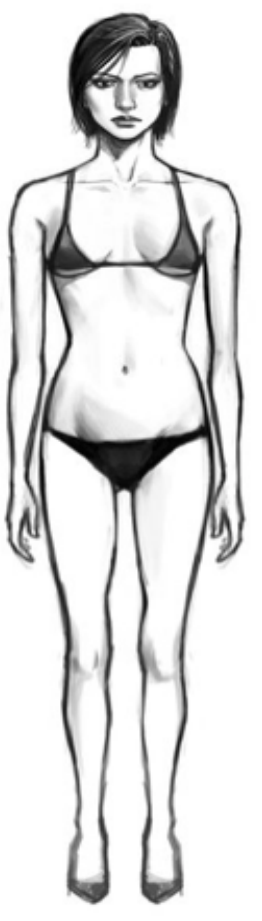

2

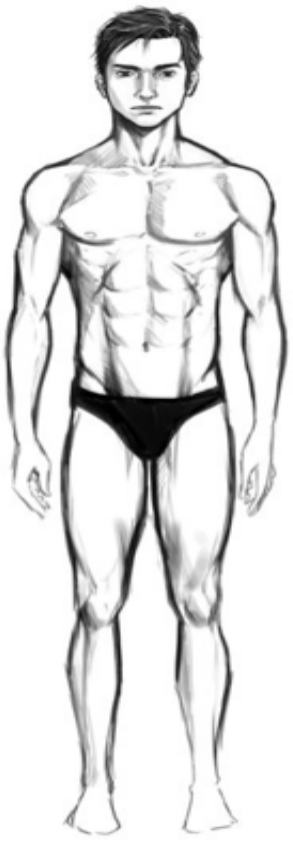

3

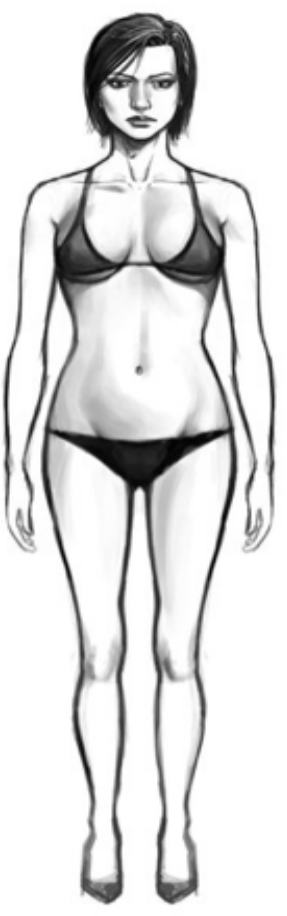

3
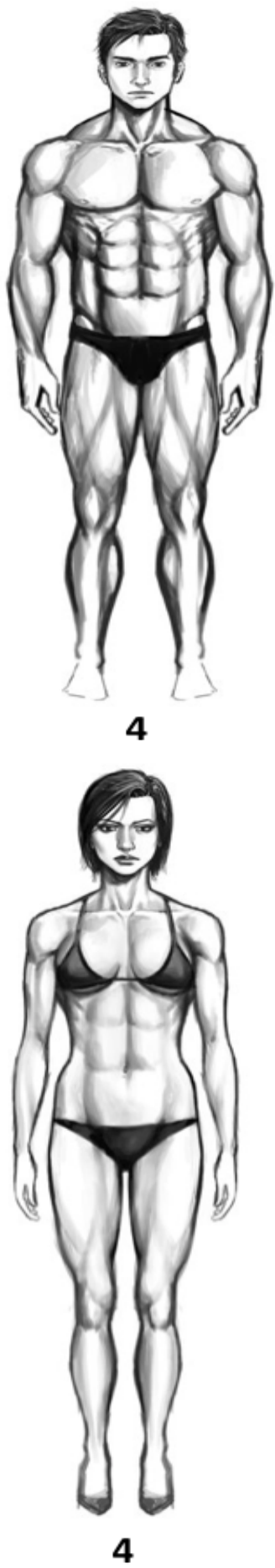

Which number shows how you currently look? Which number shows how you wish you look? 


\section{Appendix M}

Unstructured Exercise Levels

The U.S. Department of Health and Human Services recommends that children and adolescents between the ages of 6-17 participate in 30/60 minutes of physical activities each day.

Examples of Physical Activity include the following:

-walking

-jogging

-running

-lifting weights

-strength training

-stretching/flexibility r=training

-swimming

-biking

-fitness classes - yoga/dance/Pilates

1. Outside of structured organized sports, how many days do you meet the recommended guidelines for exercise during an average week?
a. 1
b. 2
c. 3
d. 4
e. 5
f. 6
g. 7 


\section{Appendix N}

Modeling Issues: Measurement Model

The proposed measurement model included four additional latent constructs assessing participants' beliefs about thinness (i.e., thinness body dissatisfaction and drive for thinness scores), beliefs about muscularity (i.e., muscularity body dissatisfaction and drive for muscularity scores), over-eating behaviors (i.e., over-eating behaviors scale, binge eating behaviors scale, and unhealthy eating behaviors scale), and under-eating behaviors (i.e., moderate under-eating behaviors scale, severe under-eating behaviors scale, and food conscious behaviors scale). The indicators of these proposed latent constructs were treated as observed variables in all subsequent analyses due to multicollinearity between participants' muscularity body dissatisfaction and drive for muscularity scale scores $(r=.38, p<.001)$, thinness body dissatisfaction and drive for thinness scale scores $(r=.43, p<.001)$, reports of engagement in different severity levels of over-eating behaviors $(r=.36-.65, p<.001)$, and reports of engagement in different severity levels of under-eating behaviors $(r=.62-.73, p<.001)$. In addition, negative error variances (i.e., factor loadings greater than 1) also resulted for the drive for thinness scale indicator and the drive for muscularity scale indicator of the beliefs about thinness and beliefs about muscularity latent constructs, respectively. Such negative error variances may have been influenced by multicollinearity between participants' scale scores (e.g., drive for thinness scale) and figure-rating scale scores (e.g., thinness body dissatisfaction) and/or because the beliefs about thinness and beliefs about muscularity latent variables were only comprised of two indicator variables. 
Appendix O

Eating Attitudes Test

\begin{tabular}{|c|c|c|c|c|c|c|}
\hline & Always & Usually & Often & Sometimes & Rarely & Never \\
\hline $\begin{array}{l}\text { 1. I am terrified about } \\
\text { being overweight }\end{array}$ & Always & Usually & Often & Sometimes & Rarely & Never \\
\hline $\begin{array}{l}\text { 2. I avoid eating when I am } \\
\text { hungry }\end{array}$ & Always & Usually & Often & Sometimes & Rarely & Never \\
\hline $\begin{array}{l}\text { 3. I find myself preoccupied } \\
\text { with food }\end{array}$ & Always & Usually & Often & Sometimes & Rarely & Never \\
\hline $\begin{array}{l}\text { 4. I have gone on eating } \\
\text { binges where I feel that I } \\
\text { may not be able to stop }\end{array}$ & ways & Usually & Often & Sometimes & Rarely & Never \\
\hline $\begin{array}{l}\text { 5. I cut my food into small } \\
\text { pieces }\end{array}$ & Always & Usually & Often & Sometimes & Rarely & Never \\
\hline $\begin{array}{l}\text { 6. I am aware of the calorie } \\
\text { content of foods that I } \\
\text { eat }\end{array}$ & ys & sually & Often & Sc & arely & Never \\
\hline $\begin{array}{l}\text { 7. I particularly avoid food } \\
\text { with a high carbohydrate } \\
\text { content (i.e. bread, rice, } \\
\text { potatoes, etc.) }\end{array}$ & Always & Usually & Often & Sometimes & Rarely & Never \\
\hline $\begin{array}{l}\text { 8. I feel that others would } \\
\text { prefer if I ate more }\end{array}$ & ys & Usually & Often & Sol & Rarely & Never \\
\hline 9. I vomit after I have eaten & Always & Usually & Often & Sometimes & Rarely & Never \\
\hline $\begin{array}{l}\text { 10. I feel extremely guilty } \\
\text { after eating }\end{array}$ & Always & ly & Often & es & rely & Tever \\
\hline $\begin{array}{l}\text { 11. I am occupied with a } \\
\text { desire to be thinner }\end{array}$ & Always & Usually & Often & Sometimes & Rarely & Never \\
\hline $\begin{array}{l}\text { 12. I think about burning up } \\
\text { calories when I exercise }\end{array}$ & Always & Usually & Often & Sometimes & Rarely & Never \\
\hline $\begin{array}{l}\text { 13. Other people think that I } \\
\text { am too thin }\end{array}$ & Always & Usually & Often & Sometimes & Rarely & Never \\
\hline $\begin{array}{l}\text { 14. I am preoccupied with } \\
\text { the thought of having fat } \\
\text { on my body }\end{array}$ & Always & Usually & Often & imes & Rarely & Never \\
\hline $\begin{array}{l}\text { 15. I take longer than others } \\
\text { to eat my meals }\end{array}$ & Always & Usually & Often & Sometimes & Rarely & Never \\
\hline $\begin{array}{l}\text { 16. I avoid foods with sugar } \\
\text { in them }\end{array}$ & Always & Usually & Often & Sometimes & Rarely & Never \\
\hline 17. I eat diet foods & Always & Usually & Often & Sometimes & Rarely & Never \\
\hline
\end{tabular}




\begin{tabular}{|l|l|l|l|l|l|l|}
\hline $\begin{array}{l}\text { 18. I feel that food controls } \\
\text { my life }\end{array}$ & Always & Usually & Often & Sometimes & Rarely & Never \\
\hline $\begin{array}{l}\text { 19. I display self-control } \\
\text { around food }\end{array}$ & Always & Usually & Often & Sometimes & Rarely & Never \\
\hline $\begin{array}{l}\text { 20. I feel that others } \\
\text { pressure me to eat }\end{array}$ & Always & Usually & Often & Sometimes & Rarely & Never \\
\hline $\begin{array}{l}\text { 21. I give too much time and } \\
\text { thought to food }\end{array}$ & Always & Usually & Often & Sometimes & Rarely & Never \\
\hline $\begin{array}{l}\text { 22. I feel uncomfortable } \\
\text { after eating sweets }\end{array}$ & Always & Usually & Often & Sometimes & Rarely & Never \\
\hline $\begin{array}{l}\text { 23. I engage in dieting } \\
\text { behavior }\end{array}$ & Always & Usually & Often & Sometimes & Rarely & Never \\
\hline $\begin{array}{l}\text { 24. I like my stomach to be } \\
\text { empty }\end{array}$ & Always & Usually & Often & Sometimes & Rarely & Never \\
\hline $\begin{array}{l}\text { 25. I have the impulse to } \\
\text { vomit after meals }\end{array}$ & Always & Usually & Often & Sometimes & Rarely & Never \\
\hline $\begin{array}{l}\text { 26. I enjoy trying new rich } \\
\text { foods }\end{array}$ & Always & Usually & Often & Sometimes & Rarely & Never \\
\hline
\end{tabular}

